\title{
ADVANCED RESERVOIR CHARACTERIZATION AND EVALUATION OF CO2 GRAVITY DRAINAGE IN THE NATURALLY FRACTURED SPRABERRY TREND AREA
}

Annual Report

September 1, 1996 - August 31, 1997

RERENDOD

By

Paul McDonald JUL 2 / 1998

OSTI

June 1998

Performed Under Contract No. DE-FC22-95BC14942

Pioneer Natural Resources

Midland, TX

\section{National Petroleum Technology Office U. S. DEPARTMENT OF ENERGY Tulsa, Oklahoma}

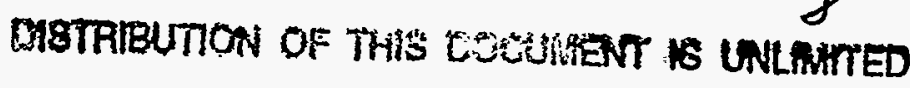




\section{DISCLAIMER}

This report was prepared as an account of work sponsored by an agency of the United States Govemment. Neither the United States Government nor any agency thereof, nor any of their employees, makes any warranty, expressed or implied, or assumes any legal liability or responsibility for the accuracy, completeness, or usefulness of any information, apparatus, product, or process disclosed, or represents that its use would not infringe privately owned rights. Reference herein to any specific commercial product, process, or service by trade name, trademark, manufacturer, or otherwise does not necessarily constitute or imply its endorsement, recommendation, or favoring by the United States Government or any agency thereof. The views and opinions of authors expressed herein do not necessarily state or reflect those of the United States Government.

This report has been reproduced directly from the best available copy.

Available to DOE and DOE contractors from the Office of Scientific and Technical Information, P.O. Box 62, Oak Ridge, TN 37831; prices available from (615) 576-8401.

Available to the public from the National Technical Information Service, U.S. Department of Commerce, 5285 Port Royal Rd., Springfield VA 22161 


\section{DISCLAIMER}

Portions of this document may be illegible electronic image products. Images are produced from the best available original document. 
$\mathrm{DOE} / \mathrm{BC} / 14942-5$

Distribution Category UC-122

Advanced Reservoir Characterization And Evaluation Of $\mathrm{CO} 2$ Gravity Drainage In The Naturally Fractured Spraberry Trend Area

\author{
By \\ Paul McDonald
}

June 1998

Work Performed Under Contract No. DE-FC22-95BC14942

\author{
Prepared for \\ U.S. Department of Energy \\ Assistant Secretary for Fossil Energy \\ Jerry Casteel, Project Manager \\ National Petroleum Technology Office \\ P.O. Box 3628 \\ Tulsa, OK 74101
}

Prepared by:

David S. Schechter

New Mexico Institute of Mining and Technology

Socorro, New Mexico 



\section{TABLE OF CONTENTS}

TABLE OF CONTENTS $\ldots \ldots \ldots \ldots \ldots \ldots \ldots \ldots \ldots \ldots \ldots \ldots$ iii

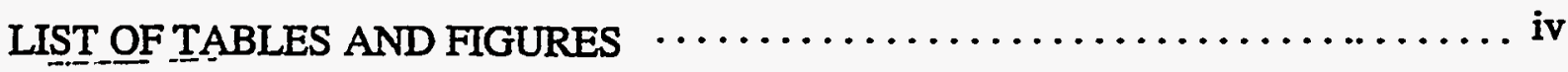

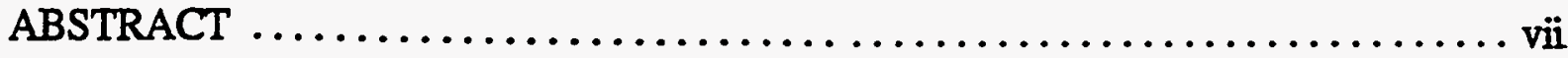

EXECUTIVE SUMMARY $\ldots \ldots \ldots \ldots \ldots \ldots \ldots \ldots \ldots \ldots \ldots \ldots \ldots \ldots \ldots \ldots \ldots \ldots$ ix

ACKNOWLEDGMENTS $\ldots \ldots \ldots \ldots \ldots \ldots \ldots \ldots \ldots \ldots \ldots \ldots \ldots \ldots \ldots \ldots \ldots \ldots$

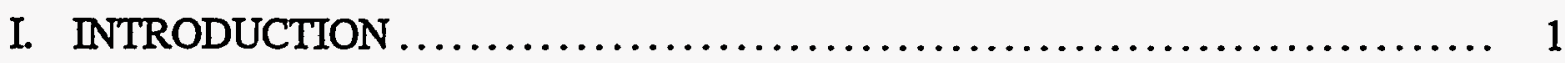

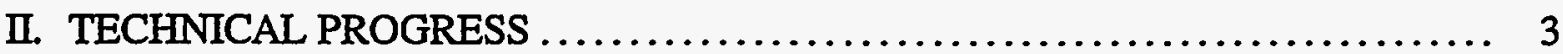

1. RESERVOIR CHARACTERIZATION $\ldots \ldots \ldots \ldots \ldots \ldots \ldots \ldots \ldots \ldots \ldots$

1.1 Acquisition of Horizontal Cores from the Dual Lateral

E.T. O’Daniel \#28 ............................. 3

1.2 Fracture Analysis of the E.T. O'Daniel \#28 Horizontal Core ....... 11

1.3 Investigation of Fracture Diagenesis from Spraberry Natural

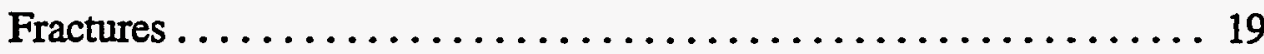

1.4 Application of Rock-Log Model to the Horizontal Core Well ...... 27

1.5 Pay Zone Identification Using "Old" Cased-Hole Logs . . . . . . . . 35

2. INVESTIGATION OF CRUDE OIL/BRINE/ROCK INTERACTION ..... 40

2.1 Comparison of Up-Scaled Imbibition Results to Field Data ........ 40

2.2 Crude Oil/Brine/Rock Interaction at High-Temperature and

Pressure Conditions ..................................61 61

3. RESERVOIR PERFORMANCE .................................69 69

3.1 Well Productivity During Primary Production ............ 69

3.2 Permeability Anisotropy Analysis $\ldots \ldots \ldots \ldots \ldots \ldots \ldots \ldots .67$

3.3 Numerical Simulation of a Water Flood Pilot in the Naturally

Fractured Spraberry Trend ............................. 101

4. INVESTIGATION OF RECOVERY MECHANISMS

BY $\mathrm{CO}_{2}$ INJECTION IN FRACTURED SYSTEMS $\ldots \ldots \ldots \ldots \ldots \ldots \ldots$

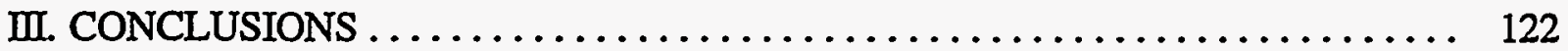




\section{LIST OF TABLES}

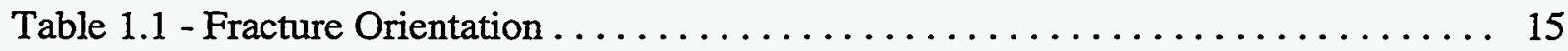

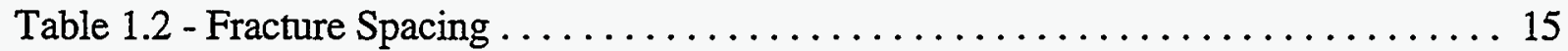

Table 1.3 - Summary of Naturally Fractured Cores . . . . . . . . . . . . . . . . . . 24

Table 1.4 - Comparison of Horizontal Cores from the $1 \mathrm{U}$ Zone in the E.T. O'Daniel \#28 . . . . . . . . . . . . . . . . . . . . . . . 24

Table 2.1 - Rock Properties and Conditions for Imbibition Experiments . . . . . . . . . 53

Table 2.2 - Reservoir Properties of the E.T. O'Daniel Unit, Spraberry Trend Area, West Texas . . . . . . . . . . . . . 53

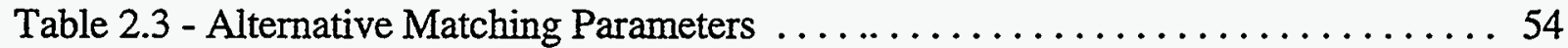

Table 2.4 - Summary of Results of Imbibition Experiments with Berea Cores and Spraberry Fluids. . . . . . . . . . . . . . 63

Table 2.5 - Properties of Fluids Used in the Experiments . . . . . . . . . . . . 64

Table 2.6 - Contact Angles Measured Using Standard Adsorption Method . . . . . . . . . 64

Table 3.1 - Parameters Used for Analyzing Performance of Spraberry Trend Area Reservoir Wells in the Driver Unit . . . . . . . . . . . 79

Table 3.2 - Production Data of Six Shut-In Test Wells in the Driver Area Spraberry Trend Area Field, Texas . . . . . . . . . . . . . . 80

Table 3.3 - Production Data of Six Regularly Producing Wells in the Driver Area, Spraberry Trend Area Field, Texas .................... 81

Table 3.4 - Reservoir Properties for the Humble Pilot Flood . . . . . . . . . . . . . 110

Table 3.5 - Reservoir Fluid Properties . . . . . . . . . . . . . . . . . . . . . 110

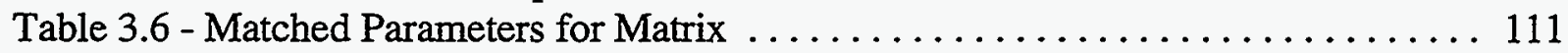

Table 3.7 - Matched Parameters for Fractures . . . . . . . . . . . . . . . . . 111

Table 4.1 - Physical Properties of Core Samples Used in the Experiments . . . . . . . 119

\section{LIST OF FIGURES}

Fig. 1.1 - Division of Spraberry Formation in the central trend area, TXL Fee "B" No. 1 Well $\ldots \ldots \ldots \ldots \ldots \ldots \ldots \ldots \ldots \ldots \ldots \ldots . \ldots \ldots$

Fig. 1.2 - Bottom hole coring and orientation assembly . . . . . . . . . . . . 9

Fig. 1.3 - A schematic diagram showing coring intervals in the E.T. O'Daniel \#28 . . . 10

Fig. 1.4 - Orientation of fractures in the $5 \mathrm{U}$ reservoir $\ldots \ldots \ldots \ldots \ldots \ldots \ldots \ldots$

Fig. 1.5 - Orientation of fractures in the $1 \mathrm{U}$ reservoir $\ldots \ldots \ldots \ldots \ldots \ldots \ldots \ldots \ldots$

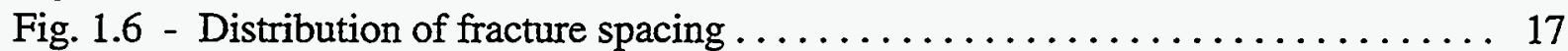

Fig. 1.7 - Correlation between core fracture and wellbore image log fracture . . . . . 18

Fig. 1.8 - Type $\log$ of Spraberry in the O'Daniel lease . . . . . . . . . . . . 25

Fig. 1.9 - Schematic diagram of the horizontal cores from the E.T. O'Daniel \#28 well . 26

Fig. 1.10 - Summary of fracture characteristics noted in the two horizontal cores from the E.T. O'Daniel \#28 well . . . . . . . . . . . . . . . . 26

Fig. 1.11 - Open-hole logs from the horizontal well E.T. O'Daniel \#28 . . . . . . 31

Fig. 1.12 - Gamma ray log from the E.T. O'Daniel \#28 well, vertical and horizontal $\operatorname{logs} \ldots \ldots \ldots \ldots \ldots \ldots \ldots \ldots \ldots \ldots$ 
Fig. 1.13 - Lithodensity/Neutron crossover $\log \ldots \ldots \ldots \ldots \ldots \ldots \ldots \ldots \ldots \ldots \ldots \ldots \ldots \ldots \ldots$

Fig. 1.14 - Crossplot of volume of shale vs. effective porosity .............. 34

Fig. 1.15 - Cased-hole logs from the E.T. O'Daniel "G" \#1 (Upper Spraberry) . . . . . . . 38

Fig. 1.16 - Effective porosity (NIP) calculated from the old neutron $\log$ (API unit)

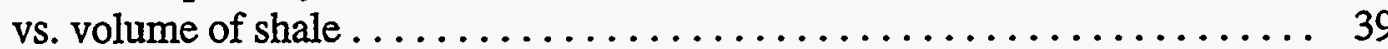

Fig. 2.1 - An analogue model for imbibition waterflooding in naturally fractured reservoirs with spontaneous imbibition acting as the rate-limiting step. . . . . 54

Fig. 2.2 - Oil recovery curves obtained from water imbibition under ambient

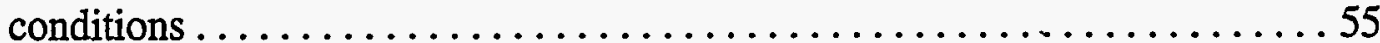

Fig. 2.3 - Brine recovery curve obtained during oil imbibition on core sample from the Spraberry Trend Area ................. 55

Fig. 2.4 - Oil recovery curves obtained from water imbibition under reservoir temperature and pressures .................... 56

Fig. 2.5 - Comparison of drainage capillary pressure curves obtained using various methods for core samples from the Spraberry Trend Area ........56

Fig. 2.6 - Comparison of imbibition capillary pressure curves obtained using various method for core samples from the Spraberry Trend Area ........ 57

Fig. 2.7 - Oil recovery curves from Fig. 2.2 plotted using dimensionless variables . . . 57

Fig. 2.8 - Comparison between composite imbibition oil recovery curves obtained from Berea sandstone and Spraberry Trend Area reservoir sandstone . . . . . 58

Fig. 2.9 - Match between imbibition scaling model and production decline data from the E.T. O'Daniel Unit, Spraberry Trend Area ........... 58

Fig. 2.10 - A typical image of oil drop attachment in contact angle measurement ..... 59

Fig. 2.11 - Comparison between imbibition model calculated oil recovery and observed oil recovery from the E.T. O'Daniel Unit, Spraberry Trend Area .. . . . . . 59

Fig. 2.12 - Match between imbibition model calculated oil recovery and observed oil recovery from the Humble pilot, Spraberry Trend Area . . . . . . . . . 60

Fig. 2.13 - Comparison between imbibition scaling model and production decline data from the Humble pilot, Spraberry Trend Area . . . . . . . . 60

Fig. 2.14 - Density and viscosity of Spraberry crude oil versus temperature ........ 65

Fig. 2.15 - IFT of Spraberry brine/cruide oil at elevated pressures . . . . . . . . . . 65

Fig. 2.16 - Thermal expansion of Spraberry crude oil ................... 66

Fig. 2.17 - Imbibition oil recovery at different temperatures ................ 66

Fig. 2.18 - Imbibition oil recovery at different pressures .................. 67

Fig. 2.19 - Imbibition oil recovery under different aging conditions . . . . . . . . . 67

Fig. 2.20 - Imbibition oil recovery from cores with different initial water saturations . . . 68

Fig. 2.21 - Normalized imbibition oil recovery curves from cores with different initial water saturations . . . . . . . . . . . . . . . . 68

Fig. 3.1 - Initial water saturation in the Spraberry Trend Area as a function of rock permeability $\ldots \ldots \ldots \ldots \ldots \ldots \ldots \ldots \ldots . \ldots \ldots$

Fig. 3.2 - Water-oil relative permeability curves for the Spraberry Trend Area ..... 82

Fig. 3.3 - Oil-gas relative permeability curves for the Spraberry Trend Area ........ 82

Fig. 3.4 - Comparison between calculated and actual oil production rates for Davenport C-6, Driver Unit, Spraberry Trend Area Field, West Texas . . . . 83

Fig. 3.5 - Comparison between calculated and actual oil production rates for 
Davenport C-8, Driver Unit, Spraberry Trend Area Field, West Texas . . . . 83

Fig. 3.6 - Comparison between calculated and actual oil production rates for Davenport B-5, Driver Unit, Spraberry Trend Area Field, West Texas ..... 83

Fig. 3.7 - Comparison between calculated and actual oil production rates for Davenport B-7, Driver Unit, Spraberry Trend Area Field, West Texas . . . . 84

Fig. 3.8 - Comparison between calculated and actual oil production rates for X.B. Cox A-4, Driver Unit, Spraberry Trend Area Field, West Texas . . . . . 84

Fig. 3.9 - Comparison between calculated and actual oil production rates for J.C. Bryans A-2, Driver Unit, Spraberry Trend Area Field, West Texas ... . 84

Fig. 3.10 - Comparison between calculated and actual oil production rates for Davenport C-5, Driver Unit, Spraberry Trend Area Field, West Texas . . . . 85

Fig. 3.11 - Comparison between calculated and actual oil production rates for Davenport C-10, Driver Unit, Spraberry Trend Area Field, West Texas . . . . 85

Fig. 3.12 - Comparison between calculated and actual oil production rates for Davenport B-8, Driver Unit, Spraberry Trend Area Field, West Texas ......

Fig. 3.13 - Comparison between calculated and actual oil production rates for Davenport B-14, Driver Unit, Spraberry Trend Area Field, West Texas . . . . 86

Fig. 3.14 - Comparison between calculated and actual oil production rates for X.B. Cox A-5, Driver Unit, Spraberry Trend Area Field, West Texas . . . . . 86

Fig. 3.15 - Comparison between calculated and actual oil production rates for J.C. Bryans A-1, Driver Unit, Spraberry Trend Area Field, West Texas .... 86

Fig. 3.16 - Type curve matching between recorded pressure and pressure . calculated by the Warren and Root model for a pre-frac buildup test .......

Fig. 3.17 - Type curve matching between recorded pressure and pressure calculated by the Warren and Root model for a post-frac buildup test $\ldots . .98$

Fig. 3.18 - Matching between recorded and calculated bottom hole pressures

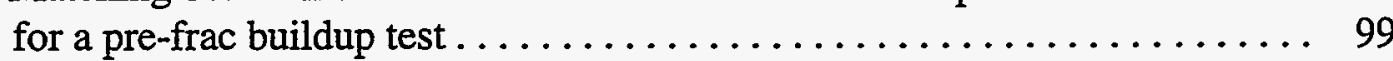

Fig. 3.19 - Matching between recorded and calculated bottom hole pressures for a post-frac buildup test . . . . . . . . . . . . . . 100

Fig. 3.20 - Grid model after orientation to $\mathrm{N} 50^{\circ} \mathrm{E}$ along the major fracture system . . . 112

Fig. 3.21 - Plot of imbibition capillary pressure curve for core samples from the Spraberry Trend Area . ........................ 113

Fig. 3.22 - Match of observed and simulated data for oil production rate in central production well (Sh. B-9) $\ldots \ldots \ldots \ldots \ldots \ldots \ldots \ldots \ldots \ldots \ldots \ldots$

Fig. 3.23 - Match of observed and simulated data for gas production rate . . . . . . . 114

Fig. 3.24 - Match of observed and simulated data for gas-oil ratio . . . . . . . . . . . 114

Fig. 3.25 - Match of observed and simulated data for water production rate . . . . . . 115

Fig. 3.26 - Match of observed and simulated data for water cut ............. 115

Fig. 3.27 - Match of observed and simulated data for bottom hole pressure ........ 116

Fig. 4.1 - Oil recovery curves obtained from three $\mathrm{CO}_{2}$ injection experiments using cores with low water saturations $\ldots \ldots \ldots \ldots \ldots \ldots \ldots \ldots \ldots . \ldots \ldots$

Fig. 4.2 - Oil recovery curve obtained from a $\mathrm{CO}_{2}$ injection experimentusing a $0.38 \mathrm{md}$ core with water saturation $0.45 \ldots \ldots \ldots \ldots \ldots \ldots . . .6120$

Fig. 4.3 - Comparison of oil recovery curves obtained from four $\mathrm{CO}_{2}$ injection experiments using different cores 


\section{ABSTRACT}

The overall goal of this project is to assess the economic feasibility of $\mathrm{CO}_{2}$ flooding the naturally fractured Spraberry Trend Area in West Texas. This objective is being accomplished by conducting research in four areas: 1) extensive characterization of the reservoirs, 2) experimental studies of crude oil/brine/rock (COBR) interactions in the reservoirs, 3) reservoir performance analysis, and, 4) experimental investigations on $\mathrm{CO}_{2}$ gravity drainage in Spraberry whole cores. This report provides results of the second year of the five-year project for each of the four areas.

In the first area, we have completed the reservoir characterization, which includes matrix description, and pay zone detection (from core-log integration), and fracture characterization. This information is found in Section 1. The first horizontal core ever taken from the Spraberry as part of this project proved beyond a doubt that Spraberry pay sands are densely fractured with not one, but three sets of natural fractures with varying orientations. The coring operation, description of the horizontal core, diagenesis investigation of fracture faces, along with application of our rock-log model to open-hole logs from the horizontal well are also provided in Section 1 . We have also included our analysis which allows application of the rock-log model to old cased hole logs.

In the second area, we have completed extensive imbibition experiments clearly indicateing that the weakly water-wet behavior of the reservoir rock may be responsible for poor waterflood response observed in many Spraberry fields. We have been able to use laboratory imbibition data, capillary pressure measurements, and contact angle evaluation to history match the waterflood performance in our designated pilot area which again indicates our understanding of the imbibition mechanism during waterflooding. We have also explored the effect of reservoir conditions on wettability determination in the Spraberry. This information is found in Section 2. Characterization of the crude oil/brine/rock interaction in the Spraberry matrix has been carried out based on results of laboratory experiments conducted at reservoir conditions in the second year. It was found that brine imbibition rate was accelerated by elevated temperature and delayed by elevated pressure. Aging condition in oil decelerated brine imbibition while the wettability index to water was essentially unchanged. Comparison has been made between the up-scaled imbibition data and production decline in areas of E.T O'Daniel lease and Humble pilot. Consistency between the up-scaled imbibition data and production decline in the two areas was observed, indicating that low imbibition rate of water into the low permeability weakly-waterwet reservoirs is the dominating mechanism for the waterflood recovery.

In the third area, we have made significant progress in analytical and numerical simulation of performance in Spraberry reservoirs as seen in Section 3. Reservoir performance has been analyzed through skin analysis in the Driver Unit wells, anisotropic fracture permeability response as indicated by pressure test data, and numerical reservoir simulation. Application of a newly developed steady-flow-model to wells in the Driver Unit indicated that fluid damage to the rock matrix is unlikely a crucial issue, while fracture permeability may have altered due to pressure decline during oil production. Using a newly developed transient-flowmodel for interpretation of single-well pressure-test data from E.T. O'Daniel \#37 indicated that the reservoir permeability is highly anisotropic and the anisotropy may have been altered by 
hydraulic fracturing treatments. Numerical simulation of the Humble pilot has confirmed that the Spraberry reservoir rocks are weakly water-wet and that the reservoir permeability is highly anisotropic.

In the fourth area, we have completed several suites of $\mathrm{CO}_{2}$ gravity drainage experiments in Spraberry and Berea whole cores at reservoir conditions and reported in Section 4 . The results of these experiments have been useful in developing a model for free-fall gravity drainage and have validated our premise that $\mathrm{CO}_{2}$ will recover oil from tight, unconfined Spraberry matrix. Carbon dioxide gravity drainage experiments have been performed using two more reservoir cores. One of the experiments was conduced with a simulated fracture around the whole core under high water saturation in the core. The other experiment was conducted using a whole core with natural fractures under gravity-stable displacement conditions The result from the former experiment indicates that free water in the core reduced the efficiency of $\mathrm{CO}_{2}$ gravity drainage. The result from the latter experiment demonstrated significantly high efficiency of the $\mathrm{CO}_{2}$ gravity drainage in naturally fractured reservoirs. 


\section{EXECUTIVE SUMMARY}

The goal of this project is to test the economic feasibility of continuous injection of $\mathrm{CO}_{2}$ in the naturally fractured Spraberry Trend Area. This project certainly represents a high level of risk due to the confounding nature of Spraberry reservoirs. The reservoir rock is highly fractured and extremely tight which presents unique challenges when designing a $\mathrm{CO}_{2}$ pilot. However, the matrix rock contains a significant amount of hydrocarbon storage and all of the characterization work performed during the course of this project indicates that a majority of this oil is not recovered during primary depletion. The tremendous size of the reservoir combined with the large residual saturation continues to make Spraberry reservoirs tempting targets for EOR through $\mathrm{CO}_{2}$ injection, regardless of the high risk involved in a project of this nature.

During the first two years of this project, progress has been made in all areas pertinent to design and implementation of the pilot $\mathrm{CO}_{2}$ flood planned for Phase $\mathrm{II}$ of this project. We have completed reservoir characterization, which includes matrix description. Pay zone detection (from core-log integration), and fracture characterization. The first horizontal core ever taken from the Spraberry as part of this project proved beyond a doubt that Spraberry pay sands are densely fractured with not one, but three sets of natural fractures with varying orientations. We have completed extensive imbibition experiments that strongly indicate that the weakly waterwet behavior of the reservoir rock may be responsible for poor waterflood response observed in many Spraberry fields. We have been able to use laboratory imbibition data to history match the waterflood performance in our designated pilot area which again indicates our understanding of the imbibition mechanism during waterflooding. We have completed several suites of $\mathrm{CO}_{2}$ gravity drainage tests in Spraberry and Berea whole cores at reservoir conditions. The results of these experiments have been useful in developing a model for free-fall gravity drainage and have validated our premise that $\mathrm{CO}_{2}$ will recover oil from tight, unconfined Spraberry matrix. The favorable results from these experiments have led us to the conclusion that the pilot phase of the project should be continued. We have also made significant progress in analytical and numerical simulation of performance in Spraberry reservoirs.

The final three years of this project involves implementation of the $\mathrm{CO}_{2}$ pilot. Up to twelve new wells are planned in the pilot area; water injection wells to contain the $\mathrm{CO}_{2}$, three production wells to monitor performance of $\mathrm{CO}_{2}, \mathrm{CO}_{2}$ injection wells including one horizontal injection well and logging observation wells to monitor $\mathrm{CO}_{2}$ flood fronts. Results of drilling these wells will be forthcoming.

David S. Schechter

October 1997 


\section{ACKNOWLEDGMENTS}

This work was financially supported by the United States Department of Energy's National Petroleum Technology Office and the following consortium of companies; Marathon Oil Co., Mobil Research and Development Corp., Mobil E\&P USA, Pioneer Natural Resources (formerly Parker and Parsley Petroleum Co.), Petroglyph Operating Co., Texaco E\&P Technology Dept., The Wiser Oil Co. and Union Pacific Resources. This support is gratefully acknowledged. Geographix Inc. donated software used in reservoir characterization. I greatly appreciate diligent efforts from the following individuals who contributed to this project. The technical capabilities of Dr. Boyun Guo are reflected throughout Sections 2, 3 and 4. The majority of work in these sections, from inception to delivery, are due to Boyun. Dr. John Lorenz from Sandia National Laboratory performed the fracture analysis of the horizontal core reported in Section 1. Martha Cather performed the fracture diagenesis work described in Section 1. Ashish Banik developed the rock-log model demonstrated in Section 1. Erwin Putra conducted the Humble waterflood pilot simulation. Hujun Li measured both imbibition curves and IFT reported in Section 4. Other acknowledgments go to Richard Baker of Epic Consulting Ltd., Steve Melzer and Loren Stiles of UTPB-CEED, Randy Miller of Reservoirs Inc. and Lincoln Elkins. Paul McDonald continues to guide this project through his company's transition from Parker and Parsley Petroleum Co. to Pioneer Natural Resources. Also acknowledgments to Tom Sheffield, Charlie Sizemore, Dave Holmes, Wendy Roberson, Charles Troxell and "Spanky". 


\section{INTRODUCTION}

The objective of the Spraberry $\mathrm{CO}_{2}$ pilot project is to determine the technical and economic feasibility of continuous $\mathrm{CO}_{2}$ injection in the naturally fractured reservoirs of the Spraberry Trend. In order to describe, understand, and model $\mathrm{CO}_{2}$ flooding in the naturally fractured Spraberry reservoirs, characterization of the fracture system is a must. Additional reservoir characterization was based on horizontal coring in the second year of the project. In addition to characterization of natural fractures, horizontal coring has confirmed our previously developed rock model for describing the Spraberry Trend shaly sands. A better method for identifying Spraberry pay zones has been verified.

We have completed the reservoir characterization, which includes matrix description and detection (from core-log integration) and fracture characterization. This information is found in Section 1. The first horizontal core ever taken from the Spraberry as part of this project proved beyond a doubt that Spraberry pay sands are densely fractured with not one, but three sets of natural fractures with varying orientations. The coring operation, description of the horizontal core, diagenesis investigations from the fracture faces, and application of our rock$\log$ model to open-hole logs from the horizontal well are also provided in Section 1. We have also included our analysis which allows application of the rock-log model to old cased hole logs.

We have completed extensive imbibition experiments that strongly indicate that the weakly water-wet behavior of the reservoir rock may be responsible for poor waterflood response observed in many Spraberry fields. We have been able to use laboratory imbibition data, capillary pressure measurements and contact angle evaluation to history match the waterflood performance in our designated pilot area which again indicates our understanding of the imbibition mechanism during waterflooding. We have also explored the effect of reservoir conditions on wettability determination in the Spraberry. This information is found in Section 2. Characterization of the crude oil/brine/rock interaction in the Spraberry matrix has been carried out based on results of laboratory experiments conducted at reservoir conditions in the second year. It was found that brine imbibition rate was accelerated by elevated temperature and delayed by elevated pressure. Aging in oil decelerated brine imbibition while the wettability index to water was essentially unchanged. Comparison has been made between the up-scaled imbibition data and production decline in areas of the E.T O'Daniel lease and Humble pilot. Consistency between the scaled-up imbibition data and production decline in the two areas was observed, indicating that low imbibition rate of water into the low permeability weakly-water-wet reservoirs is the dominating mechanism for the waterflood recovery.

We have also made significant progress in analytical and numerical simulation of performance in Spraberry reservoirs as seen in Section 3. Reservoir performance has been analyzed through skin analysis in the Driver Unit wells, anisotropic fracture permeability response as indicated by pressure test data, and numerical reservoir simulation. Application 
of a newly developed steady-flow-model to wells in the Driver Unit indicated that fluid damage to the rock matrix is unlikely a crucial issue, while fracture permeability may have altered due to pressure decline during oil production. Using a newly developed transientflow-model for interpretation of single-well pressure-test data from E.T. O'Daniel \#37 indicated that the reservoir permeability is highly anisotropic and the anisotropy may have been altered by hydraulic fracturing treatments. Numerical simulation of the Humble pilot has confirmed that the Spraberry reservoir rocks are weakly water-wet and that the reservoir permeability is highly anisotropic.

We have completed several suites of $\mathrm{CO}_{2}$ gravity drainage in Spraberry and Berea whole cores at reservoir conditions and reported in Section 4. The results of these experiments have been useful in developing a model for free-fall gravity drainage and have validated our premise that $\mathrm{CO}_{2}$ will recover oil from tight, unconfined Spraberry matrix. Carbon dioxide gravity drainage experiments have been performed using two more reservoir cores. One of the experiments was conduced with a simulated fracture around the whole core under high water saturation in the core. The other experiment was conducted using a whole core with natural fractures under gravity-stable displacement conditions The result from the former experiment indicates that free water in the core reduced the efficiency of $\mathrm{CO}_{2}$ gravity drainage. The result from the latter experiment demonstrated significantly high efficiency of the $\mathrm{CO}_{2}$ gravity drainage in naturally fractured reservoirs.

In summary, we have gained significant understanding of the naturally fractured Spraberry Trend reservoirs through this study. The weakly-wet Spraberry sands should be partially responsible for the low performance of water flooding in the Spraberry Trend reservoirs. Results of oil recovery from a low permeability Spraberry core during $\mathrm{CO}_{2}$ gravity drainage experiments are promising. This result indicates the potential of $\mathrm{CO}_{2}$ flooding in Spraberry Trend reservoirs. 


\section{TECHNICAL PROGRESS}

\section{RESERVOIR CHARACTERIZATION}

\subsection{Acquisition of Horizontal Cores from the Dual Lateral E.T. O’Daniel \#28}

\section{Introduction}

Natural fractures existing over a regional area have long been known to dominate all aspects of performance in the Spraberry Trend Area ${ }^{1}$. However, there is little or no information on the actual fracture system other than: orientation, on a gross basis, from pulse and/or tracer tests in the 50's and 60's, and fracture spacing inferred from simulation and a few existing vertical cores. Previous descriptions and old core reports did not distinguish between natural and coring induced fractures, thus almost all information from the early years, when almost all Spraberry data was obtained, provides no detailed information on the natural fracture system. The first vertical core, taken as part of the current program in 1993 from the Shackelford Spraberry Unit \#1-38A, intersected a vertical natural fracture with significant mineralization that had clearly grown into unoccupied space. This open, mineralized fracture was contained within a thin pay sand and was observed to terminate at a shale parting. This fracture was the first documented evidence of the existence of mineralized natural fractures within the pay sand.

The orientation, containment within zone, degree of mineralization, fracture aperture and spacing are important questions when considering fluid flow in naturally fractured reservoirs. However, after considerable data gathering, it became apparent that only superficial characterization of the natural fracture system was available. Recent acquisition of the horizontal core has radically altered understanding of the natural fracture system in the Spraberry Trend Area. This well, the E.T. O' Daniel \#28, was cored with the intent of intersecting natural fractures in the thin sand streaks where oil saturation is found in the Upper Spraberry. Over 100 natural fractures were intersected from the $1 \mathrm{U}$ and $5 \mathrm{U}$ pay zones exhibiting an intriguing and diverse array of fracturing behavior.

\section{Geology}

The Spraberry formation was deposited during the Permian age within the Leonardian system in the Midland Basin, a part of the province known as the Permian Basin of west Texas and southeast New Mexico. The depositional environment consisted of a combination of turbidity and density currents sourced from the northwestern shelf area. The Spraberry formation facies can be characterized as submarine fan and basin plane deposits and consists of very fine grained sandstones to coarse grained siltstones and mudstones. The various fan complexes can be traced to the north in Dawson and Lynn counties and are considered the source material for the fan lobe sequences within the area of study in eastern Midland County.

Since its discovery, the Spraberry has been subdivided into three principal intervals, the lower, middle and upper Spraberry formations. In the late 1980's, Tyler and Gholston further subdivided the Spraberry intervals to represent distinct episodes, or operational units, within each of the submarine fan complexes (Fig. 1.1) ${ }^{2}$. Six of these units were found in the Upper Spraberry and 
two in the Lower Spraberry. Only two of the six horizons in the Upper Spraberry (1U and 5U) have been identified as containing reservoir quality rock capable of making significant production contributions.

The proposed target of the horizontal core was the natural fractures within the main pay intervals of the $1 U$ and $5 U$ sands. Net pay within each of these zones averages between 8 and $14 \mathrm{ft}$. depending on location. Unfortunately, logs run following the coring of the $1 U$ interval confirmed that the core had actually come from a thinner (2-3 ft.) pay section, within the $1 \mathrm{U}$ interval, located 6-8 ft. above the main pay. Further explanation is found in Section 1.4.

\section{Core Acquisition}

One of the primary objectives in obtaining horizontal core was to provide direct measurement of fracture orientation and spacing, therefore, the well plan called for both laterals to extend perpendicular to the assumed fracture trend in order to maximize the intersection of natural fractures. The mechanics of obtaining the core in a horizontal well proved to be not unlike that of coring a vertical well. In fact, the problems which hampered horizontal coring operations were typical of problems commonly encountered in coring vertical wells.

Curve Build Bottom Hole Assembly. The bottom hole assembly (BHA) utilized to drill the curve on both the Upper Spraberry $1 \mathrm{U}$ and $5 \mathrm{U}$ targets was as follows: 6-1/2" PDC bit, 5" O.D., $5 / 6$ lobe 4 stage adjustable angle motor, flex sub, float sub with stainless steel insert float, UBHO (Universal Bottom Hole Orienting) sub, and 2 non-magnetic monel drill collars. The BHA was run on 3-1/2" IF drill pipe.

Coring Bottom Hole Assembly. The first BHA utilized to perform the coring operations was configured as follows: $6-1 / 8^{\prime \prime}$ diamond core bit, 6-1/8" O. D. scribe shoe with slip dog core catcher, 6-1/8" X 2-5/8" X 30' core barrel with aluminum inner barrel, 4-3/4" O. D. monel drill collar with electromagnetic survey (EMS) tool inside, and 2 monel drill collars (Fig. 1.2). The core bit was threaded onto the outer core barrel and was rotated by the power swivel at the surface. The inner barrel, located inside the outer barrel, was allowed to rotate independently through a bearing pack assembly. The scribe shoe, which has three scribe knives in a symmetrical position around the circumference of the shoe, was threaded onto the bottom of the inner barrel. The knives are used to keep the barrel from rotating with the outer barrel. The other function of the knives is to scribe the core with orientation lines as the core enters through the shoe into the inner barrel. The entire assembly was run in the hole on 3-1/2" IF drill pipe. After core run \#1 in the $5 U$ sand failed, the bit design was changed from a standard diamond design to a 6-1/8" X 2$5 / 8 "$ PDC design. One monel collar was dropped from the drill string. After core run \#4 in the $5 U$ sand, the core catcher assembly was strengthened by adding a basket catcher and a split ring catcher. The basket catcher was dropped from the assembly after core run \#5.

Orientation Tool And Procedure. The electronic survey instrument chosen to orient the recovered core is a three axis system utilizing accelerometers and magnetometers to determine well bore inclination, well bore direction, and core barrel scribe knife orientation. Information obtained from the survey is stored in memory and downloaded at the surface after each core run. The tool is capable of storing over 7,700 readings, has no attitude or heading limitations, and is 
programmable over a wide range of timing intervals, allowing for greater flexibility. The orientation assembly consists of an instrument pressure barrel, rotating centralizers, and spacer bars to correctly space the tool inside the non-magnetic drill collar (Fig. 1.2). The survey instrument is calibrated electronically prior to its arrival on location.

Core barrel alignment is accomplished by placing an orientation mark on the assembly distinguishing the high side of the survey instrument and aligning it to the main scribe knife in the scribe shoe. To accomplish this, the outer barrel is suspended at the surface by the rig blocks. The inner barrel is then removed and a protractor is aligned with the main scribe knife. The inner barrel is then lowered and a mark is placed on an orientation rod attached to the top of the inner barrel. The survey instrument is threaded onto the orientation rod, the marks on the rod and the instrument assembly are aligned, and the tool is set in place through the use of set screws. The core barrel assembly is then screwed back together and run in the hole.

Well Plan And Coring Proposal. The well plan called for a curve with a dogleg severity (DLS) of less than $19^{\circ} / 100 \mathrm{ft}$. to minimize deflection of the core. A radius of curvature of $400 \mathrm{ft}$., providing a DLS of $14.32^{\circ} / 100 \mathrm{ft}$. was chosen to optimize drilling time and to allow maximum flexibility. The proposed hole diameter of the curve was 6-1/2" O. D. to increase tool string mobility if the DLS became critical. Planned weight on bit (WOB) was from 3,000 lbs. to 5,000 lbs. Rotary speeds were to operate in the range of 35 RPM minimum to a maximum of 65 RPM.

The Upper Spraberry $5 \mathrm{U}$ casing exit called for a section cut from 6,788' to $6,858^{\prime}$ with a proposed kick off point (KOP) of $6,838^{\prime}$. The true vertical depth (TVD) of the $5 \mathrm{U}$ target was projected to be 7,238' TVD. The Upper Spraberry 1U casing exit called for a section cut from 6,639' to 6,709' with a proposed KOP of $6,689^{\prime}$. The $1 \mathrm{U}$ target was projected to be $7,089^{\prime}$ TVD.

Original plans were to cut and retrieve $150 \mathrm{ft}$. of 2-5/8" diameter oriented core from each zone in $30 \mathrm{ft}$. increments. Clean out and TVD correction runs were to be performed as needed, based upon core recovery and mud $\log$ information.

-Upper Spraberry 5U Casing Exit and Curve Summary. A 7- 5/8" cast iron bridge plug (CIBP) was run in the hole via electric wireline and set at a depth of $6,890 \mathrm{ft}$. A $75 \mathrm{ft}$. section of the 7-5/8" casing from 6,788 ft. to $6,863 \mathrm{ft}$. was then milled out using a 7-5/8" section mill. A caliper log was run across the interval to verify the actual amount of casing removed. For the cement kick off plug, a slurry of class "C" $\mathrm{w} / 1 \% \mathrm{CaCl}_{2}$ was pumped and allowed to set for 24 hours to attain sufficient compressive strength for kick off. The plug was then tagged with the drill string to locate the top of cement. Upon tagging the plug, the top was found below the proposed KOP, necessitating pumping a second plug. After another 24 hour curing period, the plug was tagged and dressed off to the KOP of $6,838 \mathrm{ft}$.

The curve build BHA was made up on the surface and run in the hole to the KOP. Circulation was established with a fluid rate of 50 gallons per minute (gpm) and an air rate of 150 gallons per minute equivalent (gpm eq.) at the motor. The build section was drilled on an azimuth of 167 degrees from $6,838 \mathrm{ft}$. measured depth (MD) to 7,488 ft. MD resulting in a radius of curvature of $414 \mathrm{ft}$. with a DLS of 13.85 degrees $/ 100 \mathrm{ft}$. 
Upper Spraberry 5U Coring Summary. The first coring assembly was made up on the surface and run in the hole to the KOP. Circulation was established with the foamed air/brine mixture, the assembly was run to bottom, and coring operations were initiated.

The Upper Spraberry 5U sand was cored and drilled from 7,488 ft. MD to 7,931 ft. MD for a total of $443 \mathrm{ft}$. with a net core recovery of $169 \mathrm{ft}$. (Figure 1.3). Core run \#1 resulted in zero recovery and an extremely low ROP of $35.3 \mathrm{~min} . / \mathrm{ft}$. The bit design was changed from a standard diamond core bit to a 6-1/8" X 2-5/8" PDC design, increasing ROP tremendously. Core runs \#2 and \#3 resulted in $58 \mathrm{ft}$. of core recovery. Core run \#4 was successful but the core was lost when the core catcher assembly failed at the surface during breakdown procedures. The catcher design was changed from a single slip dog catcher to a triple assembly consisting of a slip dog catcher, a basket catcher, and a split ring catcher. Core run \#5 resulted in a $20 \mathrm{ft}$. recovery. Determining that the catcher assembly was too conservative, the basket catcher was dropped for subsequent core runs. Core run \#6 resulted in only 6 in. of recovery due to rubble in the hole. After a clean up run, core runs \#7 - \#9 resulted in $89.5 \mathrm{ft}$. of recovery which terminated coring operations in the $5 \mathrm{U}$.

Upper Spraberry 1U Casing Exit and Curve Summary. A 7- 5/8" retrievable bridge plug (RBP) was run in the hole via electric wireline to a depth of $6,750 \mathrm{ft}$. but set unsuccessfully. The plug and setting tool were removed from the hole and a second plug was successfully set at 6,750 $\mathrm{ft}$. with two sacks of sand on top of the plug. A $30 \mathrm{ft}$. section of the 7-5/8" casing from $6,609 \mathrm{ft}$. to $6,639 \mathrm{ft}$. was milled out using a 7-5/8" section mill. A caliper log was then run across the milled interval to verify the actual amount of casing removed. For the cement kick off plug, a slurry of class " $\mathrm{C}$ " $\mathrm{w} / 1 \% \mathrm{CaCl}_{2}$ was pumped and allowed to set for 24 hours to attain sufficient compressive strength for kick off. The plug was then tagged with the drill string to locate the top of cement. Upon tagging the plug, the top was found below the proposed KOP, necessitating pumping a second plug. After another 24 hour curing period, the plug was tagged and dressed off to the KOP of $6,612 \mathrm{ft}$.

The curve build BHA was made up on the surface and run in the hole to the KOP. Circulation was established with a fluid rate of $50 \mathrm{gpm}$ and an air rate of $140 \mathrm{gpm}$ eq. at the motor. The build section was drilled on an azimuth of 157.7 degrees from $6,612 \mathrm{ft}$. MD to 7,330 ft. MD resulting in a radius of curvature of $457 \mathrm{ft}$. with a DLS of $12.53^{\circ} / 100 \mathrm{ft}$.

Upper Spraberry 1U Coring Summary. The coring assembly consisting of a 6-1/8" X 2-5/8" PDC bit, scribe shoe with slip dog and split ring catchers, 6-1/8" X 2-5/8" X 30' core barrel with aluminum inner barrel, 4-3/4" monel drill collar with EMS survey tool, 4-3/4" monel collar, and crossover sub was made up and run in the hole on 3-1/2" IF drill pipe to the KOP. Circulation was established with the foamed air/brine mixture, the assembly was run to bottom, and coring operations were initiated.

The Upper Spraberry $1 \mathrm{U}$ sand was cored and drilled from 7,330 ft. MD to 7,727 ft. MD for a total of $397 \mathrm{ft}$. with a net core recovery of $226 \mathrm{ft}$. (Fig. 1.3). Core runs \#1 and \#2 resulted in net core recovery of $62 \mathrm{ft}$. Core run \#3 resulted in net recovery of $8 \mathrm{ft}$. before the core barrel jammed with black shale, indicating that the well path was out of zone. After a clean out and TVD 
correction run, core runs \#4 - \#8 resulted in a net recovery of $153 \mathrm{ft}$. Core run \#9 resulted in a net recovery of $3 \mathrm{ft}$. before the barrel jammed and coring operations were terminated.

In summary, acquisition and orientation of the horizontal core was a mechanical success. Drilling procedures, in fact, proved to be not unlike that of coring a vertical well.

\section{References}

1. Schechter, D.S.: "Advanced Reservoir Characterization and Evaluation of $\mathrm{CO}_{2}$ Gravity Drainage in the Naturally Fractured Spraberry Trend Area," First Annual Technical Progress Report, Contract No. DE-FC22-95BC14942, U.S. DOE (Dec 1996).

2. Tyler, N., and Gholston, J.C.: "Heterogeneous Deep-Sea Fan Reservoir, Shackelford and Preston Waterflood Units, Spraberry Trend, West Texas," Report of Investigation No. 171, Bureau of Economic Geology, The University of Texas, Austin, 1988. 


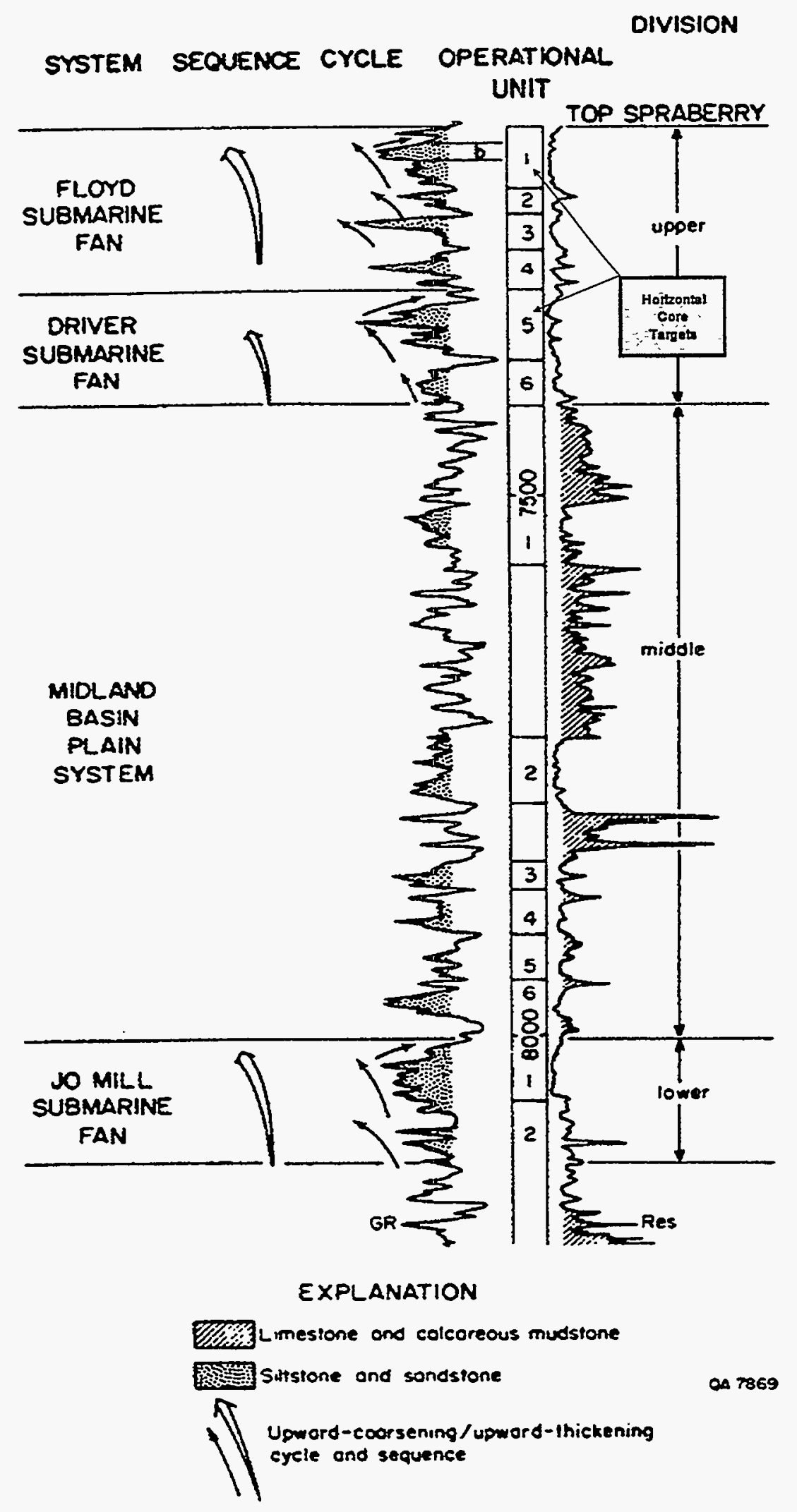

Fig. 1.1 - Division of the Spraberry Formation in the central trend area, TXL Fee "B" No. 1 Well 



Fig. 1.2 - Bottom hole coring and orientation assembly for horizontal coring of E.T. O'Daniel \#28 


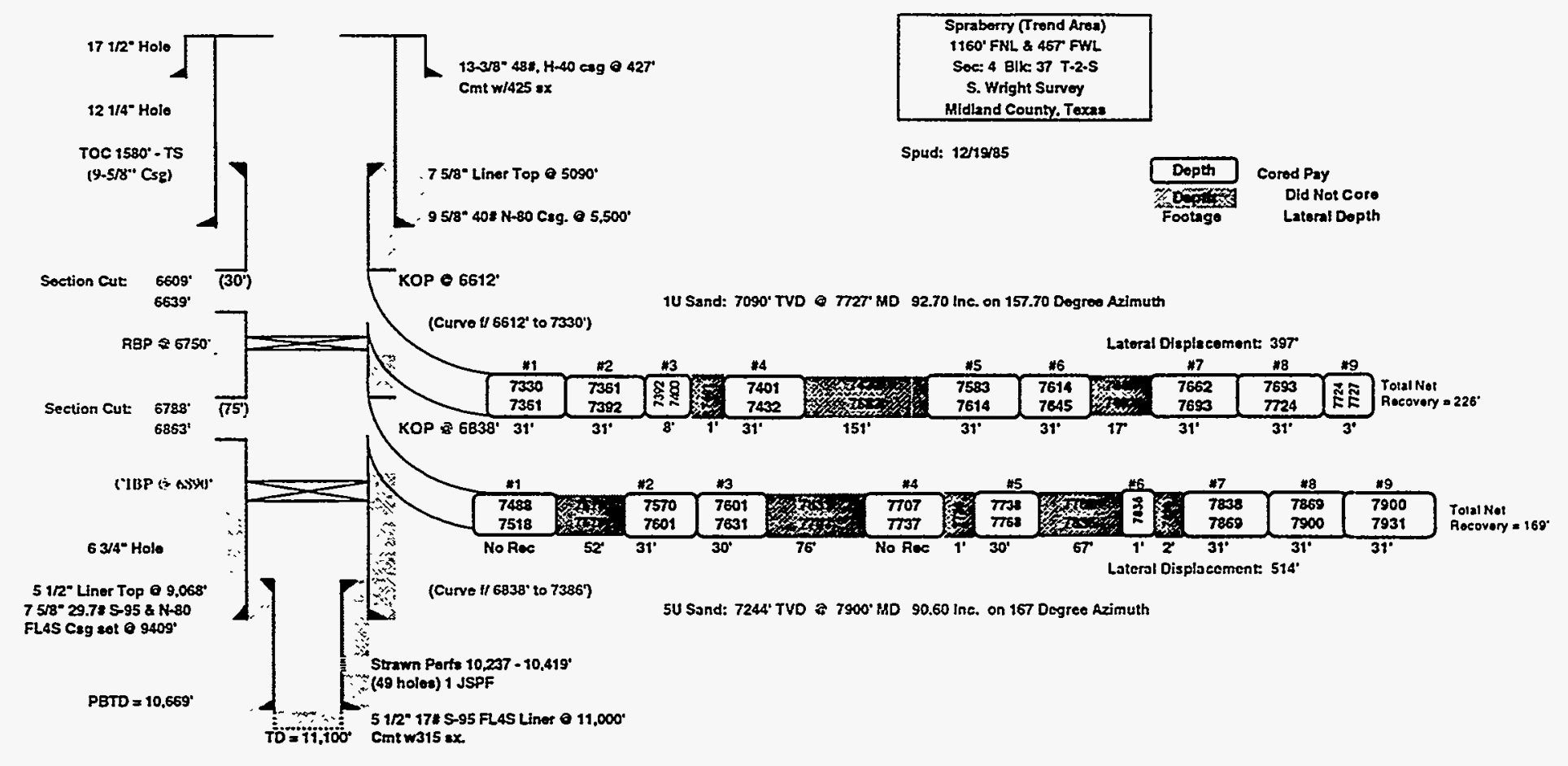

Fig. 1.3 - A schematic diagram showing coring intervals in the E.T. O'Daniel \#28 


\subsection{Fracture Analysis of the E.T. O'Daniel \#28 Horizontal Core}

Three distinct fracture sets, trending NNE, NE, and ENE, are present in cores from the $1 \mathrm{U}$ and $5 \mathrm{U}$ reservoirs. ${ }^{1} \mathrm{NE}$ fractures are commonly mineralized with barite and are found only in the $1 \mathrm{U}$ reservoir. Unmineralized NNE and ENE fractures occur in the 5U reservoir. Unmineralized ENE fractures are also more widely distributed within the black shales overlying both the $1 U$ and $5 U$ reservoirs, and locally near the top of the $1 U$ unit. However, no fractures are present in the black shales underlying either reservoir. Each fracture set has its own characteristic and distinct patterns of 1) spacing, 2) mineralization, 3) distribution with respect to lithology, 4) surface characteristics, and 5) distribution of strikes. Therefore each fracture set is most likely to have resulted from a separate stress event. Aspects of these fractures that are important to production are as follows: 1) fracture strikes are segregated by reservoir unit 2) NE fractures are typically partially mineralized, but mineralization is absent in this set at the base of the $1 U$ reservoir 3) none of the NNE or ENE fractures are mineralized 4) no fractures are present in the shales underlying both reservoirs, but ENE fractures occur in shales overlying both reservoirs.

Orientation. Three distinct natural fracture orientations are present in these horizontal cores, trending approximately NNE, NE, and ENE (Table 1.1).

Although the total range of strikes for each fracture set is about 25 degrees, the distribution of those strikes varies by set (Figs. 1.4 and 1.5). Most of the NE fractures occur within a narrow range (5 degrees) of distribution while most of the ENE fractures fall within a somewhat broader (20 degree) distribution of strikes. The ENE fracture strikes are relatively scattered within the total range of nearly 30 degrees.

Stratigraphic and Lithologic Controls. All 28 NNE fractures occur within the 5U reservoir, while the entire set of $46 \mathrm{NE}$-striking fractures is contained within the $1 \mathrm{U}$ reservoir. Fractures of the ENE fracture are not confined to either the $5 U$ reservoir or to the sandy facies of either reservoir, although they are more common in the $5 \mathrm{U}$ unit. Eleven of the ENE fractures are present within the good $5 U$ reservoir facies, seven ENE fractures are present near the top of the $1 U$ reservoir in silty zones of poor florescence, and eleven more ENE fractures are present in the black shale facies overlying both the $1 \mathrm{U}$ and $5 \mathrm{U}$ reservoirs. No fractures of any set are present in any of the long cores taken from the black shale facies below either reservoir.

Spacing. The NNE fractures are very closely spaced. The average ENE fracture spacing is significantly larger, more than double that of the NNE fractures. NE fractures also have a wide average spacing similar to that of the ENE fractures (Table 1.2).

Each fracture set has a distinct pattern to its spacing distribution. The spacing distribution for the NNE fracture set (Fig. 1.6) conforms to the log-normal pattern typical of regional fractures; i.e., numerous closely spaced fractures and fewer widely spaced fractures. The ENE fracture set (Fig. 1.6) has somewhat fewer of the fractures spaced less than one foot apart, but has a significant number of fractures within the one foot to three foot range. These ENE fractures are widely and irregularly scattered throughout the Spraberry formation, and the tail on the ENE fracture 
distribution histogram is significantly longer than that for either the NNE or NE sets, extending to 13 feet (Fig. 1.6).

In contrast, the NE fracture set is relatively regularly spaced (Fig. 1.6). The spacing distribution histogram for the $\mathrm{NE}$ fracture set shows relatively few and nearly equal numbers of both closely and widely spaced fractures, a narrow range of spacings, and a dominance of intermediate spacings of one to four feet. This fracture set is much more evenly distributed within the formation than either of the other two sets, or than is typical of regional fractures.

Apertures, Mineralization, and Surface Characteristics. Only fractures of the NE striking set (and thus only fractures in the $1 \mathrm{U}$ reservoir) contain obvious mineralization. This mineralization is inferred to be barite, and varies in extent from complete filling of original fracture apertures less than a millimeter wide to a complete absence of mineralization along hairline cracks in the intact rock. Most of the fractures of this set contain some mineralization with the average percentage of filling being on the order of $75 \%$. Where fractures are incompletely mineralized, patches of barite with local crystal faces and rosettes are common, indicating open porosity and permeability pathways at depth. Most of the unmineralized NE fractures occur near the base of the $1 \mathrm{U}$ reservoir. This relationship is consistent in both intervals where the base of the $1 \mathrm{U}$ was cored. Although the reason for this local absence of mineralization is presently unclear, it may be related to local geochemical environments caused by segregation of hydrocarbons and formation waters.

In contrast, none of the ENE or NNE fractures contain mineralization, even in those few intervals where they occur in conjunction with mineralized NE fractures. Rather, the ENE and NNE fractures have gray or brown-stained surfaces that are distinct from the fresh, irregular, coring-induced breaks in the rock. Microscopic crystalline overgrowths may be present on some of the sand grains lining these surfaces.

The ENE fracture surfaces tend to be planar and smooth, whereas many of the NNE fractures occur as anastomosed or en echelon fracture segments with rough fracture surfaces and mm-scale en echelon fracture offsets. Preferred trend to the en echelon steps suggest incipient right-lateral shear.

The NNE and ENE fractures appear as hairline cracks in the core surface where the core has remained intact across the fracture surfaces. This is suggestive of significant in situ conductivity capability along the fractures.

Possible Fracture Origins. The average strikes of the NNE and ENE fractures are respectively 11 degrees counterclockwise and 27 degrees clockwise from the average strike of the NE fracture set. This initially suggests that these three fracture sets might be interpretable as 1) a conjugate pair (the NNE and ENE fracture sets), with 2) a related NE fracture set sub-parallel to the bisector of the acute angle between the conjugate pair. Relatively small changes in stress conditions between the two reservoir units and/or subtle differences in the mechanical properties of the two units would have sufficed to create parallel vertical extension fractures in one bed and a related conjugate pair in the other bed. 
However, in addition to the fact that the NE set does not precisely bisect the strike angle between the other two sets, there are several arguments against this interpretation:

1. Only the NNE set of the supposed NNE-ENE conjugate pair shows signs of the shear stress (the en echelon steps and offsets) that should accompany conjugate fracturing.

2. The ENE half of the pair occurs throughout the formation (except in the shales below the reservoirs), and commonly as the only fracture set present, rather than being limited in distribution to an association with the NNE half of the pair. The ENE fractures show no indications of a shear stress origin.

3. The NE set of fractures is mineralized whereas the other two sets are not: this suggests that the NE fracture set had formed and was mineralized prior to the formation of the other two sets under non-mineralizing conditions.

4. Each of the three fracture sets has its own distinguishing characteristics (including unique spacing and orientation distributions, surface characteristics, and distributions with respect to lithology), which separate the fracture sets and suggest that each formed under a different condition of stress and/or lithification.

5. One, albeit ambiguous, intersection between fractures of two sets was cored, this intersection suggesting that a NNE fracture terminates against, and is therefore younger than, an ENE fracture, rather than being part of a contemporaneous pair.

The conjugate sets theory is simple and clean and it has not been abandoned entirely, but it seems untenable based on these observations. An alternative but somewhat cumbersome interpretation is to suggest three separate fracture events, with the mineralized NE fractures being oldest, the ENE fractures of intermediate relative age, and the NNE fractures youngest. If the stress orientations have not changed since the formation of the youngest fractures, the maximum horizontal in situ compressive stress should then, theoretically, parallel the youngest fracture set. While this interpretation seems uncomfortably complex for this deep basin area of minimal structure, it would seem to best explain the data as presently understood.

Correlation of Core Fractures to Wellbore Image Log. A wellbore image log was run in the horizontal hole along the upper $1 \mathrm{U}$ interval. Although the images seem to be of good quality, there is an unsettling ambiguity in the correlation of log and core fractures (Fig. 1.7).

In order to analyze this ambiguity, a six inch tolerance was used (i.e., an imaged fracture is assumed to correlate to a fracture in core if it is within plus or minus six inches of the measured core depth), and only the intervals where both core and log data are available were considered. In this interval, there are 24 fractures in core that have no correlative fractures at the equivalent depth in the image log, and 36 fractures in the image log that have no equivalents in the core. A maximum of only 15 fractures are definitively present in both the core and the image log, no matter what depth shifts are applied. Fracture swarms and isolated fractures in core, which should have made easily recognizable patterns in the image log and thus provided good core-log tie points, have not left similarly-obvious patterns on the image log. 
Nevertheless, the overall fracture strike trend indicated by the image log is nearly aligned with the average of the fracture orientations measured in core. The secondary trend of ENE fractures in the core is also present in the image log, within the approximately correct measured-depth intervals.

The reasons for agreement in strike without a one-to-one correlation of individual fractures are unclear. Stretch during conveyance of the imaging tool and the common depth ambiguity of cores make exact depth determinations difficult and may explain some of the discrepancy. However these factors can not account for the significant over count of fractures (133\%) made by the image $\log$ relative to the natural fractures in core. It has been suggested that the log is seeing fractures that were missed by the naked eye during minute core examination (unlikely, and which moreover would be insignificant to production if present). However, the images on the log do not indicate that any of the fracture apertures are significantly less than others. Coring induced fractures that formed in the wellbore but not in the core might also explain the apparent over count, but with the present images it is not possible to distinguish these from natural fractures. Moreover, this would not account for the mineralized fractures that are present in the core but not apparent in the image log.

In general, the patterns of fracture positions and the numbers of fractures in the core and image log are not compatible, although the average fracture strikes are. This suggests that image logs should be calibrated with core wherever possible.

\section{Conclusion}

Acquisition of this core unequivocally documents numerous, closely spaced natural fractures in the reservoirs of the Spraberry formation and led to the following major conclusions: 1) Three distinct fracture sets, trending NNE, NE, and ENE, are present in the cores from the $1 \mathrm{U}$ and $5 \mathrm{U}$ reservoirs. NE fractures are commonly mineralized with barite and are found only in the $1 \mathrm{U}$ reservoir. Unmineralized NNE and ENE fractures occur in the 5U reservoir. 2) Each fracture set has its distinct pattern of spacing, mineralization, distribution with respect to lithology, surface characteristics and distribution of strikes. Therefore each fracture set is most likely to have resulted from a separate stress event. 3) There was an unsettling ambiguity in the correlation of the fractures found in the core and the fractures found on the well bore image log. Orientation of the fracture sets from the core and logs were similar, however, there was a significant over count (133\%) of fractures made by the image log relative to the natural fractures in the core.

\section{References}

1. Lorenz, John: "Summary of Observations and Interim Interpretations: Fractures in Horizontal Spraberry Cores, E.T. O'Daniel Well \#28", Internal Memo to Project Team, December 12, 1996. 


\begin{tabular}{|c|c|c|}
\hline \multicolumn{3}{|c|}{ Table 1.1 - Fracture Orientation } \\
\hline \hline Fracture Set & $\begin{array}{c}\text { Average Strike } \\
\text { (deg) }\end{array}$ & $\begin{array}{c}\text { Total Range of } \\
\text { Strikes (deg) }\end{array}$ \\
\hline NNE & 32 & $20-45$ \\
\hline NE & 43 & $35-50$ \\
\hline ENE & 70 & $50-85$ \\
\hline
\end{tabular}

\begin{tabular}{||c|c|c||}
\hline \multicolumn{3}{|c|}{ Table 1.2 - Fracture Spacing } \\
\hline \hline Fracture Set & $\begin{array}{c}\text { Spacing Range } \\
\text { (ft) }\end{array}$ & $\begin{array}{c}\text { Average } \\
\text { Spacing (ft) }\end{array}$ \\
\hline NNE & $0.05-4.50$ & 1.62 \\
\hline NE & $0.73-5.75$ & 3.17 \\
\hline ENE & $0.04-13.0$ & 3.79 \\
\hline
\end{tabular}




\section{All 5U Fractures}

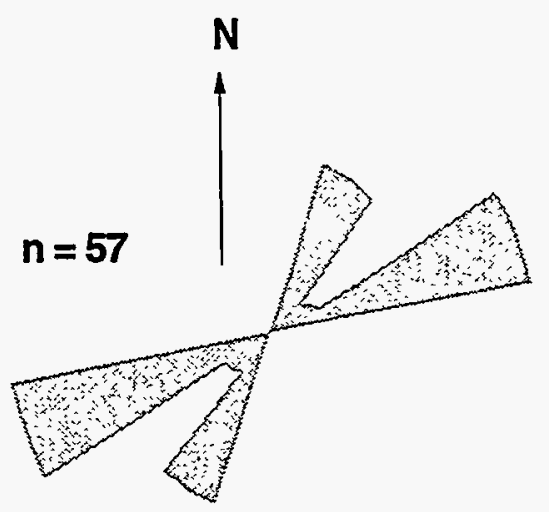

$\begin{array}{ll}\text { NNE set: } & \text { ENE set: } \\ \min 20^{\circ} & \min 60^{\circ} \\ \text { avg } 32^{\circ} & \operatorname{avg~} 70^{\circ} \\ \max 45^{\circ} & \max 85^{\circ}\end{array}$

Fig. 1.4 - Orientation of fractures in the $5 \mathrm{U}$ reservoir

\section{All IU Fractures}

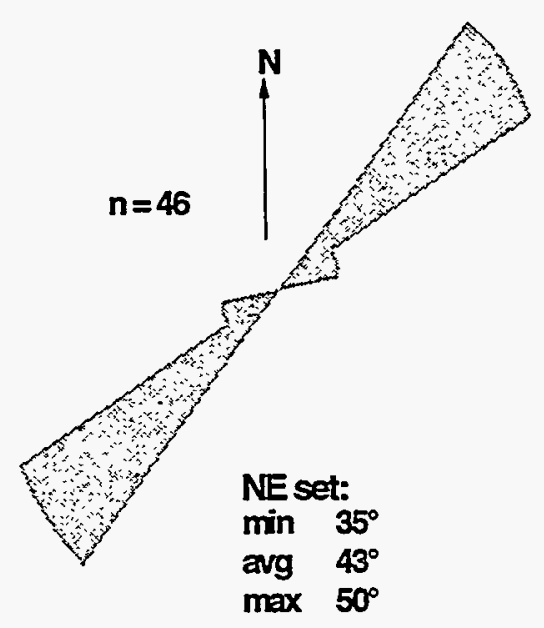

Fig. 1.5 - Orientation of fractures in the $1 \mathrm{U}$ reservoir 


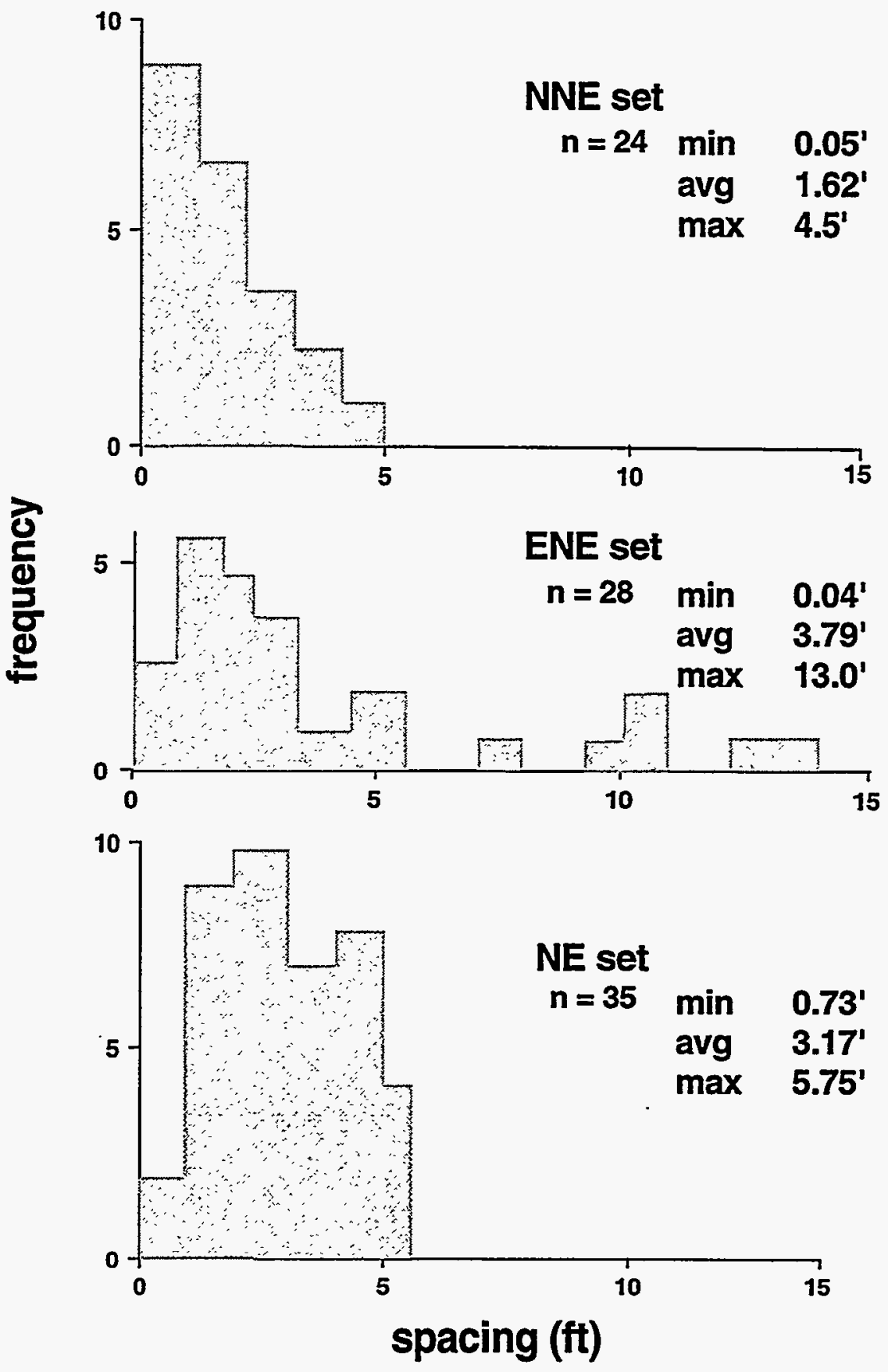

Fig. 1.6 - Distribution of fracture spacing 


\section{CORE}

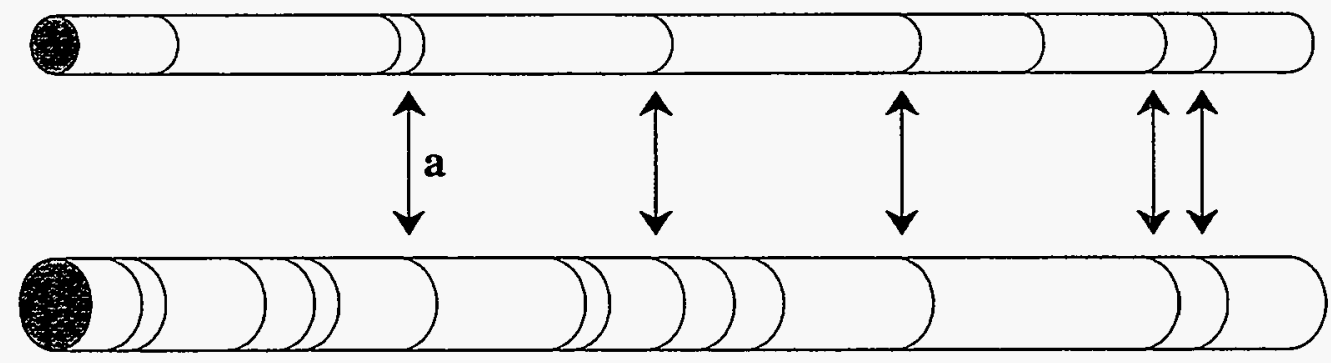

\section{WELIBORE IMAGELOG}

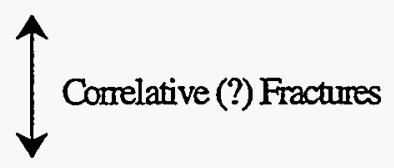

a Correlatable Fracture with unique strike in both core and log

(Log Depth 7675-7700' MD)

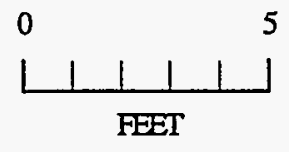

FEET

.Fig. 1.7 - Correlation between core fracture and wellbore image log fracture 


\subsection{Investigation of Fracture Diagenesis from Core Spraberry Natural Fractures}

This section summarizes diagenesis studies of the horizontal core and other fractures in the Spraberry database. We seek to answer a number of questions that have been posed about Spraberry fractures, including fracture spacing, fracture aperture, nature of mineralization, fracture paragenesis, relationship of fracture cements to diagenetic events within the rock matrix, what effect fractures and their diagenesis may have had on nearby rock matrix, and what controls, if any, the rock matrix exerts on the occurrence of the fractures.

Fractures have been examined in a number of cores at a variety of scales. Most work has been done at the core scale, where fracture spacing, orientation, vertical extent of fractures, and presence or absence of mineralization has been documented. Petrographic thin sections have been made from a number of fractures, both mineralized and unmineralized, and most recently, some fracture surfaces have been examined by SEM.

\section{Results and Discussion}

Descriptions of the various fractures from different wells follow. Refer to Table 1.3 for description of natural fractures, and Fig. 1.8 for a type log from a Spraberry well showing units and stratigraphic position of the fractures discussed in this report.

\section{Hutchinson \#9}

One length of fractured core was obtained from this well from a depth of $6850 \mathrm{ft}$. No log was available, but based on core depth and rock composition, this sample is believed to be from the Clearfork shale immediately overlying the upper Spraberry. The rock matrix is a very hard, dense, black dolostone. The fracture is unmineralized, but appears to be natural. Evidence for a natural origin of fractures in this core includes the presence of round microfossils that are broken sharply by the fracture and with no matching portion across the fracture. This implies either movement along the fracture (difficult to determine in this very homogeneous dolostone) or dissolution of material from within the fractured area. Additionally, fracture hackle plumes indicate an area of origin outside of and unrelated to the core itself. Fracture aperture is 0.05 to $0.08 \mathrm{~mm}$.

\section{Hutchinson \#7}

Two fractured cores were obtained from this well. Both were from the middle Spraberry (Fig. 1.8). One core from the middle Spraberry contains a mineralized fracture approximately $1 \mathrm{ft}$ long from a depth of 7448-7449 ft. The fracture cuts across lithological boundaries between siltstones and mudstones, but terminates on both ends in zones that become increasingly clay-rich. Three thin sections were made from this interval. The uppermost thin section consists of a carbonate grainstone/packstone underlain at a sharp contact by a very fine-grained argillaceous siltstone to mudstone. There are three distinctive diagenetic zones noted in this thin section; the lowest, a terrigenous mudstone, the middle, a silicified grainstone, and the uppermost, a carbonatecemented grainstone. Diagenetic zonation indicates that, at least locally, interbedded clay-rich units provide a source for silica cements in siltstones. The next thin section downward in the 
core contains a fine siltstone that grades down into a very fine-grained siltstone interlaminated with argillaceous siltstones and mudstones. The lowermost thin section is a very fine siltstone/mudstone containing abundant detrital clays, micas, and organic matter. The fracture filling in all thin sections is calcite. Fracture width ranges from $0.06-0.08 \mathrm{~mm}$ wide up to about $0.16 \mathrm{~mm}$ at its widest, and length is about $250 \mathrm{~mm}$ long. The widest part of the fracture is in the uppermost thin section, in the coarsest grain-sized material. There are void spaces within the fracture filling; some are apparently open in the subsurface, as there are euhedrally terminated carbonate crystals growing in the pore space. There is an open crack within the fracture that parallels fracture boundaries in one of the thin sections, but it is not apparent whether this is open in the subsurface. The fracture cuts through several very different lithological boundaries, including boundaries between clean and dirty siltstones, siltstone and mudstone, and from a medium-grained fossiliferous grainstone that is strongly silicified to a very fine-grained terrigenous mudstone. Little change in fracture character is apparent at these lithological boundaries.

The finely-laminated siltstones have a few bedding plane fractures. These openings are partially occluded by very fine-grained gypsum. Some of these partings do break through the primary vertical fracture, but there is no mineralization at the juncture to determine relative timing of fractures or mineralization.

The other middle Spraberry fractured core is from a depth of $7645-7647 \mathrm{ft}$, and it contains a fracture set showing an intersection at a 60 degree angle. Both fracture directions are mineralized; again, the only fracture-filling phase appears to be calcite. Four thin sections were made from this fracture zone. The uppermost portion of the fracture is within a laminated mudstone siltstone unit, with laminae defined by increasing and decreasing amounts of detrital clay and organic matter. One fracture terminus is present in one of the thin sections. Fracture width at the tip is only about $0.004 \mathrm{~mm}$ wide and the fracture detours around harder framework grains, making a path through the less competent clays and micritic dolomite cement. As the fracture continues, it widens and begins to break through grains, and as less clay-rich laminae are encountered the fracture becomes straighter and wider, up to $0.04 \mathrm{~mm}$ wide. Fracture character does change somewhat as laminae are crossed, becoming narrower and more sinuous in the clayrich layers and wider and straighter in harder, more quartz-rich layers. The fracture is multistrand in places, and there are parts of the fracture that contain no mineralization. Calcite crystals look corroded in places, as if dissolution had occurred.

\section{Hutchinson \#1}

There is one large mineralized fracture in the core from this well. The fracture is about $2 \mathrm{ft}$ long and is from the depth interval 6945-6947 ft. No log was available for this well, but fracture characteristics and matrix lithology are consistent with that seen in the 1U Spraberry interval in other wells. Mineralization in the large fracture includes quartz and dolomite as the earliestprecipitated phases, a later-precipitated coarsely crystalline barite, and a very finely crystalline mineral identified using qualitative waveform dispersive spectroscopy (WDS) as finely crystalline dolomite. The fracture forms the edge of the core sample and the other side is not available, so information on fracture aperture is not available. Parallel to the large mineralized fracture is a much less obvious fracture that appears unmineralized in hand specimen. 
Petrographic examination shows the presence of significant quartz mineralization in the form of euhedral quartz crystals within this fracture and along its edges. The fracture is wider and more meandering than the hairline fractures seen in the Hutchinson No. 7 well and contains many fragments of matrix rock. The maximum fracture width is about $0.45 \mathrm{~mm}$, but the average aperture of a single strand is about $0.08 \mathrm{~mm}$. This type of fracture would contribute a significant amount of porosity and permeability to a sample, and is almost invisible to the casual observer of a core. Matrix rock in this fractured interval is a clean, very fine sandstone/siltstone with some clay-rich layers and evidence of bioturbation.

\section{E. T. O'Daniel \#37}

There are two principal fractured intervals noted in this core. The most easily-identified natural fracture set is at 7134-7136 ft, within the upper Spraberry 3U sand. Several calcite-filled hairline fractures were noted in the interval. Fracture width in thin section is about $0.16 \mathrm{~mm}$, but there is a gap running along the fracture, and actual filling width is about $0.03 \mathrm{~mm}$ wide. Fracture length is about $250 \mathrm{~mm}(1 \mathrm{ft})$. There are small fracture strands parallel to the main fracture that are also calcite-filled; these are completely mineralized. The sides of the fracture do not match exactly, indicating that the gap may be open in the subsurface.

The other main zone of fracturing is in the interval from $7226 \mathrm{ft}$ to $7234 \mathrm{ft}$. The fractures are above and within the $5 U$ pay zone. Fractures are not mineralized, but were identified as natural fractures. ${ }^{2}$ Several thin sections were made from this zone, some in the horizontal plane and some in the vertical plane. One feature that was noted from thin section analysis is that fractures are not simple planes, but zones, and an individual fracture is composed of short segments that may or may not be joined in the plane of the thin section. Connections between fracture segments may be simple or complex. Also, the fracture can split into bands or zones of disrupted rock. The widest single fracture is about $0.04 \mathrm{~mm}$ wide and zones of fracturing ranged from 0.14 to 0.5 mm in width.

\section{E. T. O'Daniel \#28 (horizontal core)}

This well was originally drilled as a vertical well, but was redrilled as a horizontal well for this project as described in previous sections. Two intervals were cored within the upper Spraberry. Although it was believed that one of the cored intervals was the Spraberry $1 U$ main pay zone, an increasing body of evidence indicates that this cored interval is mostly within one of the two small sands that overlie the main $1 \mathrm{U}$ pay zone (Fig. 1.9). This evidence will be presented in a following section. The other cored interval from this well was the $5 \mathrm{U}$.

Both cores were logged for fracture orientation, fracture spacing, and large scale features. These are summarized in Figs. 1.4, 1.5, 1.6, and 1.10. A few pieces of core were recently made available for detailed petrographic examination. One sample was obtained from each of the cored intervals.

Most fractures in the $1 \mathrm{U}$ cored interval are mineralized, and the average orientation of these fractures trends N43E. Fracture spacing is about $3.17 \mathrm{ft}$, and the fracture orientation is quite uniform. There are a small number of unmineralized fractures that trend N70E and are only seen 
in the overlying black shale intervals that were penetrated in this coring operation. Surfaces of both these fracture sets are smooth and show no sign of shear as described in Section 1.2.

SEM examination of one of the mineralized fractures shows that there are at least three fracturelining mineral phases. Quartz and dolomite are the earliest deposited phases, and mineralization is nucleated on quartz grains and dolomitic cements that are adjacent to the fracture opening. The sample examined in SEM contained more quartz than carbonate cement, and approximately $30 \%$ of the fracture surface was lined with quartz cement. Crystal size is still fairly small, and there is still a significant amount of intergranular and intercrystalline porosity available to permit the flow of fluid between rock matrix and fracture. Barite forms a later fracture-filling phase and appears to form a much more significant barrier to fluid flow. Barite crystals are quite large, up to a millimeter or more in size, and they can completely cover the underlying matrix. Examination in SEM reveals almost no porosity within barite crystals. The paragenetic sequence exhibited by the fracture is similar to that seen in $1 \mathrm{U}$ sandstone from the Hutchinson \#1 and Shackelford \#1-38A. ${ }^{3}$

Fractures within the $5 U$ appear to be mostly unmineralized. One fracture sample was selected because it did appear to have some mineralization, but examination by SEM revealed that the mineral was halite, probably left over from evaporation of reservoir brine. $5 U$ fractures show two distinct orientations, N32E and N70E. Both sets are unmineralized. The N32E set is only seen within the coarser clastics of the $5 \mathrm{U}$, while the N70E set is seen within the clastics and the fine-grained black shales that overlie the $5 \mathrm{U}$. N70E fractures have a spacing of $3.79 \mathrm{ft}$ on average (Fig. 1.6). The N32E fracture set has a spacing of $1.62 \mathrm{ft}$ on average and distribution is log-normal. This fracture set has surfaces that are rougher and show evidence of a shear origin, unlike any of the other fracture sets. ${ }^{4}$

\section{Conclusions}

The examination of naturally-occurring fractures in several vertical Spraberry cores and the horizontal cores obtained from the E. T. O'Daniel \#28 demonstrates unusual complexity for a fairly homogenous and structurally uncomplicated reservoir. Fractures were noted in three main orientations, with two different surface morphologies, and having two kinds of mineralization or none at all. Fracture aperture has not yet been measured for the horizontal core, but thin section measurements show widths of $0.05-0.08 \mathrm{~mm}$ in mineralized fractures. The horizontal core was invaluable in providing evidence on fracture orientation, spacing, aperture, and mineralization within the $1 \mathrm{U}$ and $5 \mathrm{U}$, but many questions still remain to be answered concerning the origins of the various fracture sets, the relationship of the fracture network to rock matrix, and its effects on reservoir production.

\section{References}

1. Schechter, D.S.: "Advanced Reservoir Characterization and Evaluation of $\mathrm{CO}_{2}$ Gravity Drainage in the Naturally Fractured Spraberry Reservoir," quarterly technical progress report, Contract No. DE-FC22-95BC14942, U.S. DOE (Dec. 1995) (PRRC 96-12). 
2. Lorenz, J., 1997, "Horizontal Core Fracture Description," paper presented at the Spraberry Symposium, Parker \& Parsley Development Company and U.S. Department of Energy, Midland, TX (Jan. 1997).

3. "Advanced Reservoir Characterization and Evaluation of $\mathrm{CO}_{2}$ Gravity Drainage in the Naturally Fractured Spraberry Trend Area," The First Annual Technical Progress Report, Contract No. DE-FC22-95BC14942, U.S. DOE (Dec. 1996) (PRRC 96-42)

4. Nelson, R.A.: Geologic Analysis of Naturally Fractured Reservoirs, Gulf Publishing Co., Houston (1985). 
Table 1.3 - Summary of Naturally Fractured Cores

\begin{tabular}{|c|c|c|c|c|}
\hline Well Name & $\begin{array}{l}\text { Depth of Fracture } \\
\text { Interval (ft) }\end{array}$ & Formation Zone & $\begin{array}{l}\text { Pay/ } \\
\text { Nonpay }\end{array}$ & Comments \\
\hline Hutchinson \#9 & 6850 & Clearfork & $\overrightarrow{\mathrm{NP}}$ & unmineralized \\
\hline Hutchinson \#7 & 7448 & Middle Spraberry & $\mathrm{NP}$ & calcite \\
\hline Hutchinson \#1 & 7645 & Middle Spraberry & NP & calcite, 60 set \\
\hline Hutchinson \#1 & 6945 & Upper Spraberry 1U & $P$ & barite \\
\hline E.T. O'Daniel \#37 & 7135 & Upper Spraberry 3U & NP & calcite \\
\hline E.T. O'Daniel \#37 & $7226-7234$ & Upper Spraberry 5U & $\mathrm{P}$ & unmin. \\
\hline $\begin{array}{l}\text { E.T. O'Daniel \#28 } \\
\text { (horizontal core) }\end{array}$ & $\begin{array}{l}7330-7226 \mathrm{MD} \\
7082-70892 \mathrm{TVD} \\
\end{array}$ & Upper Spraberry 1U & $\mathrm{P} / \mathrm{NP}$ & barite \\
\hline $\begin{array}{l}\text { E.T. O’Daniel \#28 } \\
\text { (horizontal core) }\end{array}$ & \begin{tabular}{|}
$7851-7928 \mathrm{MD}$ \\
$7230-7250 \mathrm{TVD}$
\end{tabular} & Upper Spraberry 5U & P/NP & unmin. \\
\hline Shackelford \#138A & $7088-89$ & Upper Spraberry 1U & $\bar{P}$ & barite \\
\hline
\end{tabular}





Fig. 1.8 - Type log of Spraberry in the O'Daniel lease, showing various stratigraphic divisions and the approximate stratigraphic positions where various fractured core samples were obtained. Texas Bureau of Economic Geology subdivides the $1 U$ of the Spraberry into several subunits, of which the b-c sand is the most important pay zone. We refer to this sand as the main $1 \mathrm{U}$ pay. Logs from our type log area (E.T. O'Daniel lease) show two small sands off center above the main pay. We refer to these as the first and second sands above the $1 U$. 


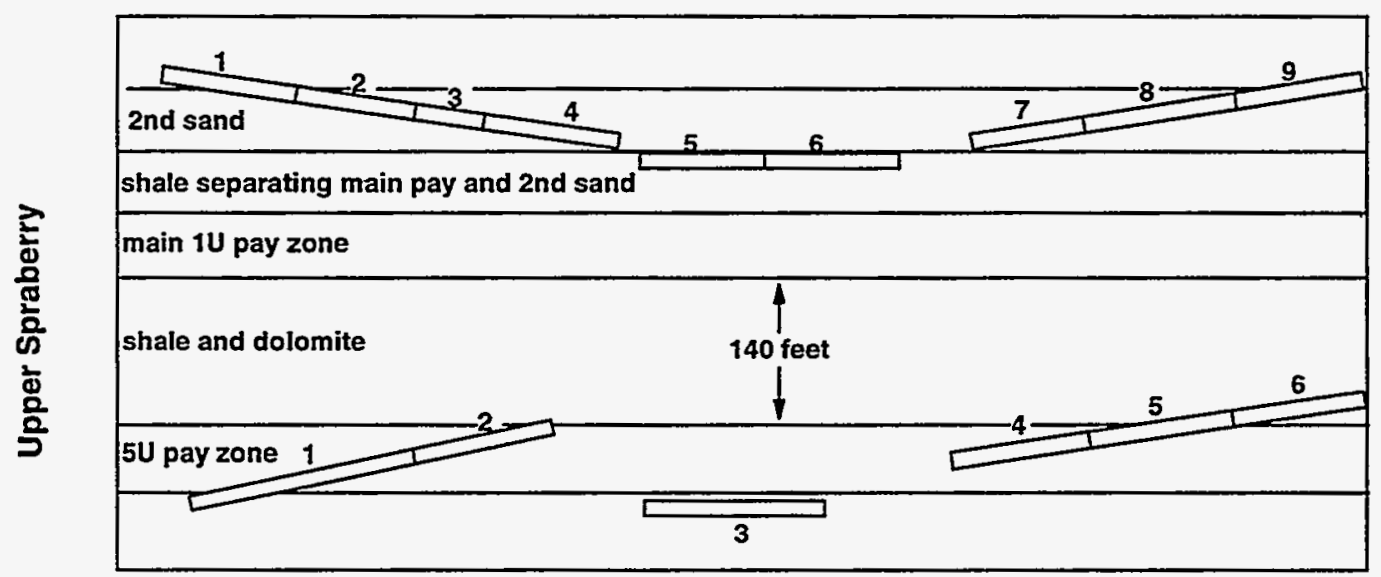

Fig. 1.9 - Schematic diagram of the horizontal cores from the E.T. O'Daniel \#28 well (not to scale).

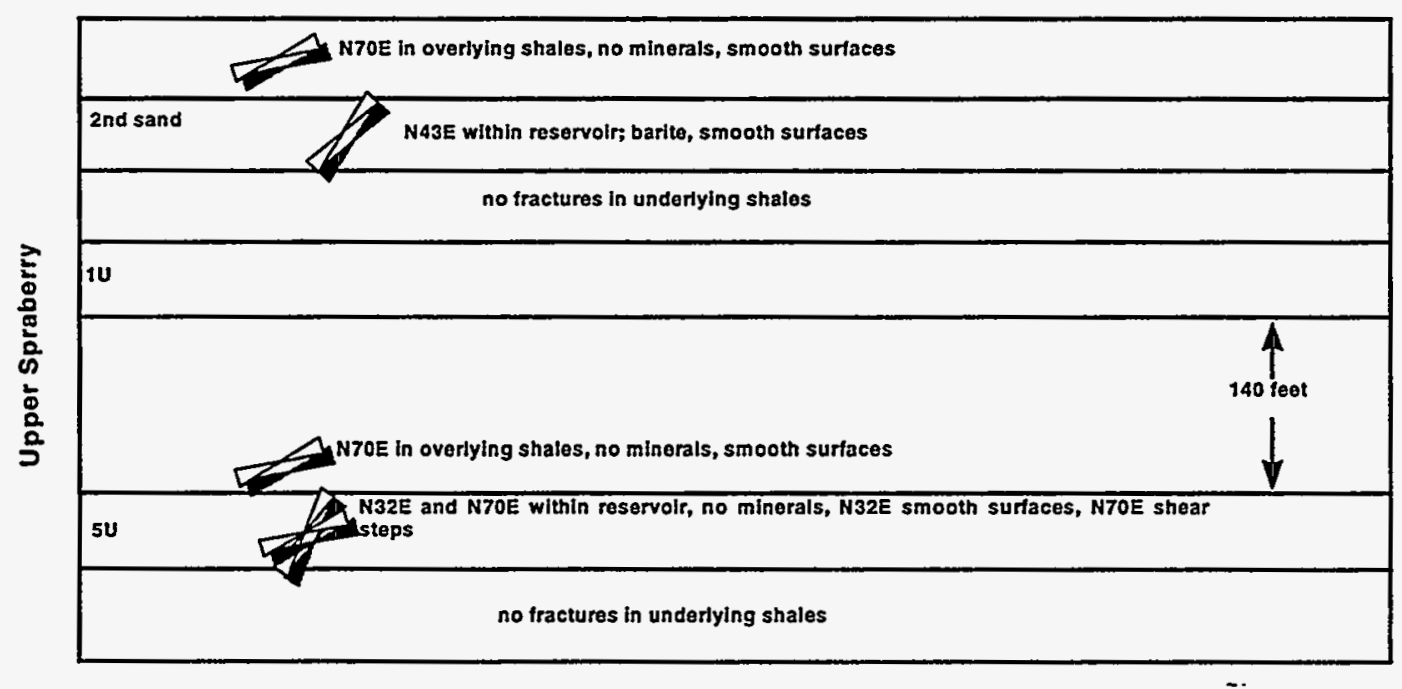

Fig. 1.10 - Summary of fracture characteristics noted in the two horizontal cores from the E. T. O'Daniel \#28 well for both pay and non-pay lithologies. 


\subsection{Application of Rock-Log Model to the Horizontal Core Well}

During the first year of this project, we developed a rock-log model for identification of pay zones in the Spraberry Trend Area reservoirs based on vertical cores and logs (reference 3 in section 1.3). This section demonstrates the capability of the rock-log model using logs from a horizontal well.

\section{Log Analysis}

Figure 1.11 shows the open-hole logs from the E.T.O'Daniel \# 28 horizontal well (Upper Spraberry). The volume of shale was calculated from gamma ray (GR) logs using the Larionov non-linear relationship. Effective porosity was calculated from the bulk-density log and integrated with whole core porosity.

As previously mentioned, there is evidence indicating that the upper cored interval of the O'Daniel \#28 horizontal well is not actually the main $1 U$ pay zone, but is one of the two thin pay sands that immediately overlie this zone (Fig. 1.9). A detailed comparison of gamma logs from the vertical $\log$ of this well and the log that was made from the horizontal redrilling shows that there is good correspondence of gamma peaks between the two logs (Fig. 1.12). As the horizontal well begins its curve from vertical to horizontal, the depths do not correspond, and the gamma peaks in the horizontal log become broader and less sharp as the log reflects the increasing curvature of the hole. Still, peaks have a good one-to-one correspondence, and the peak that constitutes the major Spraberry sand encountered in the horizontal core does not correspond to the main pay zone of the $1 \mathrm{U}$, but to the second small sand that is encountered above the 1U. A similar relationship can be seen when examining the lithodensity log. Dolomite zones, corresponding to intervals of high bulk density, can be compared. Again, the main "pay" interval is actually above the true $1 \mathrm{U}$. We were unable to log the $5 \mathrm{U}$ lateral due to the continual problem of tools getting jammed in the $5 \mathrm{U}$ curve.

Examination of the lithodensity-neutron crossover log provides further confirmation (Fig. 1.13). Within the logged interval, there are only three zones of crossover. The first is small and occurs at a log depth of $7250 \mathrm{ft}$. The second zone of crossover is thicker, from $7360 \mathrm{ft}$ to $7400 \mathrm{ft}$, and this corresponds to the second sand above the $1 U$. This is the zone that was cored. Based on the hole geometry, the sand interval is only about three feet thick, much thinner than the pay zone interval (10 ft) of the $1 \mathrm{U}$ sand as determined from application of the rock-log model to the vertical $\log$.

A fourth line of evidence supporting the argument that the primary $1 \mathrm{U}$ pay zone was not actually cored in the horizontal drilling operation is the close correlation between the core description and the well log after depth correction. At the top of core \#1, $7330 \mathrm{ft}$ core depth and $7315 \mathrm{ft}$ log depth, there is a 25-ft interval of non-pay, non-fluorescing material. At a depth of $7355 \mathrm{ft}$ (7340 $\mathrm{ft}$ log depth) sand percentage begins to increase and the core has poorly developed fluorescence. This trend continues and corresponds with the decrease in gamma count and a decrease in percent dolomite. At a measured depth of $7380 \mathrm{ft}(7365 \mathrm{ft}$ core depth), good fluorescence and the lowest gamma and bulk density readings are encountered. This corresponds to the gamma 
contact between fluorescing and non-fluorescing zones is encountered, again corresponding to the higher gamma counts seen in the well log, which indicate a zone of increased shale content.

The horizontal core well penetrated the two sand stringers that overlie the true main $1 \mathrm{U}$ pay zone. The reasonable production rates from this 3 -ft thick zone are puzzling. The well has produced water-free oil for several months, which is rare in a 40 year old waterflood unit. There are two possible explanations. One explanation may be that the various sands within the $1 \mathrm{U}$ are not in direct communication with each other. No natural fractures were seen in the shaley zones below the cored sand; however, other fractures from other cores do show continuity of fractures through small zones of lithologic change, and it could be that such fractures were simply not encountered in the small section of core that was taken from between the shale overlying the main $1 U$ pay zone (Fig. 1.10). Another possibility may be that production is controlled by fracture intensity, and fracture density is higher within thinner competent beds than in the thicker beds.

Also, crossplots of gamma ray vs. shale volume indicate that there is very little of the pay sand classified as rock type A, based on the our rock-log model ${ }^{1}$ (Fig. 1.14). It can be observed from the Fig. 1.14 that cut-off criteria previously developed from vertical well logs can accurately quantify rock type in the horizontal well. Data points, where the volume of shale is less than $15 \%$ and the effective porosity is greater than 7\% (Rock Type A) are sandiest part of the second sand above the $1 \mathrm{U}$ unit. Data points where the volume of shale is less than $15 \%$ and the effective porosity is less than 7\% (Rock Type B) are from the marginal pay of the 1U sequence. Core data indicates these zones are marginal pay. The porosity of these zones is drastically reduced due to presence of dolomite cement. Data points where the volume of shale is greater than $15 \%$ are from muddy non-pay zones of the Upper Spraberry as the horizontal wellbore traverses shale zones (Rock Type C). Most data points from the $1 \mathrm{U}$ horizontal cores lie either in regions B (marginal pay) or C (nonpay), atypical of reservoir rock from the main $1 U$ pay.

\section{Core Data Analysis}

The Upper Spraberry $1 \mathrm{U}$ sand was drilled and cored from 7,330 ft. MD to 7,727 ft. MD for a total of $397 \mathrm{ft}$. with a net core recovery of $226 \mathrm{ft}$. Core runs \#1 and \#2 resulted in net core recovery of $62 \mathrm{ft}$. Core run \# 3 resulted in net recovery of $8 \mathrm{ft}$. before the core barrel jammed with black shale, indicating that the well path was out of zone. After a clean out and TVD correction run, core runs \#4 - \#8 resulted in a net recovery of $153 \mathrm{ft}$. Core run \#9 resulted in a net recovery of $3 \mathrm{ft}$. before the barrel jammed and coring operations were terminated ${ }^{2}$. Core runs \#1 \& \#2 are from 7,330-7,390 ft. Core runs \#3 \& \#4 are from 7,390-7,430 ft. Core runs \#5 \& \#6 are from 7,587-7,643 ft. Core runs \#7 \& \#8 are from 7,662-7,693 ft. and Core run \#9 are from 7,722-7,726 ft.

Core analysis of these cores were performed by Reservoirs Inc. ${ }^{3}$ A surface gamma ray log of the each core was recorded for downhole correlation. Full diameter ultraviolet and natural photographs were taken for permanent record. Water and oil saturations were determined by Dean-Stark Extraction. Porosity was determined using Boyle's law.-Horizontal and vertical permeability to air was measured using the Hassler Sleeve Permeameter. Comparison of these cores are shown in Table 1.4. 


\section{Verification of Rock-Log Model}

Integration of core and log data indicates that cut-off criteria for log-based Rock Type A are similar to the rock properties observed in core runs \#3 \& \#4 and \#7 \& \#8. Cut-off criteria for log-based Rock Type B are similar to the core runs \#1 \& \#2 and \#9, which are considered as non pay. Cut-off criteria for the log-based Rock Type $C$ are observed in core runs \#5 \& \#6, which are non-pay muddy zones. These core observations of oil saturation in porosities greater than 7\% verify the rock-log model developed based on vertical wells.

\section{Geological Steering}

The correct placement of the wellbore within the pay zone has a crucial role in determining the subsequent commercial success of a horizontal well. However, accurate placement of horizontal wells in thin beds demands changes to present geometrical well planning and drilling techniques. Logging-while-drilling (LWD) formation evaluation in real time has opened up a powerful horizontal directional drilling technique-Geological Steering. Typical LWD tools include GR, dual resistivities, neutron porosity, density porosity, and ultrasonic caliper. Geological steering is the process of landing the well in the target zone prior to drilling horizontally and maintaining the drainhole at the optimum level within the pay.

\section{Conclusions}

The following conclusions were reached based on detailed integration and analysis of the Upper Spraberry horizontal open-hole logs and core data from the well E. T. O'Daniel \# 28:

1. The rock-log model, previously developed from open and cased-hole logs from vertical wells, can be applied successfully to the new horizontal well drilled in the Spraberry Trend and can be used successfully for placement of horizontal wells within thin pay sands.

2. Horizontal core runs \#3 \& \#4 and \#7 \& \#8 from the upper part of the $1 U$ main pay of the Upper Spraberry, have been found to exhibit characteristics of Rock Type A (massive clean siltstone, low shale volume, low bulk density, low water saturation and with strong oil fluorescence).

3. Core runs \#1 \& \#2 and \# 9 are classified as Rock Type B (porosity occluded by dolomitic cement and weak fluorescence).

4. Core runs \#5 \& \#6 are Rock Type C (non-pay mudstones, high shale volume with no oil fluorescence). 
Table 1.4 - Comparison of Horizontal Cores Taken from the 1U Zone in the E.T. O'Daniel \#28

\begin{tabular}{cccccc}
\hline $\begin{array}{l}\text { Core Run No. } \\
\text { (see Fig. 1.9) }\end{array}$ & Porosity & $\begin{array}{c}\text { Oil } \\
\text { Fluorescence }\end{array}$ & $\begin{array}{c}\text { Permeability } \\
(\mathrm{md})\end{array}$ & Water & Oil \\
$\# 1$ & $<0.07$ & No & $<0.1$ & High & No \\
$\# 2$ & $<0.07$ & No & $<0.1$ & High & No \\
$\# 3$ & $>0.07$ & Strong & $>0.1$ & $<0.20$ & $<0.15$ \\
$\# 4$ & $>0.07$ & Strong & $>0.1$ & $<0.20$ & $<0.15$ \\
$\# 5$ & $<0.07$ & No & $<0.1$ & High & No \\
$\# 6$ & $<0.07$ & No & $<0.1$ & High & No \\
$\# 7$ & $>0.07$ & Strong & $>0.1$ & $<0.20$ & $>0.10$ \\
$\# 8$ & $>0.07$ & Strong & $>0.1$ & $<0.20$ & $>0.10$ \\
$\# 9$ & $<0.07$ & No & $<0.1$ & High & No \\
& & & & & \\
\hline
\end{tabular}



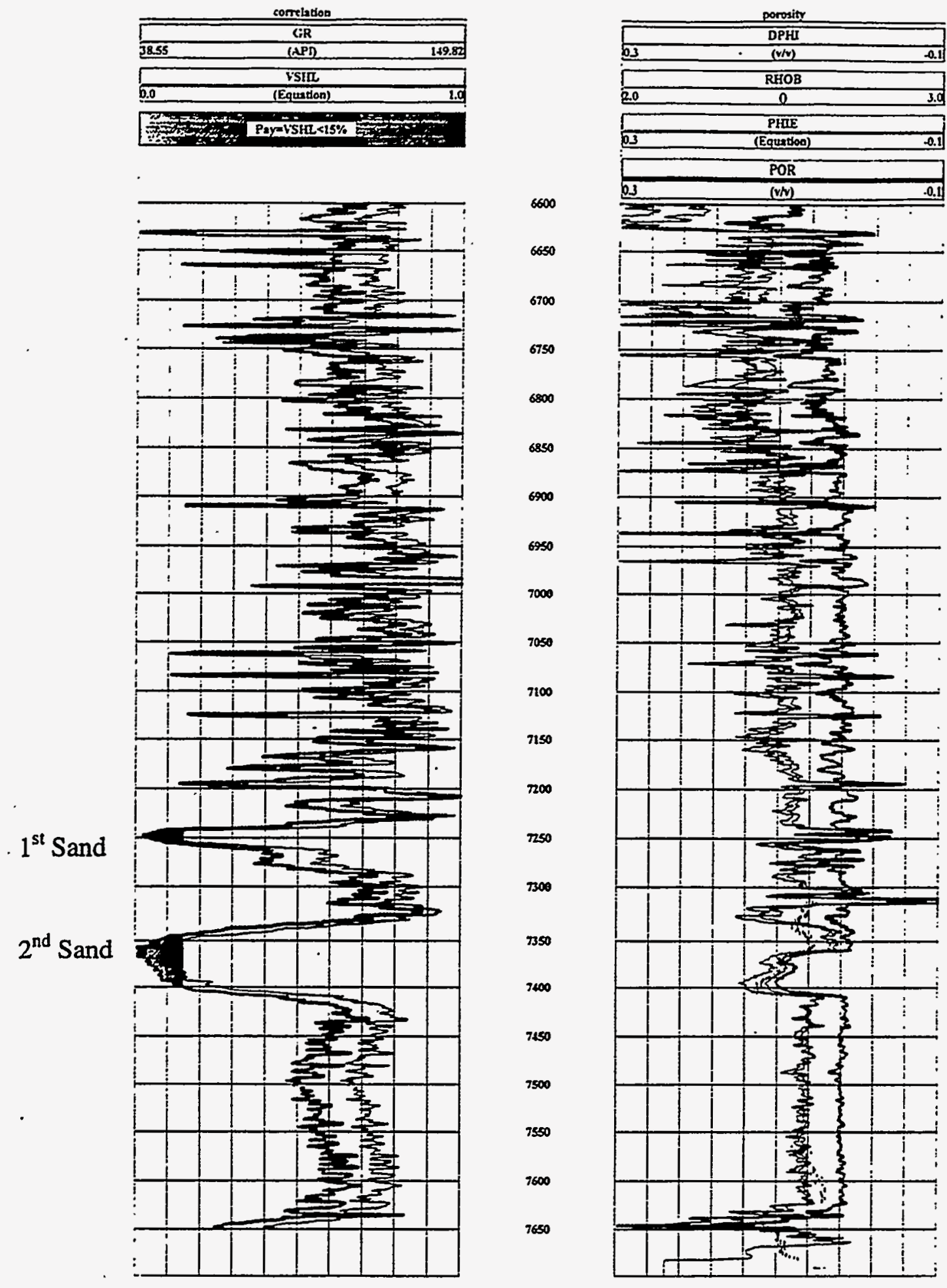

Fig. 1.11 - Open-hole logs from the $1 \mathrm{U}$ zone in the horizontal well E.T. O'Daniel \#28 


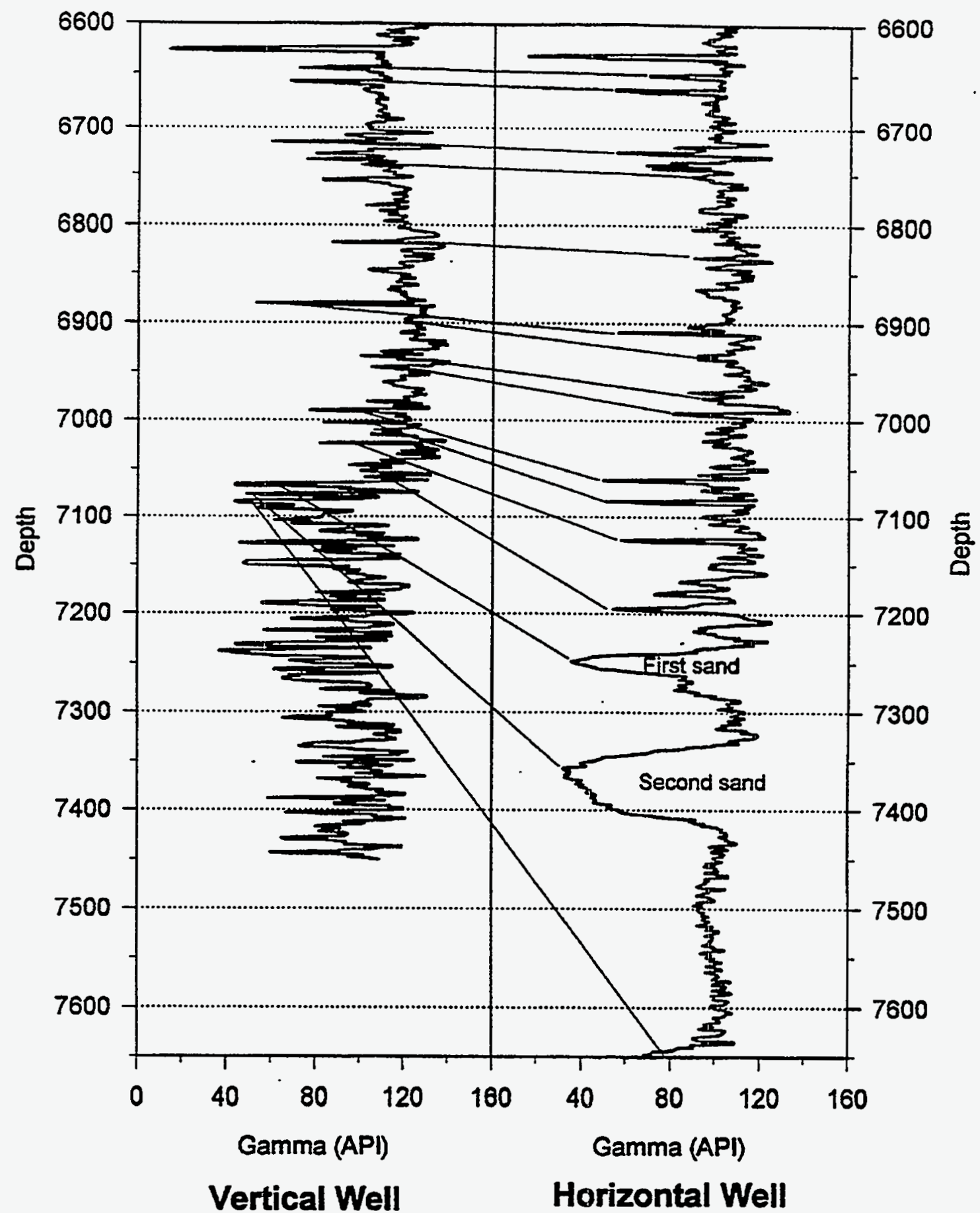

Fig. 1.12 - Comparison of gamma ray log from vertical and horizontal logs in the E.T. O'Daniel \#28 well. Note how individual beds appear to get thicker and more separated from each other as the curvature of the horizontal bore increases and approaches a horizontal line. Lines match various peaks within the Clearfork and demonstrate that the cored interval was not the main $1 \mathrm{U}$ pay zone but the sand immediately above. 


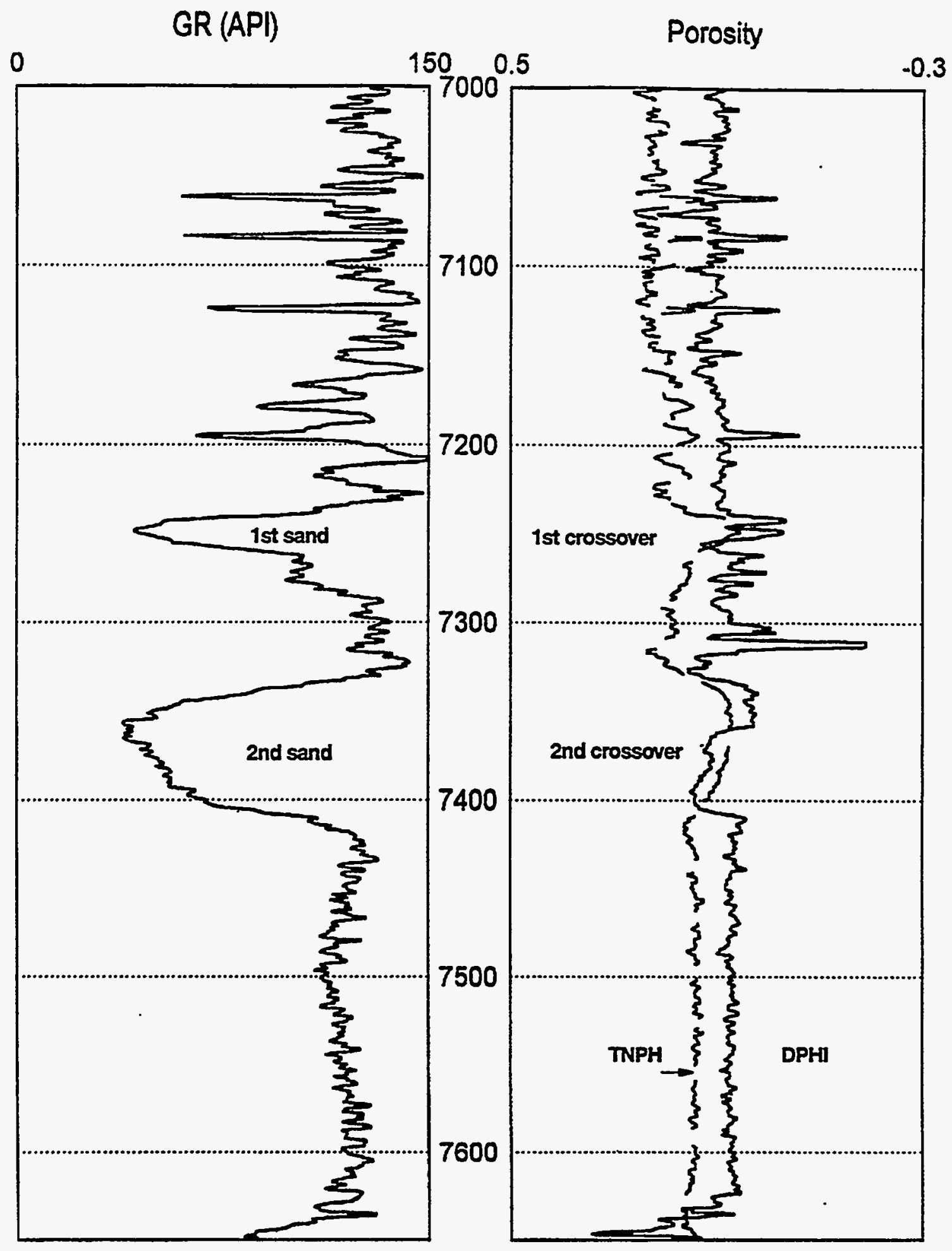

Fig. 1.13 - Lithodensity/Neutron crossover log. This log shows only two pay zones, neither of which is as thick as the $1 U$ was estimated to be in this area. The two minor pay zones correspond to the first and second sand above the $1 \mathrm{U}$ pay. 


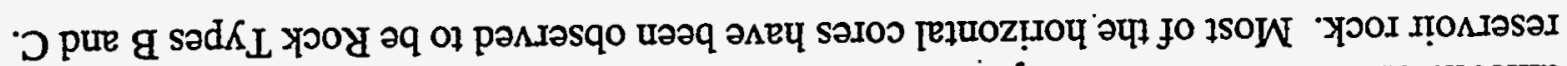

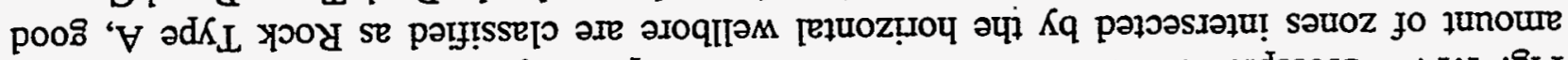

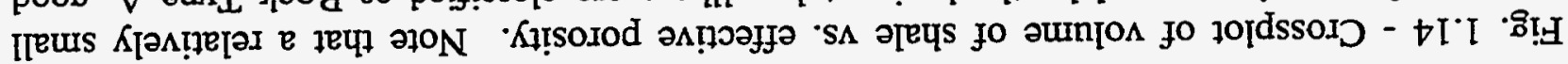

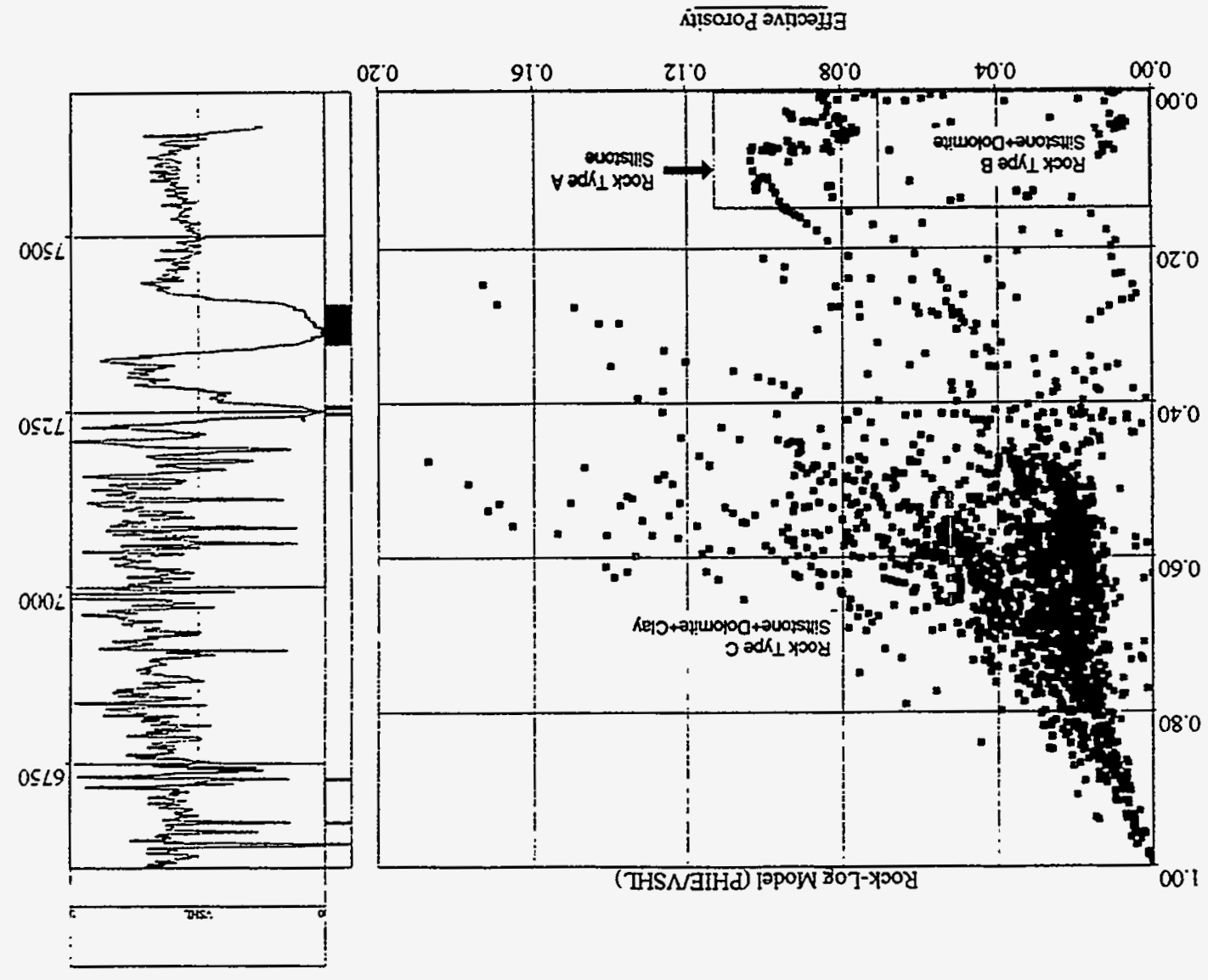




\subsection{Pay Zone Identification Using Old Cased-Hole Logs}

\section{Introduction}

We demonstrated in our first annual report ${ }^{4}$ that classic shaly-sand analysis of open-hole logs from Spraberry wells could accurately quantify thin fractured pay zones which characterize the Spraberry Trend. Based on ultraviolet observations of fluorescing intervals along with whole core analysis and open-hole log interpretation, we reported that a shale volume less than $15 \%$ and an effective porosity greater than $7 \%$ provide accurate cut-off criteria for identification of fluorescing pay zones in the Spraberry Trend Area. We also reported a rock-log model developed for identification of the highest quality pay intervals of the Spraberry Trend Area, using available open-hole well log data. Volume of shale was cross-plotted against effective porosity. Three general rock types were identified, of which only one can be classified as pay. Rock type A (1U and $5 U$ of the Upper Spraberry) has a volume of shale less than $15 \%$ and an effective porosity greater than 7\%. This type of rock is the primary reservoir rock and consists of mainly massive, clean siltstone, fluoresces strongly under ultraviolet light, has low water saturation and visible porosity is observed in thin section analysis. Rock type B (2U, 3U and $4 U$ of the Upper Spraberry) has a volume of shale less than $15 \%$ yet the effective porosity is less than $7 \%$. This type of rock has a low volume of shale with porosity occluded by dolomite cement. Rock type B mainly consists of siltstone and dolomite, fluoresces weakly relative to the $1 \mathrm{U}$ and $5 \mathrm{U}$ and is considered marginal pay. Rock type $\mathrm{C}$ has a volume of shale greater than $15 \%$. This type of rock is composed primarily of non-pay mudstones and has a high shale volume with no fluorescense under ultraviolet light.

In the second year of the project, we extended this open-hole log analysis to old cased-hole gamma ray and neutron (API, count per second or no units) logs. Good agreement is demonstrated between modern open-hole and old cased-hole logs for identification of Spraberry pay. A new method of normalizing neutron logs is also presented in this section.

\section{Case-hole Log Analysis}

Figure 1.15 is an example of a cased-hole log from the well O'Daniel "G" \#1 from the Spraberry Trend Area, and consists of an old gamma ray and neutron log in API units. This figure shows that the old neutron (API) log accurately distinguishes the $1 \mathrm{U}$ and $5 \mathrm{U}$ pay zones from the $2 \mathrm{U}, 3 \mathrm{U}$, and $4 \mathrm{U}$ marginal pay and non-pay zones. The neutron log shows high API in the 2U, 3U, and $4 \mathrm{U}$ marginal pay zones. High neutron API indicates low porosity. Accurate porosity calibration is necessary to apply the cut-off criteria derived from modern open-hole logs and core data to old cased-hole logs.

It is well known that for most old neutron logs, the counts per second or API unit is approximately an inverse linear relationship to the logarithm of porosity. ${ }^{5}$ Calibration charts of neutron logs were available from some of the service companies but most analysts found that relative calibration methods worked best most of time. In this investigation, the neutron log was first normalized to a neutron index (NI). The NI is defined as a linear scaling of the neutron log (API or counts per second) between neutron minimum and neutron maximum in the following form 


$$
N I=\frac{\text { Neutron }_{(\mathrm{log})}-\text { Neutron }_{(\min )}}{\text { Neutron }_{(\max )}-\text { Neutron }_{(\min )}}
$$

To obtain quantitative porosity values, a correlation was constructed using $\mathrm{NI}=0$ as $26 \%$ porosity and $\mathrm{NI}=1$ as $3 \%$ porosity on a semilog plot of porosity and NI, based on the cased-hole log from well O'Daniel " $G$ " \#1. A relationship was obtained through exponential regression and was used to calculate porosity from NI. The relationship is given below:

$$
\text { Porosity }=0.26 e^{-2.16(N I)}
$$

The porosity values were then corrected for matrix contribution (limestone matrix to sandstone matrix), shale effect and hydrocarbon effect to obtain effective porosity. ${ }^{5}$

\section{Discussion}

The volume of shale was calculated from gamma ray logs using the Larionov non-linear relationship. Figure 1.15 shows volume of shale (VSHL) and gamma ray (GR) on the left hand side, neutron, API (NEUT), and effective porosity (NIP) calculated from neutron API on the right hand side. Figure 1.16 shows the cross-plot of volume of shale vs. effective porosity, both calculated from old cased-hole gamma ray and neutron (API) logs from the well O'Daniel "G" \#1. Data points, where the volume of shale is less than $15 \%$ and the effective porosity is greater than 7\%, are from $1 U$ and $5 U$ pay zones of the Upper Spraberry (Rock Type A). Data points where the volume of shale is less than $15 \%$ and the effective porosity is less than $7 \%$ are from $2 \mathrm{U}, 3 \mathrm{U}$ and $4 \mathrm{U}$ units. Core data indicates these zones are non pay. The porosity of the $2 \mathrm{U}, 3 \mathrm{U}$, and $4 U$ zones is drastically reduced due to dolomite cement, thus effectively rendering these zones as non-pay (Rock Type B). Data points where the volume of shale is greater than $15 \%$ are from muddy non-pay zones of the Upper Spraberry (Rock Type C).

This investigation shows that the cut-off criteria for identifying the Spraberry pay zones and logbased rock model that we developed from modern open-hole log suites and core data can be applied successfully to old cased-hole logs in the Spraberry Trend throughout the Midland Basin.

\section{Conclusions}

The following conclusions were reached based on detailed analysis of old cased-hole logs from the Spraberry Trend Area:

1. Old cased-hole gamma ray and neutron (API, counts. per second or no units) logs can be used successfully for identification of the naturally fractured Spraberry pay zones.

2. Reliable quantitative porosity values obtained from careful calibration of open-hole logs and core data, can be obtained from old cased-hole neutron (API, counts per second or no units) logs. 


\section{References}

1. Schechter, D. S., and Banik, A. K.: "Integration of Petrophysical and Geological Data with Open-Hole Logs for Identification of the Naturally Fractured Spraberry Pay Zones," paper SPE 38913 presented at the 1997 SPE Annual Technical Conference and Exhibition, San Antonio, Texas, 5-8 October 1997.

2. McDonald, P., Lorenz, J. C., Sizemore, C., Schechter, D. S., and Sheffield, T.: "Fracture Characterization Based on Oriented Horizontal Core From the Spraberry Trend Reservoir: A Case Study," paper SPE 38664 presented at the 1997 SPE Annual Technical Conference and Exhibition, San Antonio, Texas, 5-8 October 1997.

3. "E.T. O'Daniel \# 28, 1 U Horizontal Core," report prepared by Reservoirs Inc. for Parker \& Parsley Development Company, March 10, 1997.

4. Schechter, D.S.: "Advanced Reservoir Characterization and Evaluation of $\mathrm{CO}_{2}$ Gravity Drainage in the Naturally Fractured Spraberry Trend Area," The First Annual Technical Progress Report for Contract Number DE-FC22-95BC14942. PRRC Report 96-42.

5. Hilchie, D.W.: Old Electrical Log Interpretation, Douglas W. Hilchie Inc., Boulder, Colorado, 1979. 

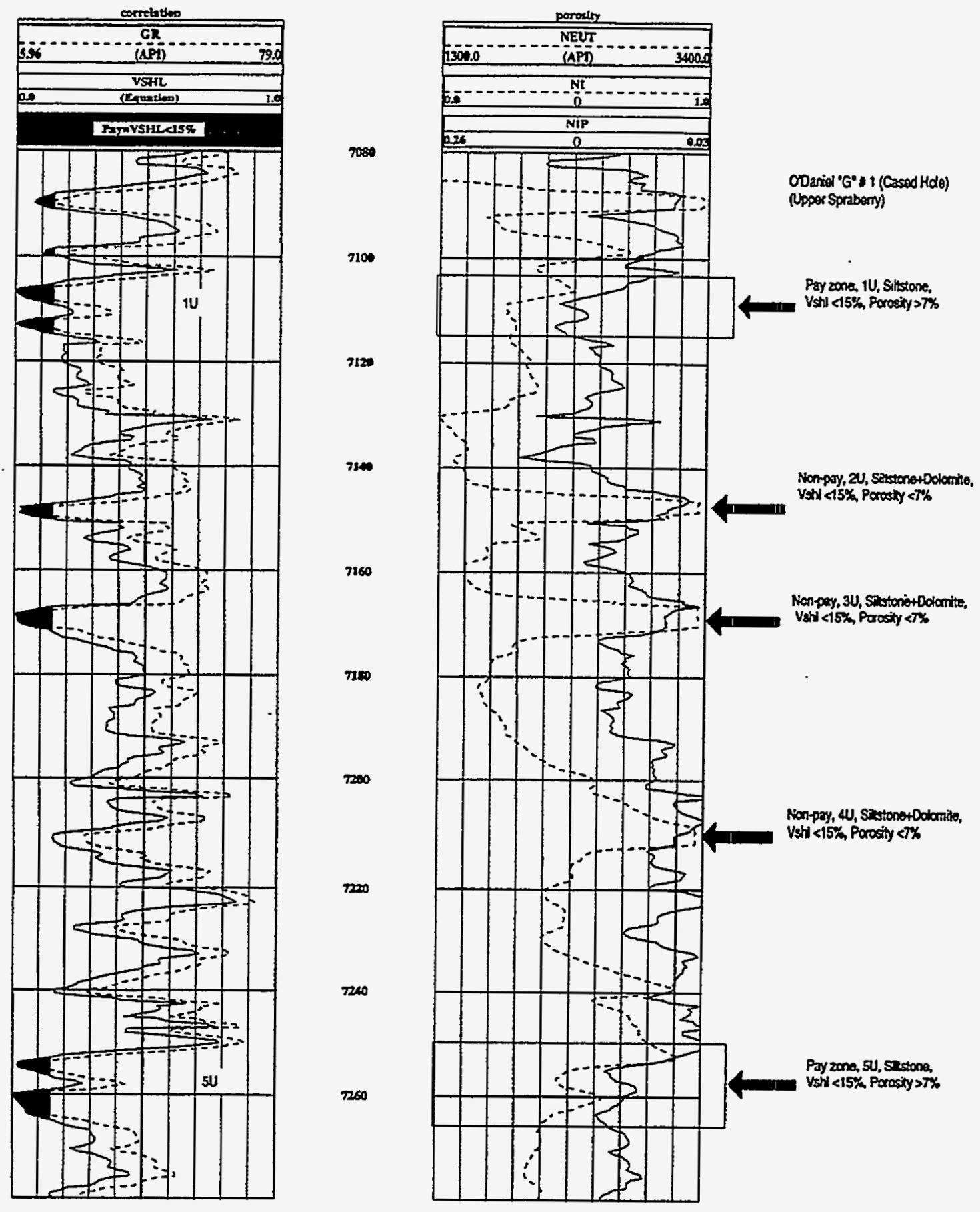

Fig. 1.15 - Cased-hole logs from the E.T. O'Daniel "G" \#1 (Upper Spraberry). Gamma Ray (GR) and volume of shale (VSHL) on the left hand side and neutron log (API) and effective porosity (NIP) on the right hand side. 


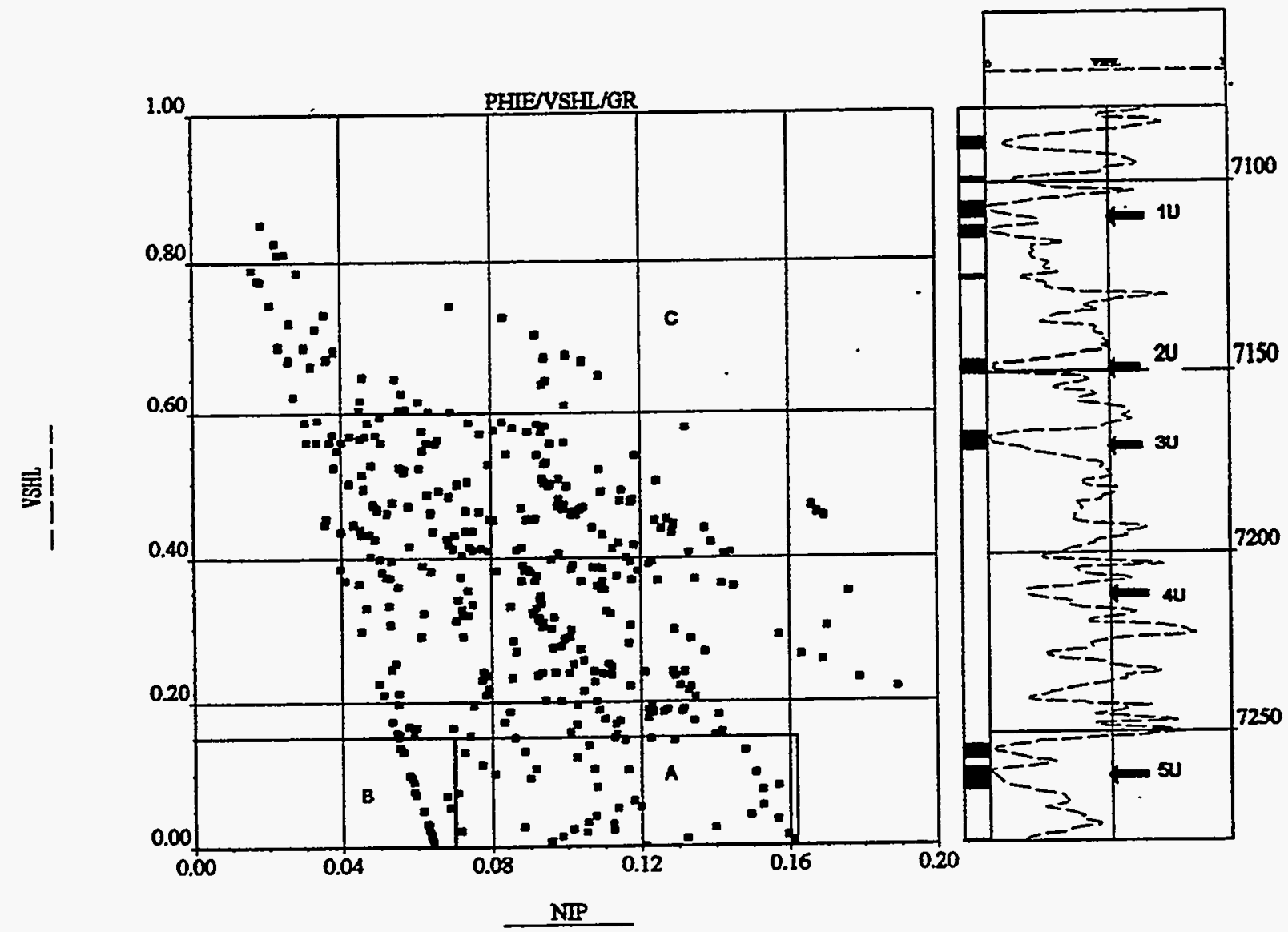

Fig. 1.16 - Volume of shale vs. effective porosity (NIP) calculated from old cased-hole neutron $\log$ (API unit). Data points where VSHL $<15 \%$ and effective porosity $>7 \%$ are from $1 \mathrm{U}$ and $5 \mathrm{U}$ pay zones (Rock Type A). Data points where VSHL $<15 \%$ and effective porosity $<7 \%$ are from $2 \mathrm{U}, 3 \mathrm{U}$ and $4 \mathrm{U}$ marginal pay zones (Rock Type B). Data points where VSHL $>15 \%$ are from muddy non-pay zones (Rock Type C). 


\section{INVESTIGATION OF CRUDE OIL/BRINE/ROCK INTERACTION}

\subsection{Comparison of Scaled Imbibition Lab Results to Waterflood Performance}

\section{Introduction}

The Spraberry Trend Area reservoirs are low permeability, naturally fractured siltstones which present unusual problems for both primary production and waterflooding. After more than 40 years of waterflooding, the current oil recovery in most areas is still less than 15 per cent. The reasons for the low waterflood recovery have never been thoroughly understood. Various hypotheses have been proposed to explain the poor performance of wide-scale waterflooding. ${ }^{1-3}$ These hypotheses include: lack of pattern confinement and injection well density, incorrect well pattern alignment, fracture mineralization which could restrict crossflow, ${ }^{1}$ low permeability to oil after waterflooding a high GOR reservoir, ${ }^{2}$ and stress-sensitive fracture conductivity. ${ }^{3}$ This section emphasizes the importance of slow imbibition of water into the tight, weakly water-wet rock matrix during waterflooding.

The pioneering work on production decline analysis during primary production was performed by $\mathrm{Arps}^{4}$ in 1944. Differential equations for pressure decline were formulated empirically based on statistical analysis of production data obtained from non-fractured reservoirs. Production decline was considered to be proportional to pressure decline through assumptions of constant wellbore pressure and constant productivity index. Exponential, hyperbolic and harmonic decline curves can be identified based on Arps' analysis. Fetkovich ${ }^{5}$ developed decline curves using type curves, so that production decline in hydraulically fractured reservoirs, stratified reservoirs, and the effect of changing backpressure could be analyzed. Laustsen ${ }^{6}$ presented an overview of methods and theory in decline curve analysis. He identified common misinterpretations and rules to avoid these misinterpretations. Two important conclusions were stated by Laustsen: ${ }^{6}$ 1) an understanding of the principals of decline analysis, depletion mechanisms, and rock and fluid characteristics is essential to establish reliable decline interpretations; and 2) subtle changes to curve fits within the engineering accuracy of the data can result in large differences in estimated reserves.

In order to analyze production decline in naturally fractured reservoirs during waterflooding, it is essential to have a simple mathematical model. Unfortunately, such a model is not available in the literature. Therefore, it is desirable to develop simple models, based on principals which govern reservoir performance, for analyzing production decline in naturally fractured reservoirs during waterflooding.

On the basis of the rate law which governs mass transfer, oil production during imbibition waterflooding in naturally fractured reservoirs has been mathematically analyzed in this study. Analytical models for oil production rate and oil recovery schedule have been developed. Imbibition experiments have been conducted using reservoir oil, synthetic reservoir brine, and low-permeability reservoir cores under room and reservoir conditions. Remarkable consistency has been observed between experimental and field data utilizing the niew model. This section demonstrates the models that match both production decline and oil recovery observed in the E.T. O'Daniel Unit waterflood and Humble pilot waterflood in the Spraberry Trend. This scaling analysis clearly indicates the link between laboratory measurements of imbibition, capillary 
pressure and wettability and twenty years of reservoir performance in the imbibition mode. It is found that slow imbibition of water into the weakly water-wet rock matrix is the limiting step for oil recovery during waterflooding Spraberry reservoirs. Since the scaling model indicates that rock permeability and fracture spacing are key factors controlling imbibition rate, it is evident that waterflooding should be sought in areas of high matrix permeability and greater fracture intensity.

\section{Physical Process}

Primary oil production from the class of naturally fractured reservoirs where storage occurs in the matrix and fractures provide reservoir permeability may be divided into three stages: 1) production from the fracture network at early time; 2) production from the fracture network and rock matrix at intermediate time; and 3) production from the rock matrix at a later time. Waterflooding is usually initiated during the mature stage of primary production. Since permeability of the fracture network is usually much higher than that of the rock matrix, it is presumed that oil production rate during waterflooding essentially depends upon the matrix permeability.

The oil production process during the mature stage of a waterflood in a naturally fractured reservoir may be analogous to a bucket of fluid with a small hole in the bottom dripping liquid onto a conveyor belt, as is illustrated in Fig. 2.1. Liquid leaking from the bucket ${ }^{7}$ is analogous to oil produced from the matrix due to water imbibition dominated by capillary forces, and the conveyor belt is analogous to water flow in the fractures that brings the produced oil to the production wellbore. Beyond a certain conveyor belt speed, increasing the speed of the conveyor belt does not matter because the limiting step is the slow discharge of liquid from the bucket. In naturally fractured reservoirs, high injection/throughput rates results in a greater amount of water production, but the imbibition process remains the rate limiting step. Since the oil rate is determined by the imbibition process, oil production is relatively constant and unaffected by injection/throughput rates above a certain threshold; thus, the only result of high injection/throughput rates is increased WOR's and reduced profitability. This production mechanism was observed from the Driver Unit waterflood in the Spraberry Trend Area, where after three cycles of high-rate water injection (during which sweep efficiency was improved), the cyclic water injection scheme produced a similar oil production rate as that produced by a steady low-rate water injection scheme. ${ }^{8}$

\section{Mathematical Models}

The imbibition process may be mathematically modeled using the following rate law governing mass transfer:

$$
\frac{d V}{d t}=-\lambda V^{\alpha}
$$

where $V$ is the volume of oil in place recoverable by imbibition, $t$ is time, $\lambda$ is a proportionality coefficient, and $\alpha$ is an empirical exponent. Equation (1) is widely used in chemical engineering 
and frequently employed by petroleum researchers such as Gupta and $\mathrm{Civan}^{9}$ for analyzing mass transfer in naturally fractured reservoirs.

If an initial condition of $V=V_{o}$ at $t=0$ is used, where $V_{o}$ is the volume of recoverable oil by imbibition, the following two solutions to Eq. (1) can be obtained:

$$
V=V_{o} e^{-\lambda t}
$$

for $\alpha=1$, and

$$
V=\left[V_{0}^{1-\alpha}-\lambda(1-\alpha) t\right]^{\frac{1}{1-\alpha}}
$$

for $\alpha$ not equal to unity.

Recovery Equations. Dimensionless oil recovery due to imbibition is defined as

$$
R_{i m b}=\frac{V_{0}-V}{V_{0}}
$$

Substitutions of Eqs. (2) and (3) into Eq. (4) result in

$$
R_{i m b}=1-e^{-\lambda t}
$$

for $\alpha=1$, and

$$
R_{i m b}=1-\left[1-\frac{\lambda(1-\alpha) t}{V_{o}^{1-\alpha}}\right]^{\frac{1}{1-\alpha}}
$$

for $\alpha$ not equal to unity.

Production Decline Equations. The volume of produced oil (cumulative oil production due to imbibition) is expressed as:

$$
V_{p}=V_{o}-V
$$

Substitution of Eq. (2) into Eq. (7) yields:

$$
V_{p}=V_{o}\left(1-e^{-\lambda t}\right)
$$

An expression for oil production rate is obtained by taking the derivative of Eq. (8) with respect to time: 


$$
q_{0}=\frac{d V_{p}}{d t}=\lambda V_{0} e^{-\lambda t}
$$

Eq. (9) represents an exponential decline model.

Other decline models can be derived from Eqs. (3) and (7). Substitution of Eq. (3) into Eq. (7) yields:

$$
V_{p}=V_{0}-\left[V_{0}^{1-\alpha}-\lambda(1-\alpha) t\right]^{\frac{1}{1-\alpha}}
$$

Taking derivative of Eq. (10) with respect to time gives:

$$
q_{o}=\frac{d V_{p}}{d t}=\frac{\lambda V_{o}^{1-\alpha}}{\left[1+\frac{\lambda \alpha t}{V_{o}^{1-\alpha}\left(\frac{\alpha}{\alpha-1}\right)}\right]^{\frac{\alpha}{\alpha-1}}}
$$

which is a hyperbolic decline model if $\alpha>1$. If $\alpha>>1$, Eq. (11) reduces to a harmonic decline model:

$$
q_{0}=\frac{\lambda V_{o}^{1-\alpha}}{1+\frac{\lambda \alpha t}{V_{0}^{1-\alpha}}}
$$

It should be emphasized that if $\alpha<1$, Eq. (11) becomes:

$$
q_{o}=\lambda V_{o}^{1-\alpha}\left[1-\frac{\lambda(1-\alpha) t}{V_{o}^{1-\alpha}}\right]^{\frac{\alpha}{1-\alpha}}
$$

which is a power-law type decline model that has not been identified previously in performance analysis. The condition of $\alpha<1$ represents a situation where the imbibition rate is not sensitive to oil volume in place. This may be the case when a very slow imbibition process occurs in a nearneutral wetting situation.

\section{Experimental Studies}

In order to understand the interaction between reservoir rock, crude oil and brine in Spraberry Trend Area reservoirs, we have determined rock wettability by performing water and oil imbibition experiments using Spraberry oil, synthetic Spraberry reservoir brine, and Spraberry reservoir rock under ambient and reservoir conditions. Water-oil interfacial tension and capillary 
pressure were also measured using reservoir oil, synthetic reservoir brine, and reservoir rock. Some of the results are presented here. Detailed information has been documented in the First Annual Technical Progress Report. ${ }^{10}$

Procedure. The whole cores received are 4-inch-diameter cores taken from the Spraberry Shackelford Unit 1-38A. Core plugs were cut to 1.5 inch in diameter and about 2 inches long. The plugs were dried in an oven before initiation of imbibition experiments. The experimental procedure for imbibition tests is as follows:

1. Measure core dimensions, weigh dry core, and measure permeability to air $\left(k_{a}\right)$.

2. Periodically inject chloroform into the core samples until the output is clear.

3. Place the chloroform-saturated cores into an oven set to $115^{\circ} \mathrm{C}$, and let the core dry for at least 72 hours.

4. Vacuum core for 72 hours, then saturate core in vacuum with synthetic reservoir brine, let the core age in brine and measure core weight until the weight stabilizes. Calculate core porosity $(\phi)$.

5. Inject brine into the core at 200 psig with 500 psig of overburden pressure for 2 pore volumes. Estimate core permeability to brine $\left(k_{w}\right)$.

6. Inject oil into the core at 200 psig. Measure brine and oil flow rate until the initial brine saturation $\left(S_{w i}\right)$ is established in the core. Estimate permeability to oil at initial brine saturation $\left(k_{o}\right)$.

7. Age the fluid-saturated core in oil and weigh the core until the core weight stabilizes.

8. Place core into an imbibition cell filled with brine at ambient or reservoir conditions. Collect produced oil and determine oil recovery. Terminate imbibition experiment when recovery stabilizes. Determine final oil recovery by imbibition $\left(R_{i m b}\right)$.

9. Displace the residual oil in the core by waterflooding at $200 \mathrm{psig}$. Determine additional oil recovery by waterflooding $\left(R_{f l d}\right)$.

10. Calculate Amott wettability index to water $\left(I_{w=} R_{i m b} /\left(R_{i m b}+R_{f l d}\right)\right)$.

Water-oil interfacial tension was measured using a pendant drop apparatus. Water-oil capillary pressure was measured using a static equilibrium method similar, in principle, to that described by Honarpour et al. ${ }^{11}$

Results. Core properties and experimental conditions are summarized in Table 2.1. Oil recovery curves obtained from water imbibition experiments conducted at ambient conditions are presented in Fig. 2.2. A brine recovery curve obtained from an oil imbibition experiment is presented in Fig. 2.3. Oil recovery curves obtained from water imbibition experiments conducted at reservoir temperature $\left(138^{\circ} \mathrm{F}\right)$ and representative pressures are presented in Fig. 2.4. The water-oil interfacial tension was measured to be 36 dynes $/ \mathrm{cm}$. Smoothed water-oil capillary pressure data are shown in Figs. 2.5 and 2.6 for drainage and imbibition cycles, respectively. 
Discussion. Figure 2.2 indicates that brine imbibition rate varied from core to core. The oil recovery at two weeks when the experiments were terminated ranged from $15 \%$ for low permeability cores to $70 \%$ for high permeability cores. The Amott wettability indices to water $\left(I_{w}\right)$ for various cores was determined and the average value was about 0.55 , indicating a weakly water-wet system.

Figure 2.3 demonstrates that a brine-saturated core spontaneously imbibed oil up to $9 \%$ of the pore volume. This implies that a small fraction of the rock surface is oil-wet, thus the reservoir rock exhibits mixed-wetting behavior.

Water imbibition for core sample SP-H8 was conducted under room temperature during the first three weeks of an extended test. As is shown in Fig. 2.4, no oil was recovered during the three weeks. The imbibition cell was transferred into an air bath at reservoir temperature. Oil recovery by water imbibition was initiated as the temperature increased. This indicates that water imbibiton rates are stimulated by increased temperature, possibly due to reduced oil viscosity. However, the final recovery due to imbibition does not seem to be affected by the viscosity reduction.

Imbibition test results from core samples SP-H2 and SP-H4, conducted at elevated pressure, indicate that pressure does not significantly affect imbibition rate.

Comparison between Figs. 2.2 and Fig. 2.4 indicate that final oil recovery due to water imbibition at reservoir temperature is lower than at room temperature. This is probably due to differences in the initial water saturations. This result could also be due to the reservoir rock becoming less water-wet at elevated temperatures. However, due to the limited amount of data, conclusions can not be drawn. In order to minimize uncertainties in the experiments and speed the investigation, more experiments were conducted to verify the temperature and pressure effects using Berea cores. The results are presented in Section 2.2.

In addition to the capillary pressure curves measured using the static equilibrium method, Figs. 2.5 and 2.6 also include capillary pressure curves obtained using the centrifuge method ${ }^{12}$ and mercury injection..$^{13,14}$ It is seen from Figs. 2.5 and 2.6 that the capillary pressure curves obtained from centrifuge measurements are significantly higher than those obtained from the static equilibrium measurements. These two figures also show that the capillary pressure curves from the static equilibrium measurements are near to those scaled from mercury injection data when a contact angle of $50^{\circ}$ is assumed.

Figure 2.5 corroborates the interpretation of mixed wetting behavior. Note that oil spontaneously imbibes at zero capillary pressure during the drainage cycle. This result is consistent with the oil imbibition experiment shown in Fig. 2.3.

\section{Scale-up of Laboratory Data to Match Reservoir Performance}

In order to apply the experimental data to field scale imbibition waterflooding using the developed mathematical models, dimensionless time $\left(t_{D}\right)$ initially proposed by Mattax and Kyte ${ }^{15}$ and modified by Ma et $a l .{ }^{16}$ is used: 


$$
t_{D}=t \sqrt{\frac{k}{\phi}} \frac{\sigma \cos (\theta)}{\mu_{g} L_{c}^{2}}
$$

where $t$ is imbibition time, $k$ is permeability, $\phi$ is porosity, $\sigma$ is interfacial tension, $\mu_{g}$ is the geometric mean of water and oil viscosities, $L_{c}$ is the characteristic length defined by Ma et al., ${ }^{15}$ and $\theta$ is contact angle. The characteristic length for a matrix block in the reservoir is half the fracture spacing.

The experimental data presented in Fig. 2.2 are plotted in Fig. 2.7 using dimensionless variables. The dimensionless oil recovery is defined by Eq. (4). Also plotted in Fig. 2.7 is the scaled oil recovery curve for Berea cores ${ }^{15}$ under varying conditions. It is seen from Fig. 2.7 that although the recovery data are plotted against dimensionless time, they still do not collapse in a narrow band as do recovery curves obtained using Berea cores. ${ }^{16}$ However, to best utilize the experimental data, an average recovery curve was established and shown in Fig. 2.8. The scaled oil recovery curve for Berea cores is also reproduced for comparison. For the purpose of simplicity, Eq. (5) is used for analyzing imbibition data from Spraberry cores. A curve fit of Eq. (5) to the experimental data shown in Fig. 2.8 is obtained when the following relation is used for Spraberry cores:

$$
\lambda t=6.2 \times 10^{-4} t_{D}
$$

Substituting Eq. (14) into Eq. (15) and solving the latter for $\lambda$ yields the following result:

$$
\lambda=6.2 \times 10^{-4} \sqrt{\frac{k}{\phi}} \frac{\sigma \cos (\theta)}{\mu_{g} L_{c}{ }^{2}}
$$

Substituting Eq. (16) into Eqs. (5) and (9) yields:

$$
R_{i m b}=1-e^{-6.2 \times 10^{-4} t \sqrt{\frac{k}{\phi}} \frac{\sigma \cos (\theta)}{\mu_{g} L_{c}^{2}}}
$$

and

$$
q_{o}=6.2 \times 10^{-4} V_{o} \sqrt{\frac{k}{\phi}} \frac{\sigma \cos (\theta)}{\mu_{g} L_{c}{ }^{2}} e^{-6.2 \times 10^{-4} t \sqrt{\frac{k}{\phi} \sigma \cos (\theta)}}
$$

The above equations are valid when consistent units are used.

Production data from the E.T. O'Daniel Unit and Humble pilot in the Spraberry Trend Area are used to test the imbibition scaling procedure. 
Case 1 - E.T. O'Daniel Unit Waterflood. This unit is located at the northern part of the Spraberry Trend Area Field. The unit covers 2,160 acres, and contains two zones. ${ }^{17}$ The upper zone is responsible for the vast majority of the production from the unit, while the lower zone is productive in only a few areas and does not significantly contribute to the overall production. ${ }^{16}$ The reservoir is known to be highly fractured. The porosity varies from $7 \%$ to $15 \%$, with the matrix permeabilities being less than $1.0 \mathrm{md}$. The original oil in place (OOIP) was estimated to be 14.3 MM STB. Well spacing in the unit is 40 acres. Primary production by solution gas drive began in 1951. At the initiation of waterflood in 1959, 7.4\% of OOIP had been recovered. Currently there are 16 active producing wells in the unit giving a total production rate of about 130 STB/day.

Production Decline. The match between observed production rate and the production rate calculated with Eq. (18) is shown in Fig. 2.9. This match indicates an exponential decline rate of $\lambda=0.00357$ per month. It can be seen from Fig. 2.9 that the observed production rate is significantly lower than the calculated production rate for the time period between 1959 and 1971. This is probably due to low sweep efficiency during the early time of waterflooding. This decline curve is extrapolated into the future to determine when the economic limit would be reached. For this case, if nothing was changed and the unit was left to reach its economic limit, it would do so at the end of 2020 . This projection is based on the limit of $3 \mathrm{STB} /$ day/active well (48 STB/day for the lease).

Parameters used in the calculations are summarized in Table 2.2. No forced matching between the observed and calculated decline curves was necessary. Interfacial tension, viscosity, oil formation volume factor, and porosity were measured in laboratories. Matrix permeability was determined based on a current well test. ${ }^{18}$ The total contributing pay thickness was estimated based on a shaly-sand rock model ${ }^{10}$ and the fact that the upper zone is responsible for the vast majority of the production from the unit. ${ }^{17}$ The initial water saturation in the reservoirs was estimated by Guo and Schechter. ${ }^{3}$ The gas saturation after reservoir repressurization by waterflooding was assumed to be $5 \%$ on average. Average fracture spacing of $2.86 \mathrm{ft}$ was observed from horizontal core data. ${ }^{19}$

As was mentioned earlier, a contact angle of $50^{\circ}$ was estimated by scaling the mercury injection data to the water-oil capillary pressure curve measured using the static equilibrium method. The contact angle can also be estimated directly from this water-oil capillary pressure curve. In fact, based on the Leverett ${ }^{20}$ relation, capillary pressure can be expressed as:

$$
P_{c}\left(S_{w}\right)=\sigma \cos (\theta) \sqrt{\frac{\phi}{k}} J\left(S_{w}\right)
$$

The measured water-oil capillary pressure curve shown in Fig. 6 indicates that $P_{c}$ is about 5 psig, or $19.7 \mathrm{psia}$, at the average initial water saturation, $S_{w i}=0.4$. If $J\left(S_{w}\right)$ is assumed to be equal to $C$, where $C$ is 0.4 for the capillary tube model, ${ }^{21,} 22$ the contact angle $\theta$ can be estimated from Eq. (19). Substituting $P_{c}=19.7 \mathrm{psia}, \sigma=36 \mathrm{mN} / \mathrm{m}, \phi=0.10, k=0.35 \mathrm{md}$, and $J\left(S_{w}\right)=0.4$ into Eq. 
(19) results in $\theta=57$ degrees. Considering the difference between the capillary tube model and reservoir rock, a $C$ value of less than 0.4 should be used. If $C$ values of 0.35 and 0.30 are used in the equation, the calculated values for $\theta$ are 52 degrees and 44 degrees, respectively. These calculations tend to confirm the estimated contact angle of 50 degrees obtained from scaling the mercury injection data to the water-oil capillary pressure curve.

Recently, we built an apparatus for contact angle measurements. A cubical stainless steel cell was constructed with a three-inch diameter circular internal cavity. Inside this cavity is a horizontal disk on the end of a vertical shaft. The disk can be rotated in a horizontal plane through a handle on top of the shaft. Extending from the bottom of the cavity is a hollow needle mounted on a valve apparatus. The apparatus enables the needle to extend and retract vertically. The cell has a water-heated jacket to enable it to be heated to reservoir temperatures. It can also be pressurized to several thousand psia using an external piston pump. Contact angles on a mica surface using reservoir brine and crude oil were measured at the reservoir temperature of $138^{\circ} \mathrm{F}$ and a pressure of 15 psig. A sheet of mica was attached horizontally to the disk. The cell was filled with synthetic Spraberry brine. A drop of Spraberry separator oil was deposited and advanced on the bottom surface of the mica by using the needle, as shown in Figure 2.10. The oil was then retracted back into the needle. The process was recorded in both analog and digital forms using a VCR and SVIP video software. The water receding and advancing contact angles were measured using the digital images and found o be 49.9 degrees and 52.4 degrees, respectively. These values are very close to the assumed contact angle of 50 degrees. The combination of imbibition capillary pressure and contact angle measurements tends to confirm that Spraberry reservoirs are not strongly water-wet.

Although our experimental data indicates that $15 \%$ to $70 \%$ of OOIP can be recovered by water imbibition, it was found that use of the average imbibition efficiency of $32 \%$ gives the best match between the observed decline data and the calculated decline curve. It was recognized that the imbibition capillary pressure curve measured using the static equilibrium method corroborates very well with this number. In fact, Table 2.1 shows that the average initial water saturation in the core samples is $40 \%$. The average initial oil saturation is then $60 \%$. The imbibition capillary pressure curve measured using the static equilibrium method, as is shown in Fig. 2.6, indicates that water imbibition ceased at $60 \%$ water saturation, leaving an oil saturation of $40 \%$ in the core. The efficiency of water imbibition is determined to be $(0.6-0.4) / 0.6=0.33$, which is very close to the value of 0.32 obtained from decline-curve matching.

Oil Recovery. Oil recovery from the unit is presented in Fig. 2.11. Calculated imbibition oil recoveries using Eq. (17) are also plotted in Fig. 2.11. Again, no matching effort was attempted between the observed oil recovery and calculated oil recovery curves. Figure 2.11 indicates that the ultimate recovery is about $36 \%$ of the OOIP by the end of 2020 .

Discussion. Figure 2.11 shows that the actual oil recovery is slightly lower than the model calculated recovery. Reasons for this discrepancy are not clearly understood. It is speculated that one of the reasons is mineralization of the fractures that hinders mass transfer during water imbibition. This hypothesis is partially supported by recent horizontal core data that indicates an average percentage of mineral filling being on the order of $75 \%$ in one of the primary fracture 
sets. $^{19}$

It is important to note that the match shown in Figs. 2.9 and 2.11 can be made using other combinations of matrix permeability and fracture spacing. Some of the combinations are presented in Table 2.3. This means that the uncertainty about one of the parameters may be narrowed through the match if the other parameter is known with confidence.

Case 2 - Humble Pilot Waterflood. This pilot waterflood program was inaugurated on Humble's L.H. Shackclford B lease in the west central portion of the Spraberry Trend in March, 1955. This pilot was considered a successful Spraberry waterflood. Full-scale waterflooding did not emulate the results of the Humble pilot. Understanding the difference between this pilot and field-wide waterflooding is vitally important for improving waterflood performance in the Spraberry Trend Area.

The Humble pilot area is located in the west central portion of the Spraberry Trend Area. The pilot flood consisted of a single 80-acre five-spot. Four injection wells and one center producing well were completed in the Upper Spraberry sand. ${ }^{23}$

Oil Recovery. Oil recovery from the Humble pilot is presented in Fig. 2.12. Calculated imbibition oil recoveries using Eq. (17) are also plotted in Fig. 2.12. Matching was achieved using the same parameters presented in Table 2.2 except for a confinement factor of $40 \%$ and a fracture spacing of $0.6 \mathrm{ft}$.

Production Decline. The comparison between observed production rate and the production rate calculated with Eq. (18) is shown in Fig. 2.13. No further matching effort was made after oil recovery match. It can be seen from Fig. 2.13 that the observed production rate is significantly lower than the calculated production rate for the early time of waterflooding. This is probably due to low sweep efficiency during the early time of waterflooding. Figure 2.13 indicates an exponential decline rate of $\lambda=0.08891$ per month.

Discussion. The production decline rate of $\lambda=0.08891$ per month indicated by Fig. 2.13 is much higher than the long-term decline rate of $\lambda=0.00357$ per month in the E.T: O'Daniel Unit. Reasons for this discrepancy are not understood. It is speculated that one of the reasons is poor fluid confinement due to natural fractures. Some of the oil released from the rock matrix during water imbibition was probably washed out of the pilot area due to excess water injection. Quick response of water injection was observed in the wells out of the pilot area in the on-trend direction, ${ }^{23}$ which tends to support this argument.

It is indicated by Eqs. (17) and (18) that oil recovery and oil production rate from the rock matrix are controlled by reservoir properties. Among these reservoir properties, matrix permeability and fracture intensity have major influences on waterflood performance. In fact, comparison between the matching parameters shows that the major differences in achieving the match between the two waterfloods are matrix permeability and fracture spacing. Other properties such as matrix porosity, and water and gas saturations also affect oil rate performance. Since reservoir properties can not be altered during the waterflood, the best waterflood performance should be expected in areas of high permeability, high porosity, high fracture intensity, thick pay zones, and low water 
and gas saturations.

\section{Conclusions}

An integrated study of imbibition waterflooding in the naturally fractured Spraberry Trend Area reservoirs has been performed. The imbibition process was investigated both experimentally and analytically, and scaled-up to match reservoir performance. Based on experimental results and comparison to field data, the following conclusions can be drawn:

1. Water imbibition in Spraberry reservoir rock samples is significantly slower than that in strongly water-wet Berea sandstone samples after scaling with dimensionless time $\left(t_{D}\right)$. This indicates that the Spraberry reservoir rock is not strongly water-wet.

2. The Spraberry Trend Area reservoir rock tends to be weakly water-wet with mixed-wetting behavior. The estimated average water-rock contact angle used in the scaling analysis is about 50 degrees. This value is fortified by imbibition, capillary pressure, and contact angle measurements.

3. Low rate water imbibition is the dominating mechanism for oil production during the waterflooding in the E.T. O'Daniel Unit and Humble pilot in the Spraberry Trend Area. The scaling model applied to the E.T. O'Daniel Unit and Humble pilot indicates that fracture spacing and matrix permeability may vary from area to area in the Spraberry Trend Area field.

4. The scaling model indicates that the best waterflood performance should be expected in areas of better permeability and porosity, high fracture intensity, thick pay zones, and low water and gas saturations.

5. Production decline models have been derived from a description of imbibition mechanisms. The decline models demonstrate exponential and hyperbolic (including harmonic) declines. A power-law type decline may exist in the case of very slow imbibition.

\section{Nomenclature}

$I_{w}=$ Amott wettability index to water

$k=$ permeability, md

$k_{a}=$ air permeability, md

$k_{o}=$ effective permeability to oil at initial water saturation, md

$k_{w}=$ water permeability, $\mathrm{md}$

$L_{c}=$ characteristic length, $\mathrm{ft}$

$P_{c}=$ capillary pressure, $\mathrm{psig}$

$q_{o}=$ oil production rate, $\mathrm{STB} /$ day

$R_{i m b}=$ scaled imbibition oil recovery, dimensionless

$R_{f l d}=$ scaled waterflood oil recovery, dimensionless

$t=$ time, day

$t_{D}=$ scaled time, dimensionless

$V=$ oil in place recoverable by imbibition, bbl 
$V_{o}=$ original oil in place recoverable by imbibition, bbl

$V_{p}=$ oil recovered by imbibition, bbl

$\alpha=$ rate exponent, dimensionless

$\theta=$ contact angle, degrees

$\lambda=$ rate coefficient in exponential decline, day ${ }^{-1}$

$\mu_{g}=$ effective fluid viscosity (geometric average of water and oil viscosities), cp

$\sigma=$ interfacial tension, $\mathrm{mN} / \mathrm{m}$

$\phi=$ porosity, dimensionless

\section{References}

1. Schechter, D.S., McDonald, P., Sheffield, T., and Baker, R.: "Reservoir Characterization and $\mathrm{CO}_{2}$ Pilot Design in the Naturally Fractured Spraberry Trend Area," paper SPE 35469, presented at the SPE Permian Basin Oil \& Gas Recovery Conference held in Midland, Texas, 27-29, March 1996.

2. Baker, R.O.: "Reasons for the Relatively Low Recovery of the Spraberry Waterfloods," PRRC Spraberry Database, June, 1996.

3. Guo, B. and Schechter, D.S: "Use of a Simple Mathematical Model for Estimating Formation Damage in Wells Intersecting Long Fractures," paper SPE 38178 presented at the 1997 SPE European Formation Damage Conference held in The Hague, The Netherlands, 2-3 June 1997.

4. Arps, J.J.: "Analysis of Decline Curves," paper T.P. 1758 in Petroleum Technology, AIME, September 1944.

5. Fetkovich, M.J.: "Decline Curve Analysis Using Type Curves," JPT (June 1980), pp. 10651077.

6. Laustsen, D.: "Practical Decline Analysis, Part 1 -- Uses and Misuses," JCPT (November 1996), pp. 34-38.

7. Baker, R.O.: "Practical Implications of Imbibition and Fracture Characterization to Spraberry Waterflood Operations,"'memorandum from the Epic Consulting Services Ltd., PRRC Spraberry Database, January 1997.

8. Elkins, L.F., Skov, A.M., and Gould, R.C.: "Progress Report on Spraberry Waterflood Reservoir Performance, Well Stimulation and Water Treatment and Handling," JPT (September 1968), pp. 1039-1049.

9. Gupta, A. and Civans, F.: "Correlation of the Imbibition Drive Matrix-to-Fracture Oil Transfer," paper SPE 28929 submitted for publication in the SPE Journal, January 30, 1996.

10. Schechter, D.S.: "Advanced Reservoir Characterization and Evaluation of $\mathrm{CO}_{2}$ Gravity Drainage in the Naturally Fractured Spraberry Trend Area," First Annual Technical Progress Report to DOE under Contract No. DE-FC22-95BC14942, PRRC Report 96-42, Dec. 17, 1996.

11. Honarpour, M.M., Huang, D.D., and AI-Hussainy, R.: "Simultaneous Measurements of Relative Permeability, Capillary Pressure, and Electrical Resistivity_with Microwave System for Saturation Monitoring," paper SPE 30540, presented at the SPE Annual technical Conference and Exbibition held in Dalas, Texas, 22-25 October, 1995.

12. Reservoirs Inc.: "Oil-Water Capillary Pressure Data, Parker \& Parsley E.T. O’Daniel No. 37 Well, Midland County, Texas," PRRC Spraberry Database, January 1997. 
13. Parker \& Parsley: "Upper Spraberry Capillary Pressure, Judkins A\#5," PRRC Spraberry Database, July 1995.

14. Parker \& Parsley: "Mercury Injection Capillary Pressure, Parker \& Parsley Shackelford No. 1-38A Well, SRS 2097/RSH 3300A," PRRC Spraberry Database, June 1996.

15. Mattax, C.C. and Kyte, J.R.: "Imbibition Oil Recovery from Fractured, Water Drive Reservoirs," SPEJ (June 1962), pp. 177-184.

16. Ma, S., Zhang, X., and Morrow, N.R.: "Influence of Fluid Viscosity on Mass Transfer between Rock Matrix and Fractures," paper CIM 95-94, presented at the $46^{\text {th }}$ Annual Technical Meeting of the Petroleum Society of CIM held in Banff, Alberta, Canada, May 1417, 1995.

17. Baker, R.O.: "Parker \& Parsley Waterflood Surveillance E.T. O'Daniel Unit," PRRC Spraberry Database, February 1997.

18. Baker, R.O. and Spenceley, N.K.: "Pre and Post Hydraulic Fracture Buildup tests on E.T. O'Daniel \#37," Correspondence with Parker and Parsley, PRRC Spraberry Database, December 1996.

19. Lorenz, J.: "Summary of Observations and Interim Interpretations: Fractures in Horizontal Spraberry Cores, E.T. O’Daniel Well \#28," PRRC Spraberry Database, Dec. 12, 1996.

20. Leverett, M.C.: "Capillary Behavior in Porous Solids," Trans. AIME (1941) 142, 152-169.

21. Zhou, D. and Stenby, E.H.: "Immiscible Displacement in a Porous Medium Simulated by a Statistical Model. In: Buller et al. (Editors). North Sea Oil and Gas Reservoirs --- II. Graham and Tortman, London, UK, 271-280.

22. Schechter, D.S., Zhou, D., and Orr, Jr., F.M.: "Low IFT Drainage and Imbibition," J. of Petroleum Science and Engineering, 11 (1994), 283-300.

23. Barfield, E.C., Jordan, J.K., and Moore, W.D.: "An Analysis of Large-Scale Flooding in the fractured Spraberry Trend Area Reservoir," JPT (April 1959), 15-19. 
Table 2.1 - Rock Properties and Conditions for Imbibition Experiments

\begin{tabular}{lrccc}
\hline Core No. & $\begin{array}{c}\phi \\
(\%)\end{array}$ & $\begin{array}{c}k_{w} \\
(\mathrm{md})\end{array}$ & $\begin{array}{c}S_{w i} \\
(\%)\end{array}$ & $\begin{array}{c}\text { Experimental } \\
\text { Condition }\end{array}$ \\
SP-11 & 13.2 & 0.31 & 38 & Ambient \\
SP-21 & 14.4 & 0.35 & 36 & Ambient \\
SP-22 & 10.1 & 0.25 & 42 & Ambient \\
SP-24 & 11.6 & 0.36 & 38 & Ambient \\
SP-27 & 10.6 & 0.29 & 39 & Ambient \\
SP-28 & 7.8 & 0.09 & 53 & Ambient \\
SP-33 & 13.9 & 0.41 & 35 & Ambient \\
SP-1 & 12.0 & 0.34 & 40 & Ambient \\
SP-10* & 14.3 & 0.45 & 32 & Ambient \\
SP-H8 & 9.5 & 0.46 & 53 & Ambient and $138^{\circ} \mathrm{F}$ \\
SP-H9 & 10.4 & 0.45 & 65 & $138^{\circ} \mathrm{F}$ \\
SP-R4 & 9.3 &.-- & 22 & $138^{\circ} \mathrm{F}$ \\
SP-R5 & 9.6 & 0.07 & 22 & $138^{\circ} \mathrm{F}$ \\
SP-H2 & 11.0 & 0.58 & 40 & $138^{\circ} \mathrm{F} / 1040 \mathrm{psig}$ \\
SP-H4 & 10.5 & 0.55 & 49 & $138^{\circ} \mathrm{F} / 1040 \mathrm{psig}$ \\
Average & 11.2 & 0.35 & 40 & \\
& & & & \\
\hline
\end{tabular}

* Oil imbibition into a brine-saturated core

Table 2.2 - Reservoir Properties of the E.T. O'Daniel Unit, Spraberry Trend Area, West Texas

\begin{tabular}{lcc} 
& & Source \\
Total pay zone thickness, $\mathrm{ft}$ & 20 & Ref. 10 \\
Matrix permeability, md & 0.03 & Ref. 18 \\
Matrix porosity & 0.11 & Table 2.1 \\
Initial water saturation & 0.40 & Table 2.1 \\
Gas saturation after repressurization & 0 & Assumed \\
Advancing contact angle, degrees & 50 & Imbibition $P_{c}$ \\
Effective fluid viscosity, cp & 0.95 & Ref. 10 \\
Oil-water interfacial tension, $\mathrm{mN} / \mathrm{m}$ & 36 & Ref. 10 \\
Oil formation volume factor, rb/STB & 1.2 & Ref. 10 \\
Efficiency of water imbibition, $\%$ & 32 & Imbibition $P_{c}$ \\
Fracture spacing, $\mathrm{ft}$ & 2.86 & Ref. 19 \\
\hline
\end{tabular}


Table 2.3 - Alternative Matching Parameters

\begin{tabular}{cc}
\hline $\begin{array}{c}\text { Effective Matrix Permeability } \\
(\mathrm{md})\end{array}$ & $\begin{array}{c}\text { Fracture Spacing } \\
(\mathrm{ft})\end{array}$ \\
& \\
0.03 & 2.86 \\
0.06 & 3.40 \\
0.12 & 4.05 \\
0.24 & 4.81 \\
0.36 & 5.32 \\
0.48 & 5.72 \\
\hline
\end{tabular}

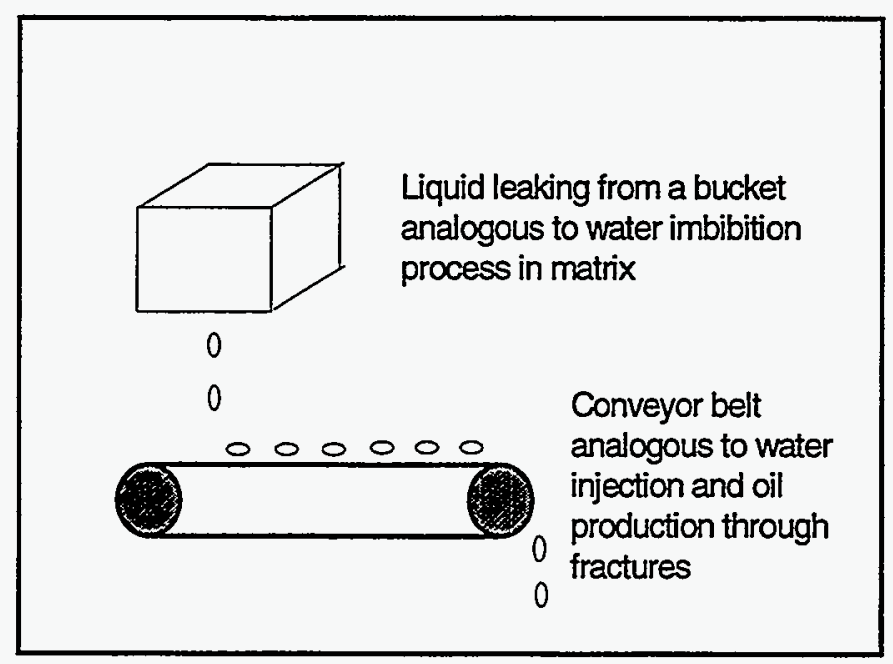

Fig. 2.1 - An analogue model for imbibition waterflooding in naturally fractured reservoirs with spontaneous imbibition acting as the rate-limiting step. 


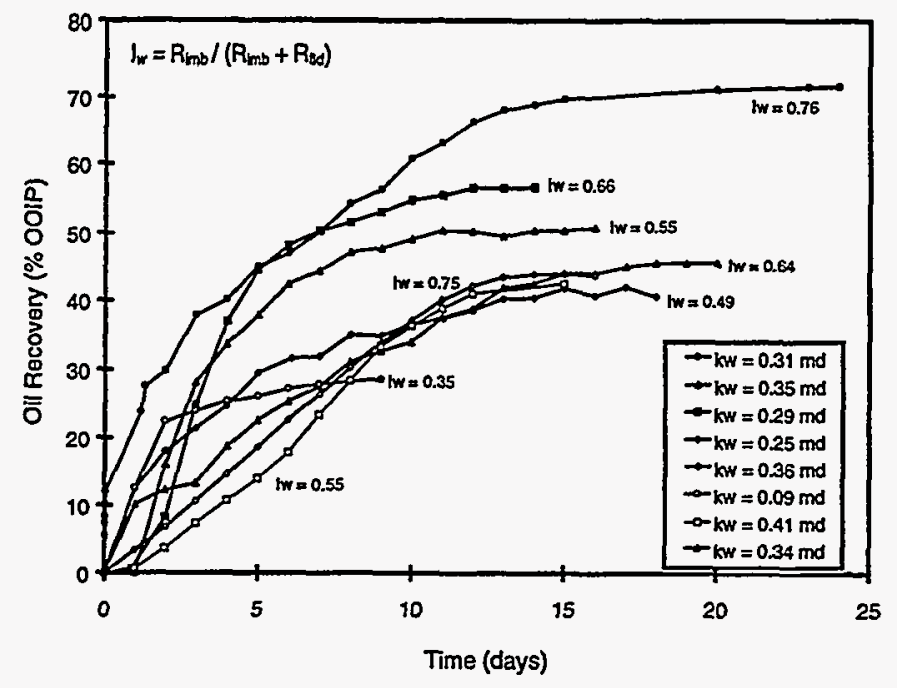

Fig. 2.2 - Oil recovery curves obtained from water imbibition under ambient conditions. Values of wettability index, $I_{w}$, are shown for each experiment.

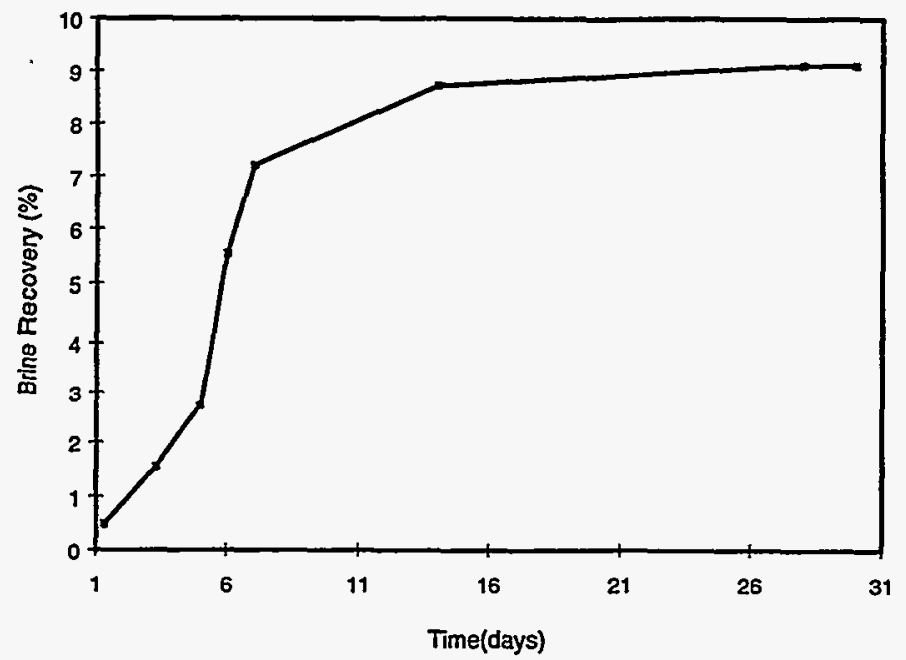

Fig. 2.3 - Brine recovery curve obtained during oil imbibition on an core sample from the Spraberry Trend Area. 


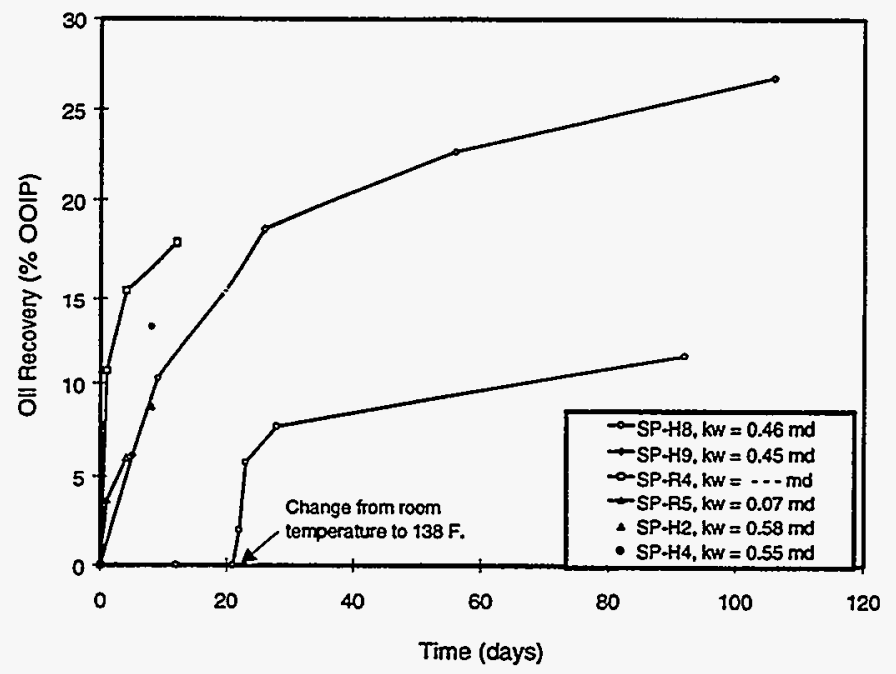

Fig. 2.4 - Oil recovery curves obtained from water imbibition under reservoir temperature and pressures. Experimental conditions are summarized in Table 2.1.

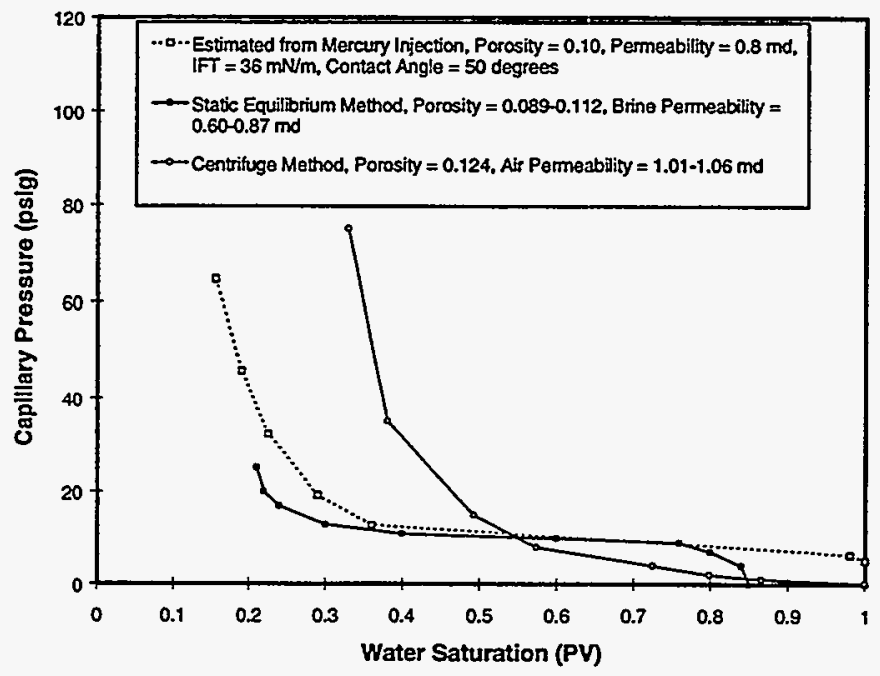

Fig. 2.5 - Comparison of drainage capillary pressure curves obtained using various methods for core samples from the Spraberry Trend Area. 


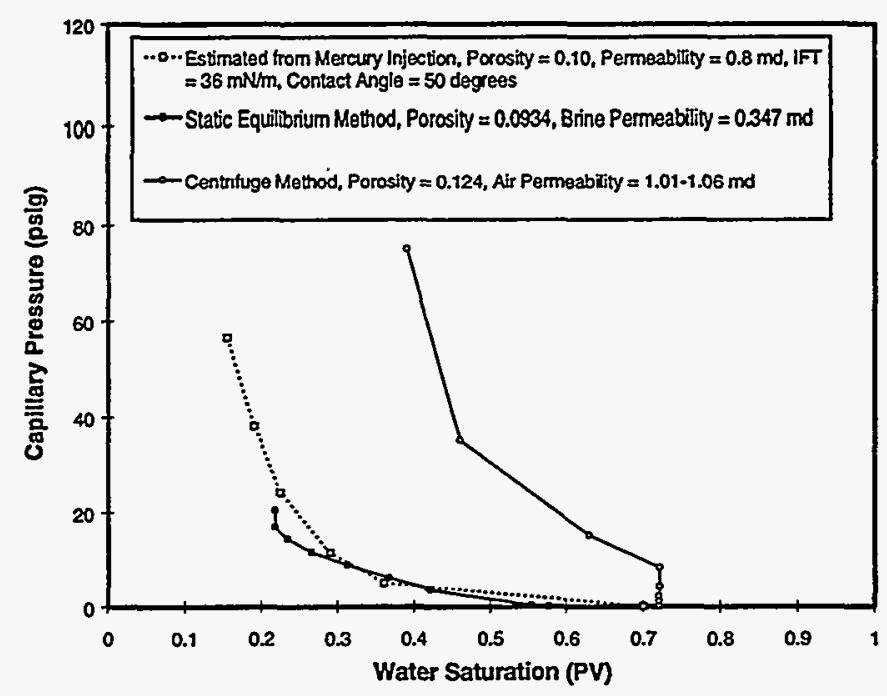

Fig. 2.6 - Comparison of imbibition capillary pressure curves obtained using various methods for core samples from the Spraberry Trend Area.

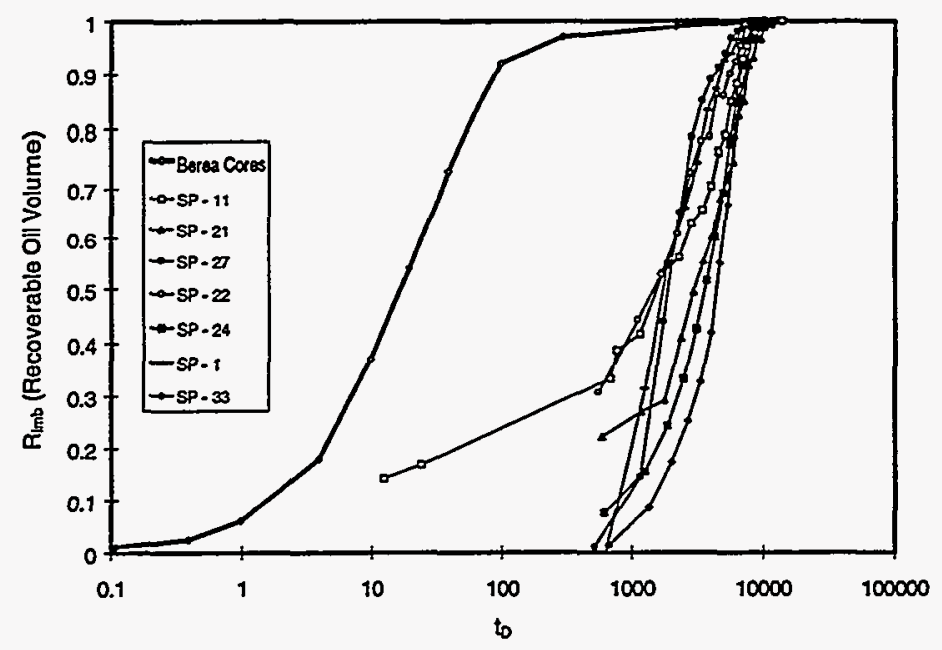

Fig. 2.7 - Oil recovery curves from Fig. 2.2 plotted using dimensionless variables and compared with a strongly water-wet composite curve measured from Berea cores. 


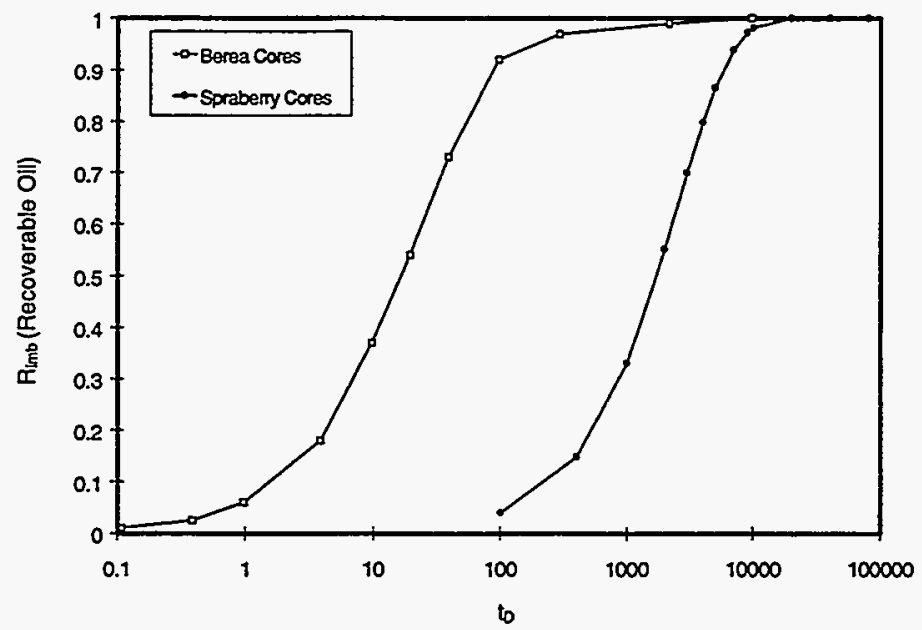

Fig. 2.8 - Comparison between composite imbibition oil recovery curves obtained from Berea sandstone and Spraberry Trend Area reservoir sandstone.

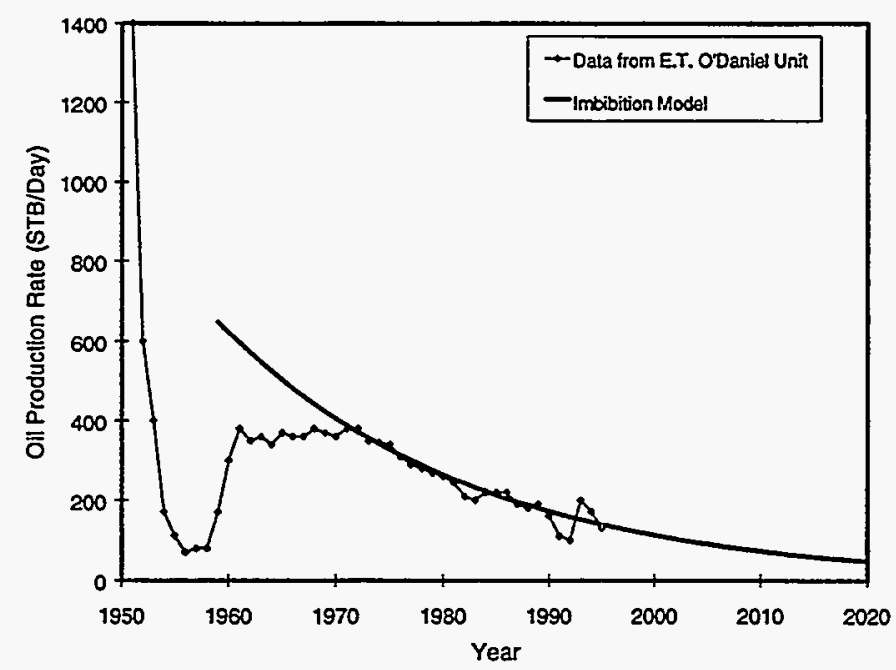

Fig. 2.9 - Match between imbibition scaling model and production decline data from the E.T. O'Daniel Unit, Spraberry Trend Area. 


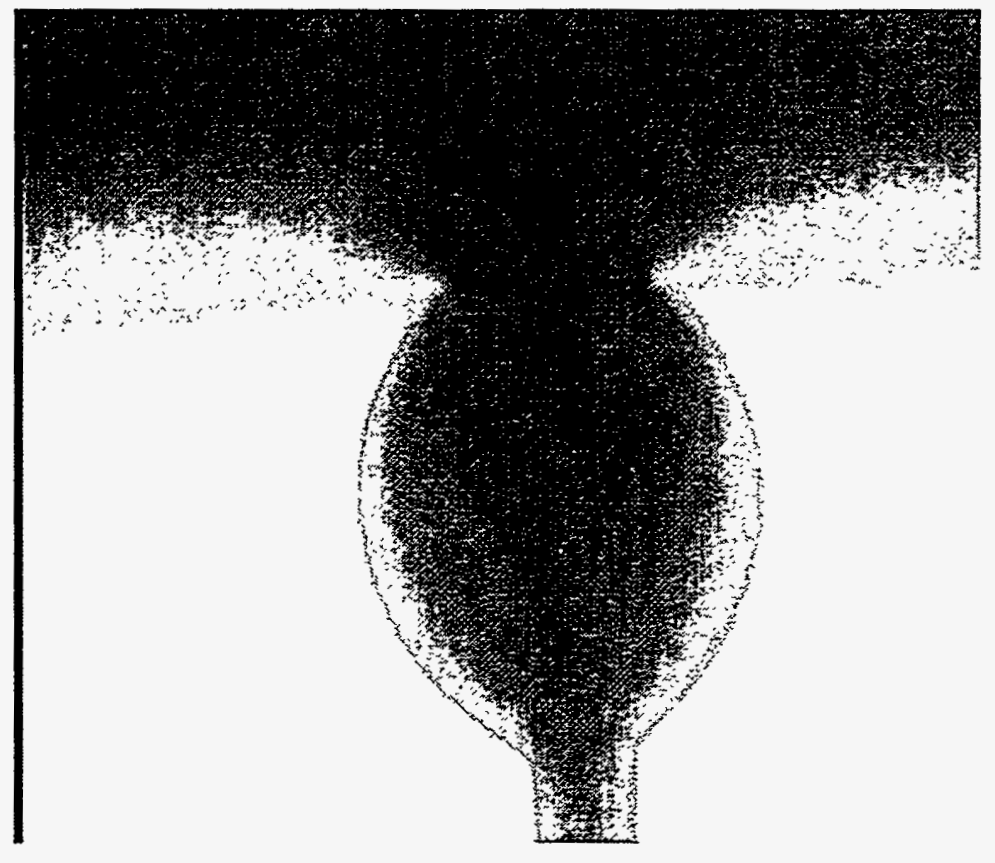

Fig. 2.10 - A typical image of oil drop attachment during contact angle measurement.

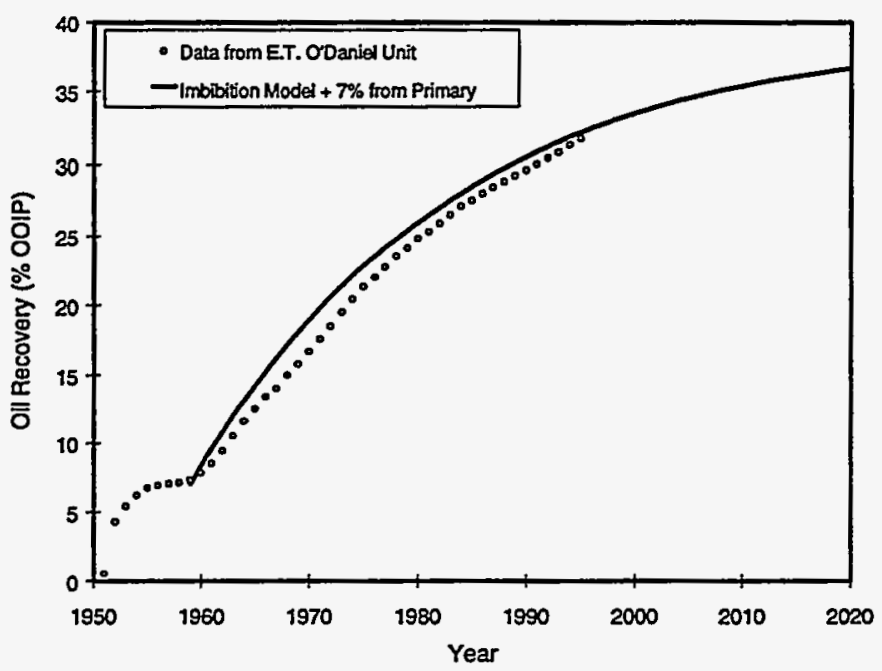

Fig. 2.11 - Comparison between imbibition model calculated oil recovery and observed oil recovery from the E.T. O'Daniel Unit, Spraberry Trend Area 


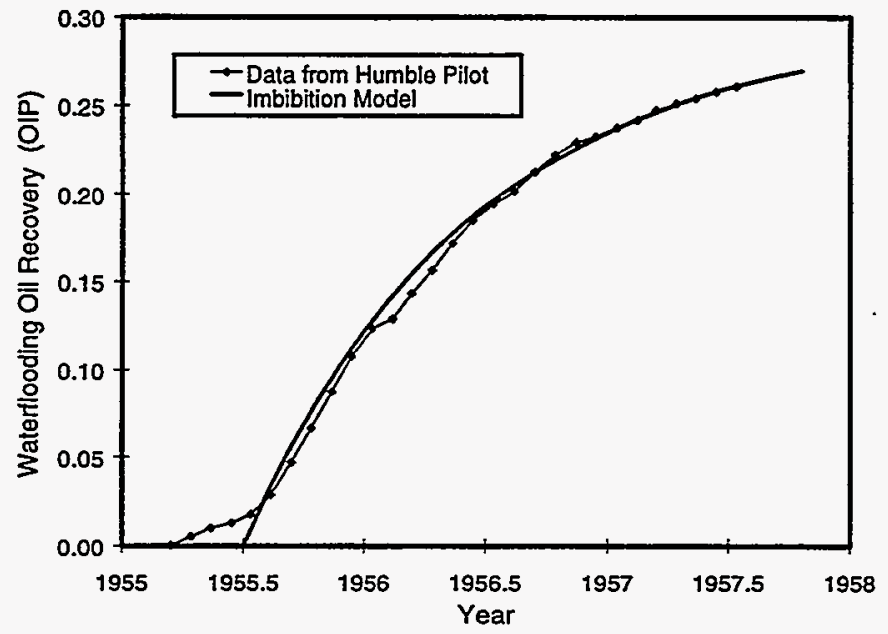

Fig. 2.12 - Match between imbibition model calculated oil recovery and observed oil recovery from the Humble pilot, Spraberry Trend Area

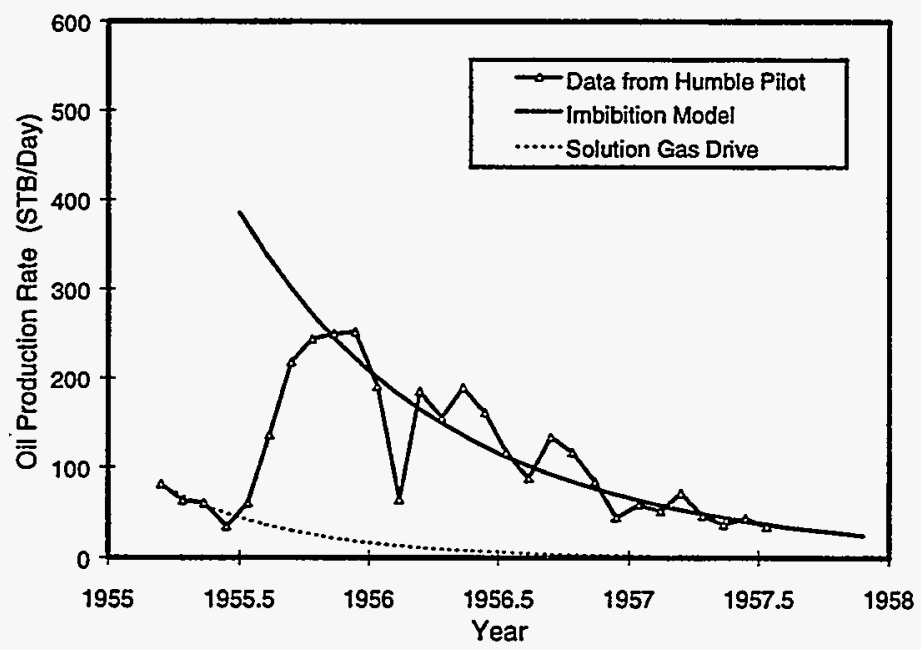

Fig. 2.13 - Comparison between imbibition scaling model and production decline data from the Humble pilot, Spraberry Trend Area. 


\subsection{Crude Oil/Brine/Rock Interaction at High-Temperature and Pressure Conditions}

\section{Introduction}

As mentioned in the previous section, because data from imbibition experiments on reservoir rocks was both limited and inconsistent, it was difficult to draw conclusions regarding the effects of temperature and pressure on rock wettability and imbibition efficiency. In order to minimize uncertainties in the experiments and decrease investigation time, more experiments were conducted to verify the temperature and pressure effects using Berea cores.

Experimental results for Berea cores seem to indicate that elevated temperature increased the rate of water imbibition while rock wettability was not significantly affected. However, aging of cores in oil at different temperatures reduced the water imbibition rate and hence wettability to water to differing degrees. Increased pressure seems to slow down the water imbibition process. The experimental work has not been sufficient to date to draw a conclusion. This section presents the results of our experimental investigations on the effect of temperature and aging on water imbibition and rock wettability using Berea cores.

\section{Core and Fluid Properties}

Berea cores were utilized in this laboratory investigation. Dimensions and physical properties of the core plugs are presented in Table 2.4. Core porosity ranges from 0.16 to 0.21 . Permeability to brine varies between $215 \mathrm{md}$ and $243 \mathrm{md}$. Initial brine saturations ranging from $25 \%$ to $39 \%$ was achieved by displacing brine with oil.

Synthetic Spraberry brine was used in the experiments. It contains $122.7 \mathrm{~g} / \mathrm{L}$ of $\mathrm{N}_{\mathrm{a}} \mathrm{Cl}$ and $7.5 \mathrm{~g} / \mathrm{L}$ of $\mathrm{C}_{\mathrm{a}} \mathrm{Cl} \cdot 2 \mathrm{H}_{2} \mathrm{O}$. Density, viscosity, and interfacial tension (IFT) with oil at room and reservoir temperatures are summarized in Table 2.5.

Spraberry separator oil was used in the investigation. Oil density, viscosity, and IFT with the brine at room and reservoir temperatures are summarized in Table 2.5. Density, viscosity, IFT and thermal expansion data at various temperatures are presented in Figs. 2.14, 2.15, and 2.16 respectively.

\section{Experimental Results}

Experimental procedures were similar to those described in Section 2.1 except that the core cleaning process using chloroform was not necessary for Berea cores and the oil injection pressure was 10 to $12 \mathrm{psig}$. Results of the investigations with Berea are presented hereafter.

\section{Effect of Temperature}

Presented in Fig. 2.17 are oil recovery curves obtained from brine imbibition tests conducted at room and reservoir temperatures. It is seen that elevated temperature increased the rate of brine imbibition but did not change the final recovery. The reason may be that the reduced oil viscosity at high temperature made the oil easily displaced by brine.

\section{Effect of Pressure}


A brine imbibition test was conducted under room temperature and 1,200 psig in a pressure vessel. Oil recovered from the core was displaced from the vessel periodically and the recovered oil volume was recorded. The oil volume was utilized to determine oil recovery during the experiment. The calculated oil recovery curve is plotted in Fig. 2.18 and compared with recovery curves shown in Fig. 2.17. It is seen from Fig. 2.18 that the oil recovery rate at 1,200 psig is much lower than that at room pressure. One of the possible explanations is that the oil recovered from the core was not fully washed out from the pressure vessel. Another possible reason is the increased oil viscosity due to elevated pressure, although this effect is not likely to be significant. More experiments are being performed to resolve this conflict.

\section{Effect of Aging}

The effect of aging in oil before brine imbibition was investigated using two Berea cores. One core was aged for 6 hours at room temperature, the other was aged for 6 hours at $138^{\circ} \mathrm{F}$. Oil recovery curves during brine imbibition for the two cores are compared with that obtained without the aging process in Fig. 2.19. This comparison indicates that aging at room temperature caused reductions in both imbibition rate and final oil recovery. However, aging at the reservoir temperature of $138^{\circ} \mathrm{F}$ caused a reduction in the imbibition rate. It appears that aging caused the rock surface to become less water-wet for one core. However, these inconsistent results made it difficult to draw a quantitative conclusion. In order to quantitatively characterize the effect of aging on rock wettability, oil imbibition experiments were run with the same cores after termination of brine imbibition tests. Wettability index to water $\left(I_{w}\right)$, index to oil $\left(I_{0}\right)$ and AmottHarvey wettability index $\left(\mathrm{I}_{\mathrm{w}-\mathrm{o}}\right)$ were determined. The results are shown in Table 2.4. These data are also inconclusive regarding the effect of aging on rock wettability.

The effect of aging in oil on wettability was also investigated using the standard adsorption method developed by a group of researchers ${ }^{1,2}$ at the New Mexico Petroleum Recovery Research Center. Advancing and receding contact angles of a Muscovite Mica/Spraberry brine/Spraberry oil system were measured at different aging conditions. The results are summarized in Table 2.6. It is seen from the table that aging at $60^{\circ} \mathrm{C}$ for one day increased contact angles, while aging at the same temperature for 21 days made the contact angles lower. These data are again inconclusive regarding the effect of aging time and temperature on rock wettability.

\section{Effect of Initial Water Saturation}

Imbibition experiments were performed using Berea cores with different initial water saturations. The oil recovery curves are plotted in Fig. 2.20. This figure appears to indicate that water imbibition rates are higher in cores with higher initial water saturations during the early time of the experiments. To eliminate the inconsistencies due to other factors, these oil recovery curves are normalized and plotted in Fig. 2.21 using dimensionless time ( $\left.t_{D}\right)$ defined by Eq. (14) in Section 2.1 assuming zero contact angle in the water phase. It is seen from Fig. 2.21 that the water imbibition rate increases with initial water saturation for initial water saturations between $25 \%$ and $39 \%$.

\section{Summary}

Water and oil imbibition experiments were conducted using Berea cores, synthetic reservoir 
brine, and reservoir oil under elevated temperatures and pressure. Water imbibition rate increased with temperature and decreased with pressure. While aging of cores in crude oil caused the rate of water imbibition to decrease, its effect on rock wettability was not fully evidenced due to a limited amount of data.

\section{References}

1. Buckley, J.S. and Morrow, N.R.: Characterization of Crude Oil Wetting Behavior by Adhesion Tests," paper SPE/DOE 20263 presented at the 1990 SPE/DOE EOR Symposium held in Tulsa, OK, April 23-25.

2. Liu, Y. and Buckley, J.S.: "Evolution of Wetting Alteration by Adsorption from Crude Oil," paper SPE 28970 presented at the 1995 International Symposium on Oilfield Chemistry held in San Antonio, TX, Feb. 14-17, 1995.

Table 2.4 - Summary of Results of Imbibition Experiments with Berea Cores and Spraberry Fluids

\begin{tabular}{lcccccccccc}
\hline Core No. & $\begin{array}{c}d \\
(\mathrm{~cm})\end{array}$ & $\begin{array}{c}L \\
(\mathrm{~cm})\end{array}$ & $\phi$ & $\begin{array}{c}k_{w} \\
(\mathrm{md})\end{array}$ & $S_{w i}$ & $S_{\text {or }}$ & $\begin{array}{c}R_{\text {fotal }} \\
(\text { OOIP) }\end{array}$ & $I_{w}$ & $I_{o}$ & $I_{w-o}$ \\
\hline B-A5* & 3.60 & 5.16 & 0.16 & 236 & 0.33 & 0.44 & 0.34 & 1.00 & 0.29 & 0.71 \\
B-A6 & 3.60 & 4.97 & 0.21 & 227 & 0.39 & 0.40 & 0.34 & 1.00 & 0.20 & 0.80 \\
B-A7 & 3.79 & 4.65 & 0.19 & 215 & 0.39 & 0.41 & 0.33 & 1.00 & 0.17 & 0.83 \\
B-A8 & 3.79 & 4.93 & 0.18 & 228 & 0.41 & 0.24 & 0.60 & 1.00 & 0.13 & 0.87 \\
B-A9 & 3.80 & 4.91 & 0.17 & 226 & 0.37 & 0.42 & 0.33 & 1.00 & 0.23 & 0.77 \\
B-A10 & 3.79 & 5.46 & 0.19 & 225 & 0.36 & 0.45 & 0.30 & 1.00 & 0.20 & 0.80 \\
B-A11 & 3.80 & 6.17 & 0.20 & 233 & 0.25 & 0.40 & 0.47 & 0.98 & 0.41 & 0.57 \\
B-A12 & 3.80 & 6.19 & 0.19 & 233 & 0.33 & 0.36 & 0.47 & 1.00 & 0.35 & 0.65 \\
B-A13 & 3.79 & 6.41 & 0.17 & 243 & 0.31 & 0.23 & 0.66 & 0.99 & 0.38 & 0.61
\end{tabular}

* Note: Imbibition test was performed at room temperature for core B-A5. Imbibition tests were performed at $138^{\circ} \mathrm{F}$ for the rest of cores.

$d=$ diameter; $L=$ length; $\phi=$ porosity; $k_{w}=$ permeability to brine; $S_{w i}=$ initial brine saturation; $S_{o r}=$ residual oil saturation after brine imbibition; $R_{\text {rotal }}=$ total oil recovery after waterflood; $I_{w}=$ wettability index to water; $I_{o}=$ wettability index to oil; $I_{w-o}=$ Amott-Harvey wettability index. 
Table 2.5 - Properties of Fluids Used in the Experiments

\begin{tabular}{lccr}
\hline Fluid Property & Temperature $\left({ }^{\circ} \mathrm{F}\right)$ & Brine & Crude Oil \\
& & & \\
\hline \multirow{2}{*}{ Viscosity (cp) } & 75 & 1.184 & 10.380 \\
& 138 & 1.170 & 7.930 \\
Density (gr/cc) & 75 & 1.091 & 0.870 \\
& 138 & 1.076 & 0.834 \\
Interfacial Tension (mN/m) & 75 & \multicolumn{2}{c}{30.75} \\
& 138 & \multicolumn{2}{c}{24.13} \\
\hline
\end{tabular}

Table 2.6 - Contact Angles Measured Using Standard Adsorption Method for a Muscovite Mica/Spraberry Brine/Spraberry Oil System

\begin{tabular}{cccc}
\hline $\begin{array}{c}\text { Aging Time } \\
\text { (days) }\end{array}$ & $\begin{array}{c}\text { Aging Temperature } \\
\left({ }^{\circ} \mathrm{C}\right)\end{array}$ & $\begin{array}{c}\text { Advancing Angle } \\
\text { (Deg.) }\end{array}$ & $\begin{array}{c}\text { Receding Angle } \\
\text { (Deg.) }\end{array}$ \\
\hline & & & \\
1 & Room Temp. & 22 & 16 \\
1 & 60 & 40 & 19 \\
21 & Room Temp. & 34 & 20 \\
21 & 60 & 24 & 17 \\
\hline
\end{tabular}




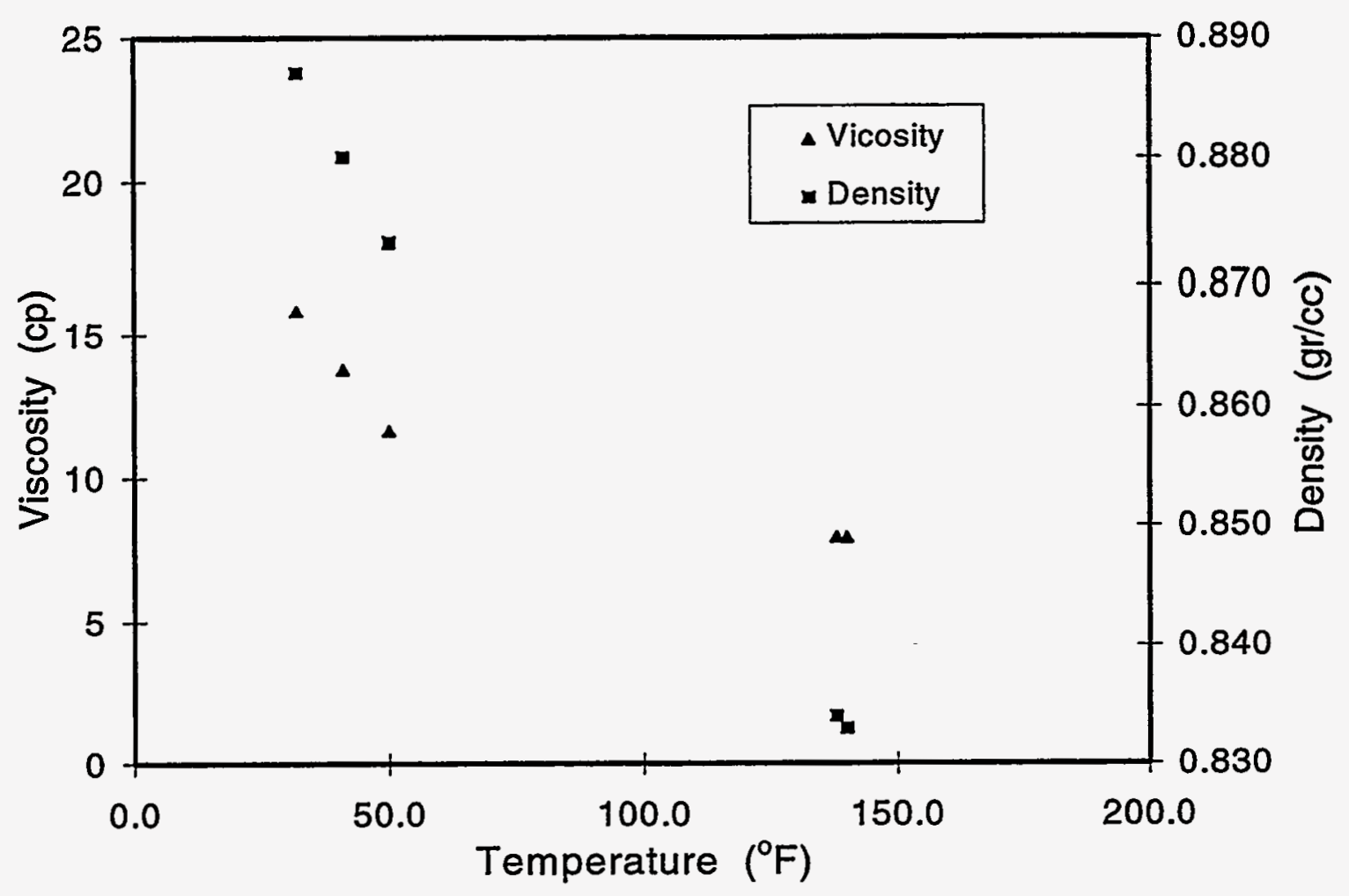

Fig. 2.14 - Density and viscosity of Spraberry crude oil versus temperature

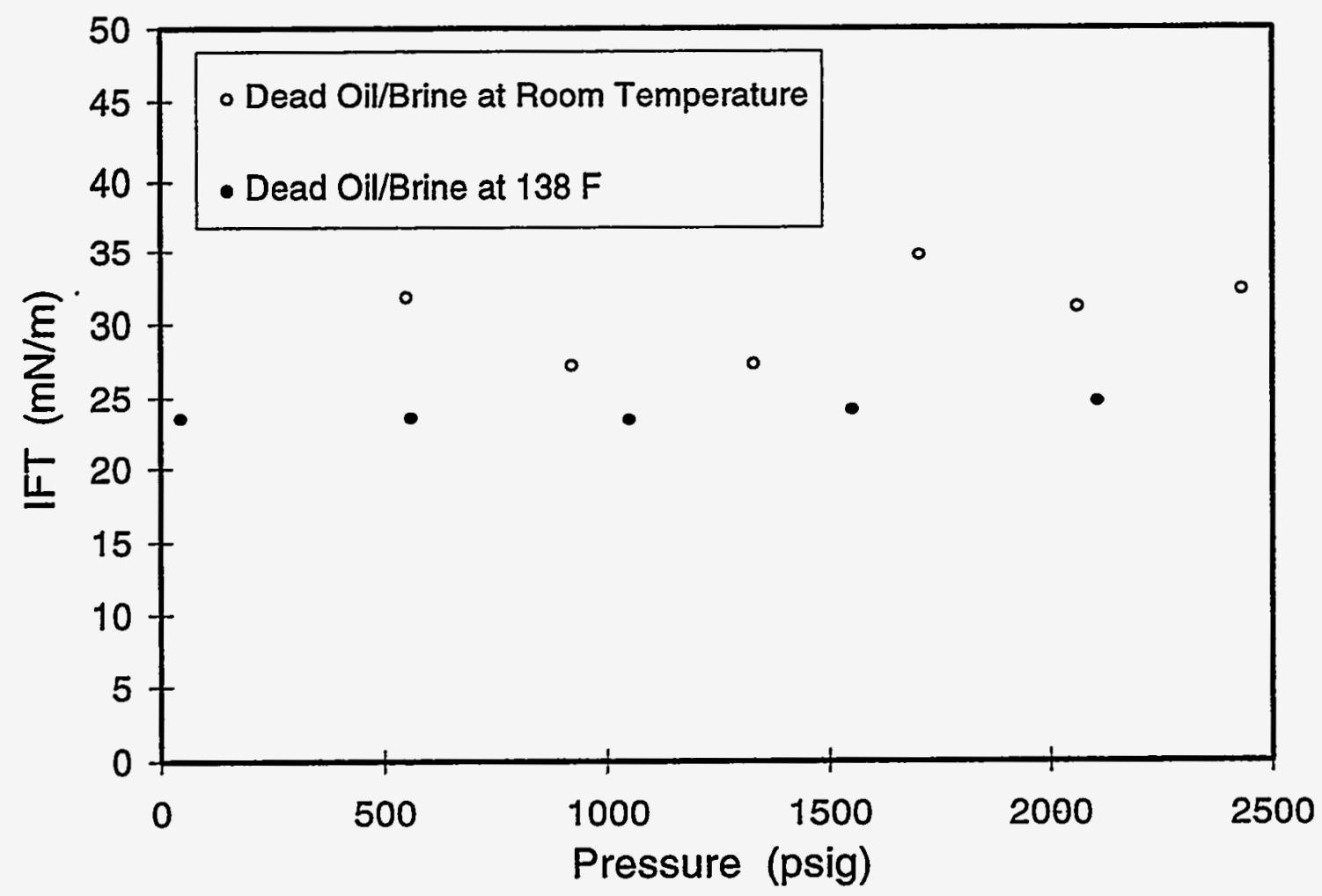

Fig. 2.15 - IFT of Spraberry brine/cruide oil at elevated pressures 


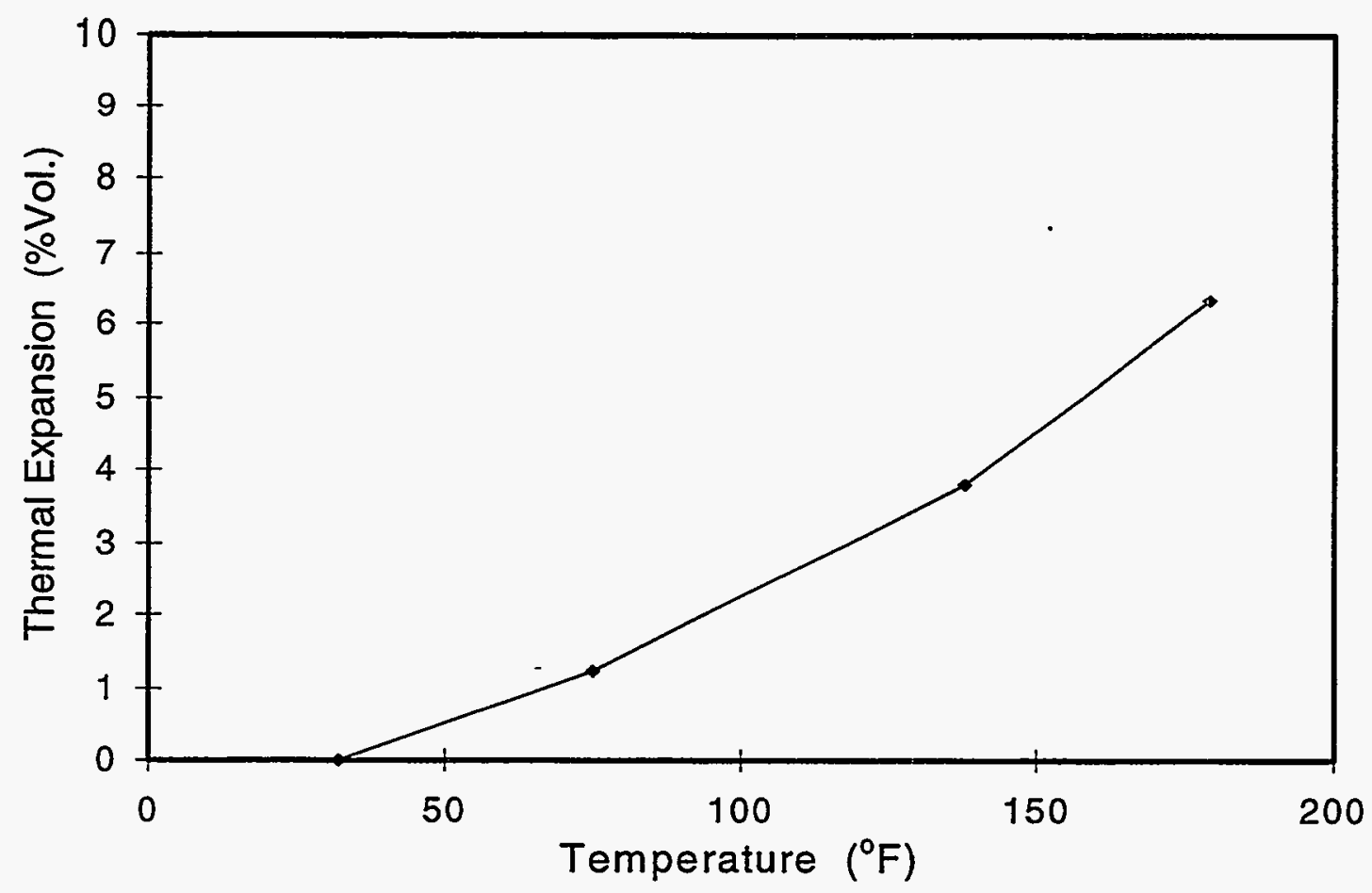

Fig. 2.16 - Thermal expansion of Spraberry crude oil

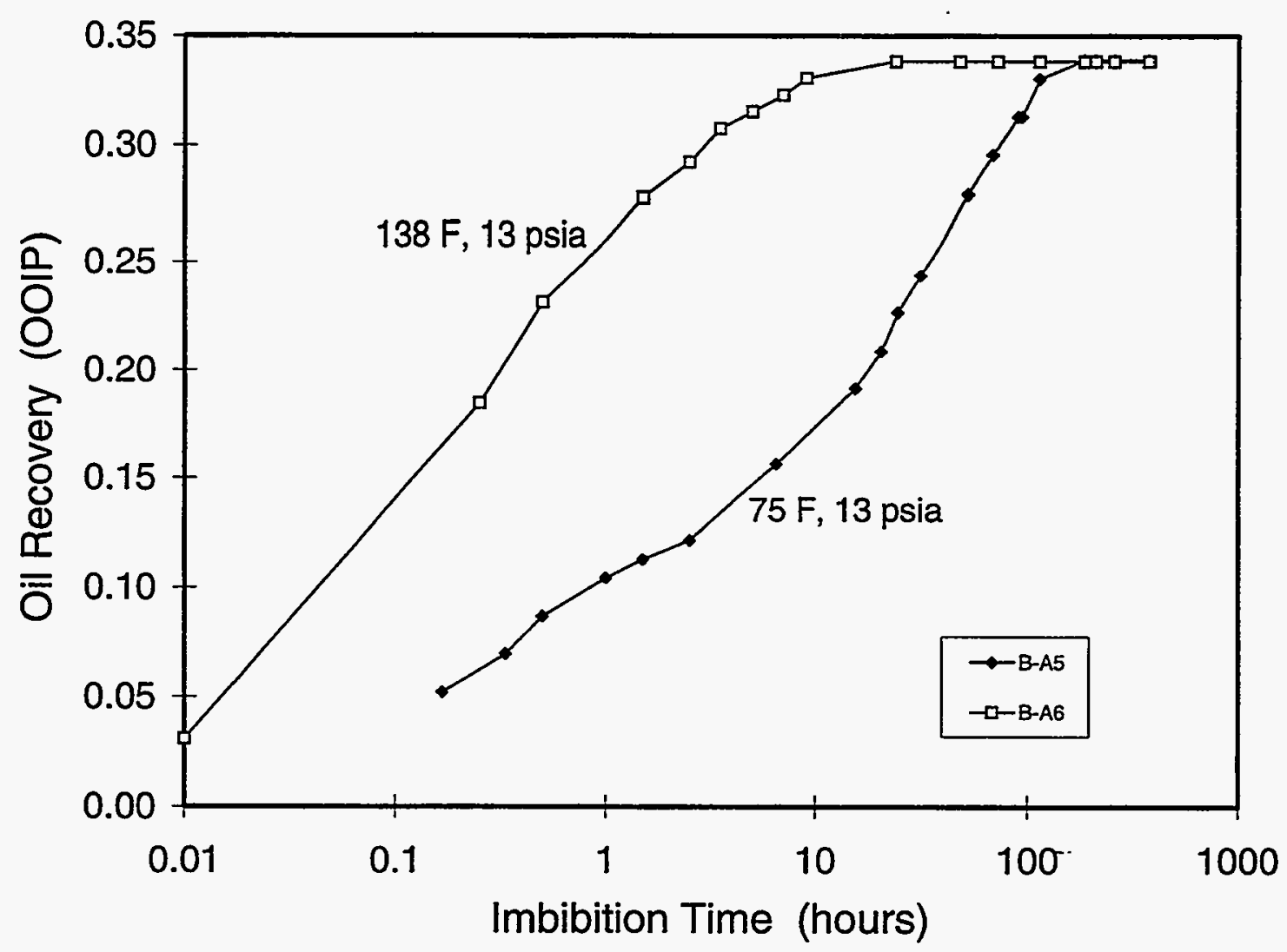

Fig. 2.17 - Imbibition oil recovery at different temperatures 


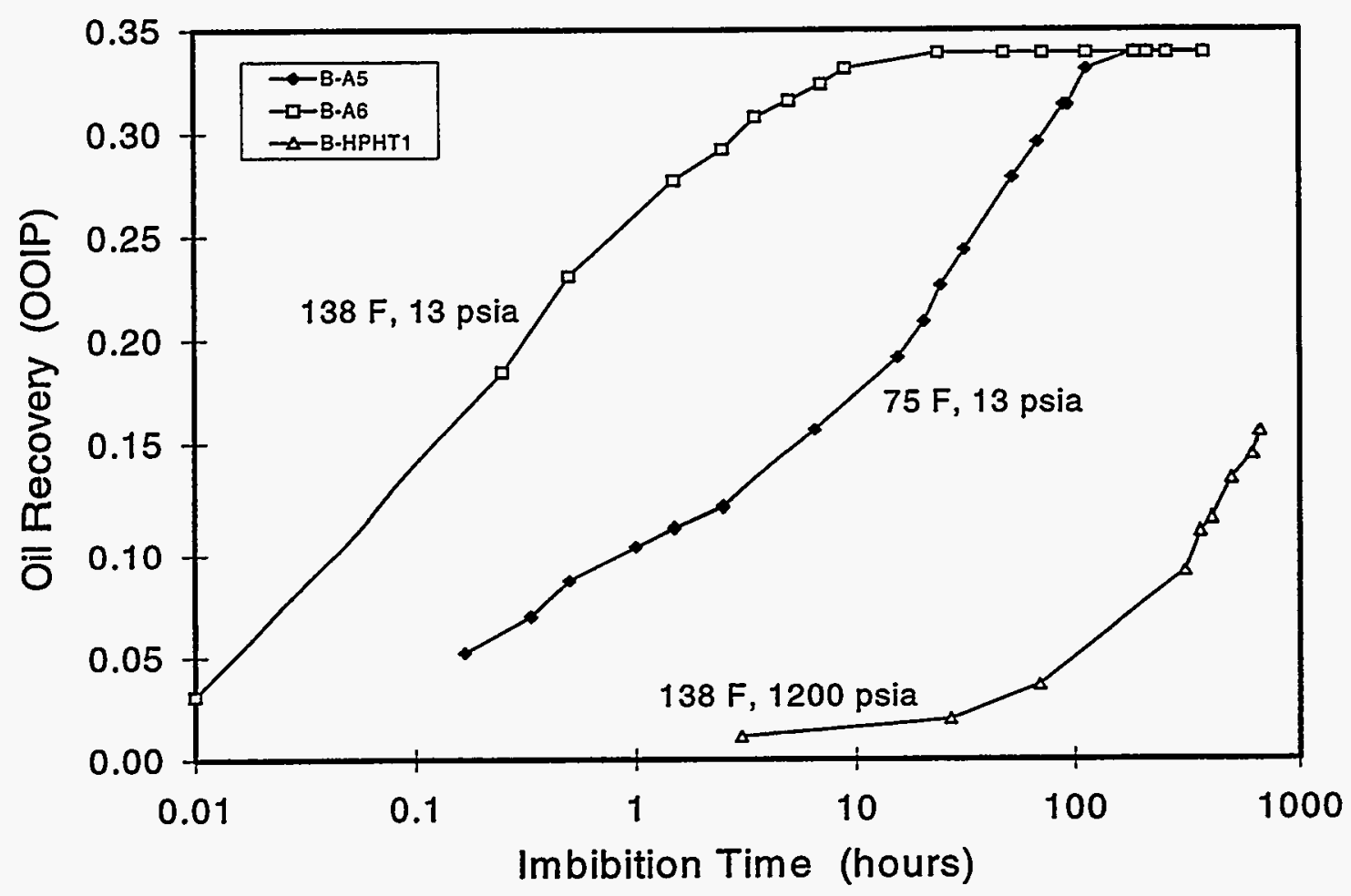

Fig. 2.18 - Imbibition oil recovery at different pressures

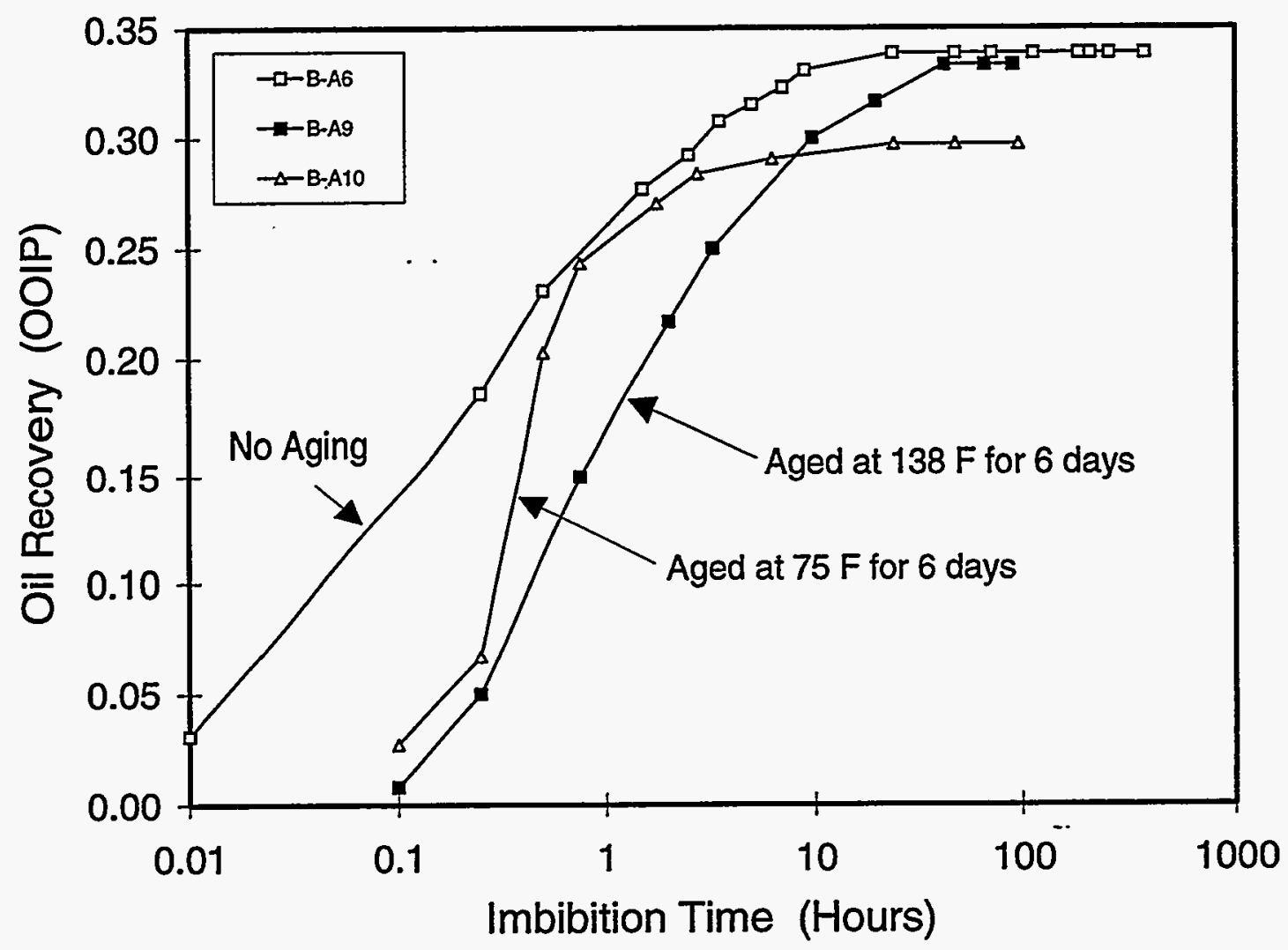

Fig. 2.19 - Imbibition oil recovery under different aging conditions 


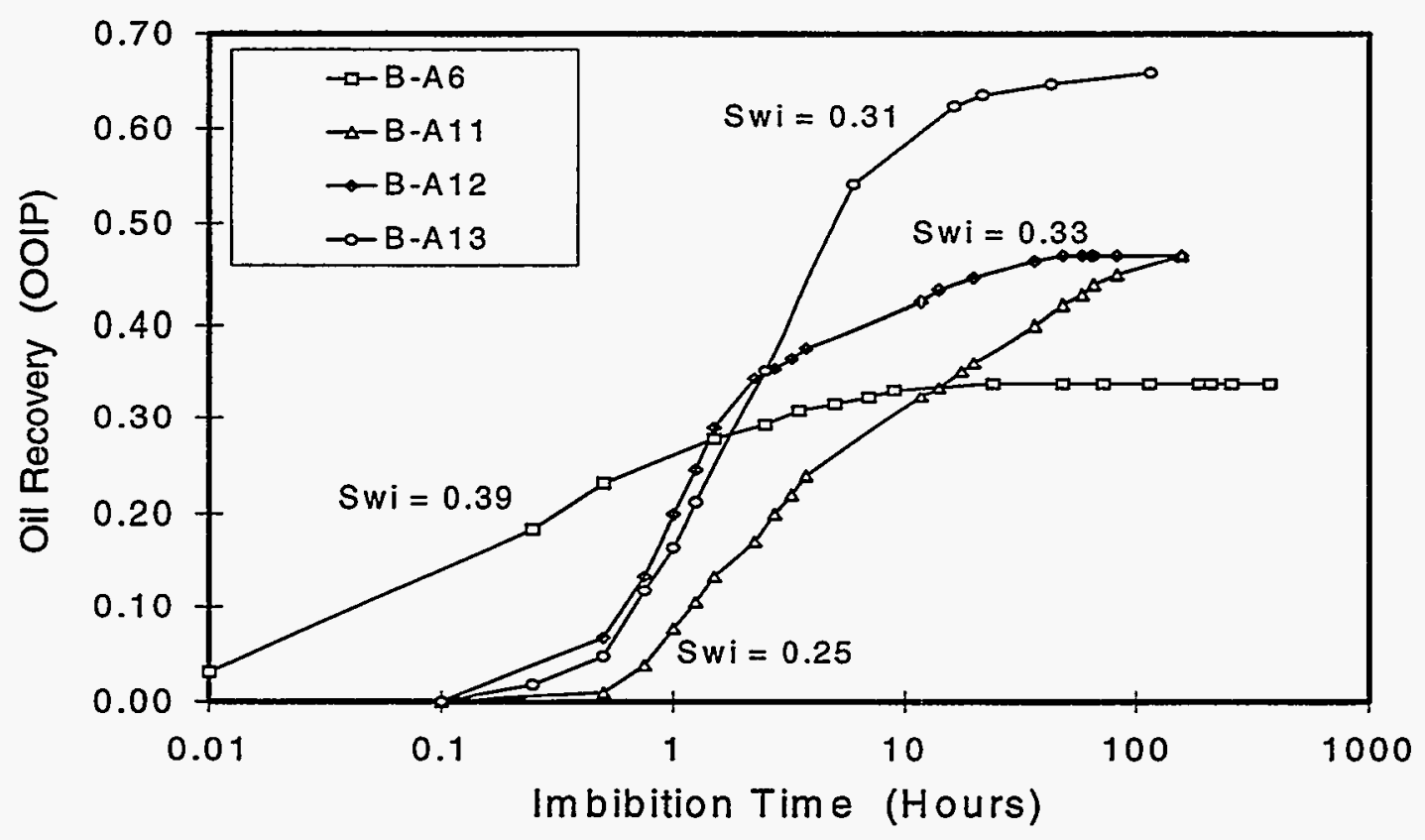

Fig. 2.20 - Imbibition oil recovery from Berea cores with different initial water saturations without core aging.

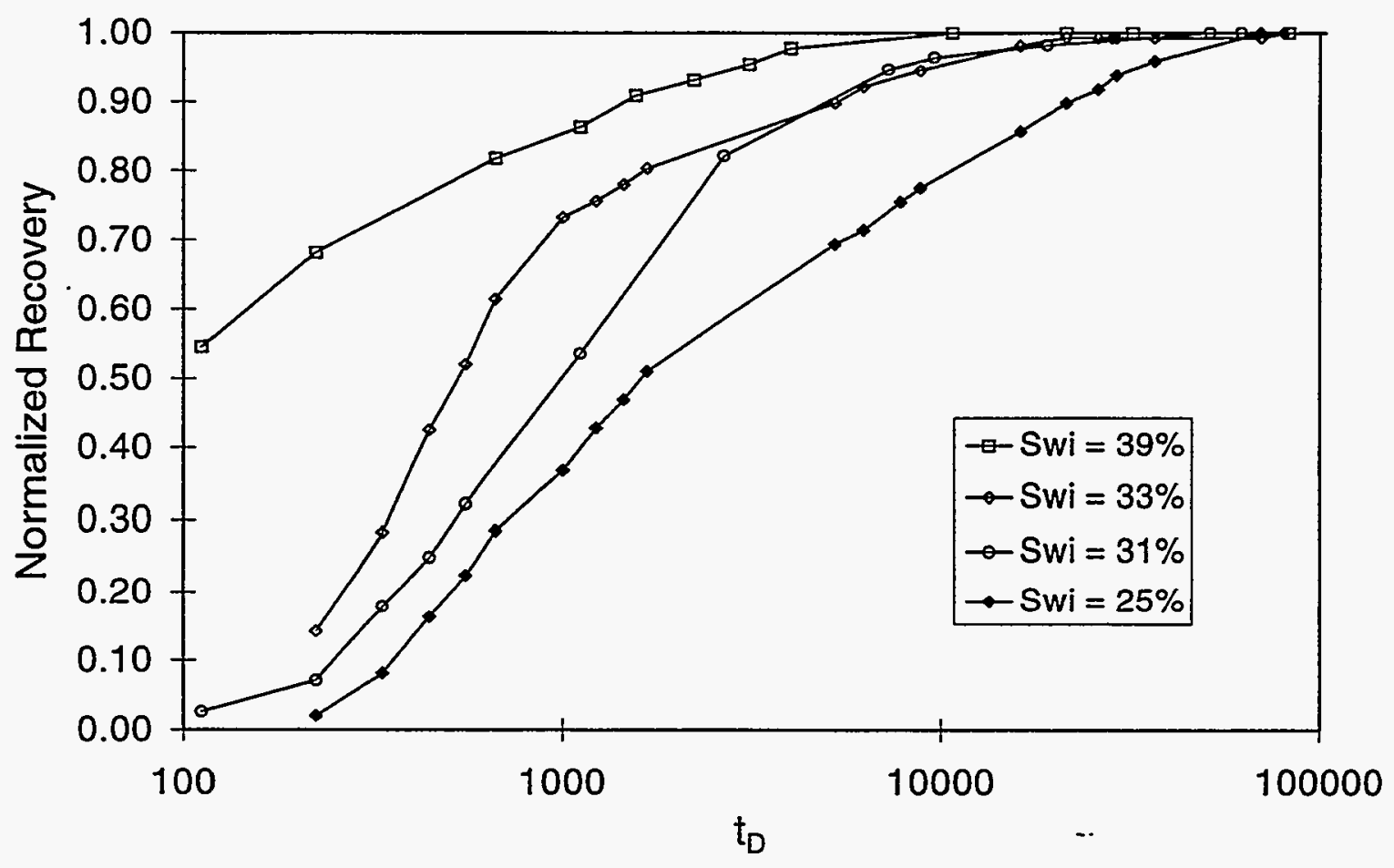

Fig. 2.21 - Normalized imbibition oil recovery curves from cores with different initial water saturations without core aging 


\section{RESERVOIR PERFORMANCE}

\subsection{Well Productivity During Primary Production}

\section{Introduction}

During the first year of this project, we analyzed the productivity behavior of Spraberry wells using a newly developed mathematical model. We concluded that stress-sensitive fracture conductivity may be partially responsible for the decline of well productivity in the Spraberry Trend Area. In the second year of this project, we modified the mathematical model with consideration of mechanical skin due to fluid damage to the matrix permeability. This section addresses the possibility of the effect of formation damage on well productivity in the Spraberry Trend Area during the primary oil production.

The Spraberry Trend Area presents unusual problems for both primary production and waterflooding. After more than 40 years of waterflooding, the current oil recovery is still less than 15 per cent. A model study of a waterflood pilot in the Spraberry Trend Area indicated a NE-SW trend of the major fractures. ${ }^{1}$ A contrast of $144 / 1$ was required for the major/minor fracture trend permeability ratio to match the pilot response. This strong anisotropic effective permeability implies the existence of well inter-connected, long natural fractures in the Spraberry reservoir. A characteristic of flow in long natural fractures is that the pressure variation along the fracture should be significantly higher compared to that in a hydraulic fracture or a short natural fracture. Unfortunately, a method for analyzing flow behavior in reservoirs with long fractures is not readily available from the literature.

Several analytical solutions have been presented for transient flow in fractured reservoirs. ${ }^{2-8}$ Numerical models have also been developed for simulating fluid flow in fractured reservoirs. ${ }^{9,10}$ However, it is still desirable for reservoir engineers to use steady flow equations for identification of formation damage in fractured reservoirs. This is not only because the analytical transient-flow solutions and numerical simulators are not convenient to use, but also because steady or pseudo-steady flow prevails as the dominating flow mechanism in the lifetime of most oil wells. Therefore, steady flow equations are attractive for formation damage analysis.

This section demonstrates that use of a modified steady-flow model for matching production data aided in understanding of the unusual behavior of Spraberry Trend Area reservoirs. The use of the model has captured the characteristics of rapid decline in productivity of Spraberry vertical wells. The results indicate that even though high gas saturation could hinder the productivity of the Spraberry wells, the wells should still have higher oil production rates if the formation was not damaged. Comparison between the effects of matrix skin and fracture conductivity reduction due to pressure drawdown indicates that the stress-sensitive fracture conductivity is probably responsible for the productivity loss of these wells during primary production.

\section{Existing Models}

Van Poollen ${ }^{11}$ investigated productivity versus permeability damage in hydraulically induced fractures by means of mathematical analyses of electrical-model analogs. The maximum simulated fracture length was 0.6 times the drainage radius. Productivity of fractured wells was 
graphically presented in terms of ratio of oil production rate with fractures and without fractures. Van Poollen ${ }^{11}$ concluded that damage to the formation immediately surrounding the fracture has only a minor effect on the productivity of the well, while the damage to the fracture flow capacity has a major effect on the productivity of the well.

Dyes et al. ${ }^{12}$ reported the influence of fracturing in well productivity based on experimental results obtained from a Carter Electric Analyzer. The maximum simulated fracture length was 0.75 times the drainage distance between the well and the element boundary. McGuire and Sikora ${ }^{13}$ provided more experimental data obtained from the Carter Electric Analyzer. The maximum simulated fracture length was equal to the drainage distance between the well and the element boundary. The effect of vertical fractures on well productivity was graphically presented in terms of ratio of well productivity with fractures to that without fractures.

Raymond and Binder ${ }^{14}$ presented their mathematical analyses on productivity of wells in vertically fractured, damaged formations. Their mathematical models were formulated assuming pressure at any given radial position is the same throughout the entire drainage area so that the isobars form a set of concentric circles. Since the models did not consider the pressure drop necessary to move fluid from a point in the formation to the fracture, excessive error was observed ${ }^{14}$ at large ratios of fracture length to drainage radius, as compared to the results given by McGuire and Sikora. ${ }^{13}$

The first mathematical model for analyzing productivity of horizontal wells intersecting fractures was presented by Giger et al. ${ }^{15,16}$ Two solutions were proposed for short horizontal wells and long horizontal wells respectively. For both cases, flow in the rock matrix and flow in the fractures were formulated separately, and then combined to obtain an equation for the entire flow path from external boundary to wellbore. Radial flow was assumed in the fracture for both short and long wellbore cases. For the case of a short horizontal well, they employed a radial flow equation presented by Muskat ${ }^{17}$ for matrix flow from external boundary to a small fracture. For the long horizontal well case, a flow equation developed by Houpeurt ${ }^{18}$ for flow in matrix from an external boundary to an extended fracture was utilized. Giger's approach may be considered to be less rigorous because the equations for flow from external boundaries to the fractures were derived based on the assumption that pressure in the fracture is uniform, or invariant, along the fracture length. Karcher et al. ${ }^{9}$ calculated productivity increase of fractured horizontal wells over fractured vertical wells using equations presented by Giger. ${ }^{16}$ They also investigated issues of increasing productivity, reducing coning, and improving sweep efficiency by multi-fractured horizontal wells using their numerical simulator for infinite conductivity fractures. Joshi ${ }^{19}$ proposed a steady state flow equation for analyzing productivity of horizontal wells. His equation for flow in the matrix was also derived based on the assumption of constant pressure in the fracture. Joshi ${ }^{20}$ presented a review of horizontal well technology. He pointed out that in most fracture jobs it is difficult to obtain infinite conductivity and, moreover, fracture conductivity decreases over time. Mukherjee and Economides ${ }^{21}$ developed a simplified steady-state approach to calculate the number of infinite conductivity fractures equivalent to a drainhole. Their model was developed on the basis of the inflow performance relationship suggested by Joshi ${ }^{19}$ with Prats ${ }^{22}$ correlation for dimensionless wellbore radius. Economides et al. ${ }^{10}$ performed a comprehensive simulation of horizontal-well performance. Their results agreed well with Joshi' ${ }^{19}$ equation. Raghavan and Joshi ${ }^{23}$ presented a steady flow solution based on uniform flux along the fracture length. This solution was presented as valid for finite-conductivity fractures 
with a specific dimensionless fracture conductivity value of $\mathrm{C}_{\mathrm{fD}}=4.4$. Guo and Evans $\mathrm{s}^{24}$ performed analyses similar to that of Giger's ${ }^{16}$ except that direct flow from matrix to wellbore, reservoir anisotropy, and multi-phase flow were included in the mathematical models. Like Giger's ${ }^{16}$ model, Guo and Evans ${ }^{24}$ models were also derived assuming uniform pressure in the fracture when flow in matrix was formulated using Darcy's law. Li et al. ${ }^{25}$ presented an approximate formula for predicting performance of fractured horizontal wells. It was assumed that oil first flows linearly from the external reservoir boundary to the vicinity of a vertical fracture, then turns 90 degrees and flows linearly to the fracture face while pressure in the fracture is equal at all points. Flow in the fracture was assumed to be linear away from the wellbore and radial near the wellbore. The drawback of their formulation is similar to that of Giger's and Guo and Evans'.

It is seen that most steady flow equations presented by previous investigators for productivity analysis of fractured horizontal wells rely on the assumption of infinite conductivity fractures when the flow from the external boundary to the fracture face was formulated. While the mathematical problems were very much simplified by using this assumption, accuracy of the solutions is questionable. Only one analytical solution dealing with horizontal wells intersecting finite-conductivity fractures was reported in the literature. ${ }^{23}$ This solution may be applicable to fractured reservoirs where fractures have dimensionless conductivity of 4.4 and the flux in the fractures is uniform, which may not occur in practice. Therefore, Guo and Schechter ${ }^{26}$ proposed a simple and more rigorous mathematical model for predicting performance of vertical and horizontal wells intersecting fractures fully penetrating reservoir sections.

\section{New Model}

Derivation of the mathematical model was presented in detail in Guo and Schechter's paper. ${ }^{26}$ Resultant equations are summarized in this section.

Infiow Performance Relationship (IPR). Production rate $\mathrm{Q}$ from a well intersecting $N$ fractures is given by Eq. (1) in field units:

$$
Q=\frac{0.00508 N k_{m} h\left(1-e^{-\sqrt{c x_{f}}}\right)}{B_{o} \mu\left(z_{e} \sqrt{c}+S\right)}\left(p_{e}-p_{w}\right)
$$

where $k_{m}$ is the matrix permeability, $h$ is fracture height (assumed to be equal to pay thickness), $x_{f}$ is fracture half-length, $p_{e}$ is the pressure at the drainage distance $\left(z_{e}\right), p_{w}$ is the flowing bottom hole pressure, $B_{o}$ and $\mu$ are formation volume factor and viscosity of oil respectively, $S$ is skin factor for rock matrix, and $c$ is defined as a group of variables:

$$
c=\frac{2 k_{m}}{z_{e} w k_{f}}
$$

where $w$ and $k_{f}$ are fracture width (aperture) and permeability respectively. Productivity index $(P D)$ for the well is given by

$$
P I=\frac{Q}{p_{e}-p_{w}}=\frac{0.00508 N k_{m} h\left(1-e^{-\sqrt{c x_{f}}}\right)}{B_{o} \mu\left(z_{e} \sqrt{c}+S\right)}
$$


The productivity index can also be defined using the average reservoir pressure $(\bar{p})$ as:

$$
J=\frac{Q}{\left(\bar{p}-p_{w}\right)}=\frac{0.00508 N k_{m} h}{B_{o} \mu\left(z_{e} \sqrt{c}+S\right)\left[\frac{1}{1-e^{-\sqrt{c x_{f}}}}-\frac{1}{2 x_{f} \sqrt{c}}\right]}
$$

If the reservoir is not fractured, the productivity index, $J_{o}$, is defined in a similar way as Eq. (4):

$$
J_{o}=\frac{0.00708 k_{m} h}{\mu B_{o}\left(\ln \frac{r_{e}}{r_{w}}-\frac{3}{4}+S_{o}\right)}
$$

where $r_{e}$ is the radius of drainage area, $r_{w}$ is wellbore radius, and $S_{o}$ is the skin factor for the unfractured well. Dividing Eq. (4) by Eq. (5) yields:

$$
\frac{J}{J_{o}}=\frac{0.72 N\left(\ln \frac{r_{e}}{r_{w}}-\frac{3}{4}+S_{o}\right)}{\left(z_{e} \sqrt{c}+S\right)\left[\frac{1}{\left.1-e^{-\sqrt{c x_{f}}}-\frac{1}{2 x_{f} \sqrt{c}}\right]}\right.}
$$

which is an equation for estimating productivity improvement of a fractured well over an unfractured well. Guo and Schechter ${ }^{26}$ showed that upon comparison to the McGuire-Sikora model, Eq. (6) gives higher $J / J_{o}$ values in the low fracture conductivity region and lower $J / J_{o}$ values in the high fracture conductivity region.

\section{Model Studies on Driver Unit Wells in the Spraberry Trend}

The new mathematical model has been used for productivity analyses of twelve wells in the Driver Unit of the naturally fractured Spraberry Trend Area, west Texas.

Reservoir Parameters. The thickness of the productive sands varies from 8 to 16 feet. All productive sands have porosities of $7-15$ per cent. ${ }^{27}$ Initial reservoir pressures were approximately 2,300 psi in the Upper Spraberry. Bubble point pressure of Spraberry oil is about $1,900 \mathrm{psi}^{28}$ Spraberry wells typically produced $100-400$ bopd initially after hydraulic fracture treatment. Primary oil recovery was less than 10 per cent of the oil in place.

The mechanism of primary oil production in the Spraberry Trend Area is believed to be dominated by solution gas drive. ${ }^{29}$ Performance of twelve wells drilled in the Driver Unit is evaluated using the mathematical model. Six of the wells were shut-in test wells and the other six were regularly producing wells. In order to make such an evaluation, the values of parameters that appear in Eqs. (1) and (2) are determined as follows and summarized in Table 3.1.

A composite plot between core permeability and initial water saturation is shown in Fig. 3.1 for the Spraberry reservoir sands. Data are based on analyses of selected core samples from 46 wells obtained during the early time of field development. Although air permeability of these cores 
varies from $0.1 \mathrm{md}$ to $3.4 \mathrm{md}$, production history indicates that major oil production was from Spraberry sands having matrix permeabilities of $1 \mathrm{md}$ or less. ${ }^{27,29}$ An average matrix absolute permeability of $0.8 \mathrm{md}$ is assumed for the Upper and Lower Spraberry sands in the Driver Unit. For a $0.8 \mathrm{md}$ sand, an initial water saturation of 0.30 is estimated based on Fig. 3.1.

The water-oil relative permeability curves shown in Fig. 3.2 were constructed based on analyses of cores taken from well V.P. Tippett \#5 in 1963. Gas-oil relative permeability curves were determined based on numerical reservoir simulation, ${ }^{30}$ and are presented in Fig. 3.3. Gas saturation in the Spraberry sands during primary production was estimated by Elkins ${ }^{31}$ to be about 0.24 . However, this number may vary from area to area depending upon reservoir pressure. The following empirical relation between production gas-oil-ratio (GOR) and gas saturation $\left(S_{g}\right)$ is used in this analysis based on data presented by Elkins ${ }^{31}$ :

$$
S_{g}=0.24+0.10 \log (G O R)
$$

Corresponding to practical GOR's of 1 to 12 MCF/STB in the Driver Area, Eq. (7) yields gas saturation values between 0.24 and 0.34 , which are comparable to that given by Elkins. ${ }^{31}$ The effective matrix and fracture permeabilities to oil are estimated based on the absolute permeability, relative permeability curves and saturations.

According to interpretations of a tracer test, ${ }^{32}$ fracture lengths in Spraberry are probably less than the interwell distance $(<1,800$ feet). Since the well spacing is 40 acres, the average fracture halflength is assumed to be 660 feet. As shown by Guo and Schechter, ${ }^{26}$ the fracture half-length does not significantly affect the result as long as it exceeds a minimum value. This is because the value of the exponential function in Eq. (1) is much smaller than 1 when fracture half-length $\left(x_{f}\right)$ is long.

Based on recent fracture characterization, ${ }^{33}$ three distinct fracture sets, trending NNE, NE, and ENE, are present in cores from the $1 \mathrm{U}$ and $5 \mathrm{U}$ units in the Upper Spraberry zone. The average fracture spacing of the three fracture sets are 1.62, 3.17, and 3.79 feet, respectively, as was shown in Section 1.2. The unmineralized NNE and ENE fractures appear as hairline cracks in the 5U unit, while the NE fractures are commonly mineralized with barite and only found in the $1 U$ unit. Although it is unclear which set of fractures plays a more important role in fluid transport within Spraberry Trend Area reservoirs, recent studies on waterflooding ${ }^{34}$ tend to support that the NNE fractures are less dominant in fluid transport. If the conductivity of the NNE fractures are assumed to be much lower than that of the ENE fractures in the SU unit, the average fracture spacing in the Upper Spraberry sands (1U and 5U units) is 3.48 feet.

Based on 111 measurements of fracture openings, Elkins ${ }^{29}$ reported that the fracture width ranged up to 0.013 inch and averaged 0.002 inch. This number agrees with Christie's ${ }^{28}$ estimation of fracture width of 0.002-0.004 inch based on flow rates and measurement of the fractures in cores. Browscombe and Dyes ${ }^{35}$ reported 0.002-0.003 inch fracture width and 3-4 foot fracture spacing. The in-situ fracture width in the reservoir may be estimated based on well tests. Well testing ${ }^{36,37}$ has not clearly demonstrated dual porosity pressure transient behavior in the Spraberry Trend. This indicates that fracture volume is less than $1 / 1000$ of the matrix volume. ${ }^{38}$ Assuming that matrix volume is on the order of $8,000 \mathrm{bbl} /$ acre then the fracture volume should be less than $8 \mathrm{bbl} / \mathrm{acre}$, or 45 cubic feet in a square area of $209 \mathrm{ft}$ by $209 \mathrm{ft}$ assuming a 10-foot- 
thick pay zone. If fracture spacing of 3.48 feet is assumed in the area, at most, 60 fractures should exist in the area. The maximum fracture width can then be estimated to be 0.004 inch. Based on these data, the average initial (before oil production) fracture width is assumed to be 0.0025 inch in this analysis.

Mineralized fractures were found in the $1 \mathrm{U}$ unit of the Upper Spraberry ${ }^{31}$ with an average percentage of mineral-filling in the fractures of about $75 \%$. Fractures found in the $5 \mathrm{U}$ unit of the Upper Spraberry are not mineralized. It is believed that the conductivities of non-mineralized fractures are more sensitive to stress. An average initial (before oil production) fracture porosity of 0.7 is used in this analysis.

Similar to the cubic law ${ }^{40}$ which describes the relationship between fracture width and fracture conductivity, a simple relation between fracture width and fracture permeability was derived analytically by Guo and Schechter as: ${ }^{26}$

$$
k_{f}=\frac{\phi_{f}^{3} w^{2}}{12}
$$

where $\phi_{f}$ is the fracture porosity accounting for volume of minerals, crushed rock, and proppant introduced during hydraulic fracturing operations. From the initial fracture porosity and width, the initial fracture permeability is estimated with Eq. (8) to be about 115 darcies.

It has been reported that productivity of some gas wells intersecting naturally fractured reservoirs declines rapidly as wellbore/reservoir pressure declines. ${ }^{39}$ It has been postulated that partial closure of fractures is responsible for this behavior. As the pressure in the fracture decreases, fracture aperture decreases and effective stress at the fracture face increases to support the matrix. The partially closed fracture should have a lower conductivity resulting in lower productivity of the well. Walsh's model ${ }^{40}$ for conductivity of a fracture is frequently employed for correlating both laboratory and field data. ${ }^{39}$ Similar to Walsh's model, Guo and Schechter ${ }^{26}$ proposed the following relation for estimating stress-sensitive fracture conductivity:

$$
w k_{f}=w_{o} k_{f o}[1-D \ln (\sigma-\alpha p)]^{\frac{3}{2 n}}
$$

where $w_{o}$ and $k_{f o}$ are initial (before oil production) fracture width and permeability at unity effective stress respectively, $\sigma$ is total stress, $p$ is pore pressure, $\alpha$ is the poroelastic parameter defining the effective-stress law. The $(\sigma-\alpha p)$ term represents the effective stress. The constant $D$ is referred to as stress factor, and its value reflects sensitivity of fracture conductivity to the effective stress. The exponent $n$ is a constant for a given rock type.

As observed by Guo and Schechter, ${ }^{26}$ pressure drawdown $\left(p_{e}-p_{w}\right)$ gives better results than the effective stress $(\sigma-\alpha p)$ in Eq. (9) for history matching, thus $\left(p_{e}-p_{w}\right)$ is employed to replace ( $\sigma$ $\alpha p$ ) in this analysis for determination of fracture conductivity under varying pressure drawdown.

It can be shown that if the cubic law ${ }^{38}$ for a fracture is used, the exponent $3 / 2 n$ in Eq. (9) is 4. Warpinski and Teufel showed that the value of $n$ varies for different rocks and an $n$ value of 0.515 for chalk was reported. This corresponds to an exponent $3 / 2 n$ of 2.91 for chalk. ${ }^{39} \mathrm{~A}$ value of $1 / 3$ for $n$ is used in this analysis, based on Walsh's equation.

The number of fractures interconnected by a well is estimated based on fracture spacing and an overall permeability anisotropy ratio which is obtained from pressure analysis. In the Driver unit, 
the average overall permeability anisotropy ratio is $13 / 1$ based on pressure analysis data. ${ }^{29}$ Using this number and fracture spacing of 3.48 feet, it is estimated that each well interconnects 14.6 fractures on average.

Reservoir pressure and flowing bottom hole pressure for twelve wells in the Driver unit were provided by Elkins. ${ }^{29}$ For the given pressure range, oil viscosity varies from $0.9 \mathrm{cp}$ to $1 \mathrm{cp}$. Oil formation volume factor is between 1.285 and 1.310. Estimated properties of reservoir rock, fracture, and fluids are summarized in Table 3.1. Production data are presented in Table 3.2 and Table 3.3 for the six shut-in test wells and six regularly producing wells, respectively.

Results. Using the parameters determined above, oil production rates from twelve wells in the Driver unit were first calculated assuming constant fracture conductivity $(D=0)$ and zero skin factor. Although the effect of gas saturation on oil production rate was considered in the calculation, the calculated oil production rates are still 2 to 10 times greater than the actual oil production rate of these wells. This calculation appears to disprove the hypothesis ${ }^{32}$ that high gas saturation may be responsible for poor performance of Spraberry wells. The discrepancy between the actual oil production rate and the calculated rate is then attributed to formation damage. Two types of formation damage may exist in Spraberry reservoirs: 1) damage to matrix permeability as a result of drilling and/or fracturing fluids, and 2) damage to fracture conductivity as a result of partial closure of fractures during oil production. While the damage of rock matrix permeability by drilling/fracturing fluid is reflected by the positive skin factor $S$ in Eq. (1), the loss of fracture conductivity (to some degree) due to production drawdown may be inferred by the positive value of the stress factor $D$ in Eq. (9). The poor performance of Spraberry wells may be due to combination of the two types of formation damage. Although it is difficult to distinguish their effects quantitatively, the maximum effect of each type of damage may be estimated by assuming the other type of damage is null. Figures 4 through 15 demonstrate matching between actual oil production rates and calculated oil production rates for the twelve wells. Figs. 3.4 through 3.8 are for the six shut-in test wells, and Figs. 3.9 through 3.15 are for the six regularly producing wells.

Discussion. Figs. 3.4 through 3.15 indicate that the low production rates of Spraberry wells during primary production may be due to stress-sensitive fracture permeability. If this is true, the maximum stress factor $(D)$ is about 0.095 (well Davenport B-14). However, the low performance may also be attributed to matrix skin. If this is the case, the maximum skin factor is about 0.85 (Davenport B-14). Although it is not clear which type of formation damage is more important in the Spraberry wells, it appears that stress-sensitive fracture conductivity may dominate. This is inferred by comparison of production rate and drawdown for these wells. It is generally believed that a higher draw down (lower flowing bottom hole pressure) usually yields a higher production rate. However, this is not true in the Driver Unit. For example, although the pressure drawdown for well J.C. Bryans A-2 was relatively low compared to that for other shut-in test wells, this well still produced oil at a higher rate. Also, the pressure drawdown for well X.B. Cox A-5 was relatively low compared to that for other regularly producing wells, this well again produced oil at a higher rate. This phenomena can be explained by the theory of stress-sensitive fracture conductivity: less reduction in fracture conductivity at low drawdown resulted in higher productivity of the two wells. Comparison of production rates of shut-in test wells with those of the regularly producing wells shows a similar effect. The former is generally higher than the latter, because the reservoir pressures are higher around the shut-in test wells, although pressure 
drawdown is within the same range. These observations indicate that stress-sensitive fracture conductivity is the more dominant factor that affects productivity of Spraberry wells.

\section{Conclusion}

Application of a new mathematical model to analysis of inflow performance of Spraberry Trend Area wells indicates that the rapid decline of well productivity during the primary oil production may be mainly attributed to stress-sensitive fracture conductivity.

\section{Nomenclature}

$\mathrm{B}_{\mathrm{o}}=$ formation volume factor of oil, $\mathrm{L}^{3} / \mathrm{L}^{3}, \mathrm{rb} / \mathrm{STB}$

$\mathrm{c}=\mathrm{a}$ group of variables defined by Eq. $(2), \mathrm{L}^{-2}, \mathrm{ft}^{-2}$

$\mathrm{C}_{\mathrm{fD}}=$ specific dimensionless fracture conductivity

$\mathrm{D}=$ stress-sensitivity factor, dimensionless

$\mathrm{h}=$ fracture height, $\mathrm{L}, \mathrm{ft}$

$\mathrm{J}=$ productivity index of fractured well, $\mathrm{L}^{4} \mathrm{t} / \mathrm{m}$, bopd/psi

$\mathrm{J}_{\mathrm{o}}=$ productivity index of fractured well, $\mathrm{L}^{4} \mathrm{t} / \mathrm{m}$, bopd/psi

$\mathrm{k}_{\mathrm{f}}=$ permeability of fracture, $\mathrm{L}^{2}, \mathrm{md}$

$\mathrm{k}_{\mathrm{fo}}=$ permeability of fracture at unity effective stress, $\mathrm{L}^{2}$, md

$k_{m}=$ permeability of matrix, $L^{2}$, md

$\mathrm{N}=$ number of fractures interconnected to wellbore

$\mathrm{n}=$ conductivity exponent, dimensionless

$\mathrm{p}=$ pore pressure, $\mathrm{m} / \mathrm{Lt}^{2}$, psia

$\mathrm{p}_{\mathrm{e}}=$ pressure at drainage boundary, $\mathrm{m} / \mathrm{Lt}^{2}$, psia

$\mathrm{PI}=$ productivity index, $\mathrm{L}^{4} \mathrm{t} / \mathrm{m}$, bopd/psi

$\mathrm{p}_{\mathrm{w}}=$ flowing bottom hole pressure, $\mathrm{m} / \mathrm{L} \mathrm{t}^{2}$, psia

$\mathrm{Q}=$ oil production rate, $\mathrm{L}^{3} / \mathrm{t}$, bopd

$\mathrm{r}_{\mathrm{e}}=$ radius of drainage area, $\mathrm{L}, \mathrm{ft}$

$\mathrm{r}_{\mathrm{w}}=$ radius of wellbore, $\mathrm{L}, \mathrm{ft}$

$\mathrm{S}=$ skin factor of fractured well, dimensionless

$\mathrm{S}_{\mathrm{o}}=$ skin factor of unfractured well, dimensionless

$\mathrm{w}=$ fracture width (aperture), $\mathrm{L}$, in

$\mathrm{w}_{\mathrm{o}}=$ fracture width (aperture) at unity effective stress, $\mathrm{L}$, in

$\mathrm{x}_{\mathrm{f}}=$ length of a fracture wing, $\mathrm{L}, \mathrm{ft}$

$\mathrm{z}_{\mathrm{e}}=$ distance between fracture face and drainage boundary, $\mathrm{L}, \mathrm{ft}$

$\alpha=$ poroelastic parameter defining effective stress law, dimensionless

$\mu=$ oil viscosity, $\mathrm{m} / \mathrm{Lt}, \mathrm{cp}$

$\sigma=$ confining stress, $\mathrm{m} / \mathrm{Lt}^{2}$, psi

$\phi_{\mathrm{f}}=$ fracture porosity, dimensionless

$\phi_{f_{0}}=$ fracture porosity at unity effective stress, dimensionless

\section{References}

1. Barfield, E.C., Jordan, J.K. and Moore, W.D.: "An Analysis of Large-Scale Flooding in the Fractured Spraberry Trend Area Reservoir," J. Pet. Tech. (April 1959) 15-19. 
2. Soliman, M. Y., Hunt, J.L., and El Rabaa,W.: "Fracturing Aspects of Horizontal Wells," J. Pet. Tech. (Aug. 1990) 966-73.

3. Chen, C.C., Ozkan, E., and Raghavan, R.: "A Study of Fractured Wells in Bounded Reservoirs," paper SPE 22717 presented at the 1991 SPE Annual Technical Conference and Exhibition held in Dallas, Texas, Oct. 6-9, 1991.

4. Cinco-L., H., Samaniego-V., F., and Dominguez-A., N.: "Transient Pressure Behavior for a Well with a Finite-Conductivity Vertical Fracture," SPEJ (Aug. 1978) 253-64.

5. Ozkan, E., and Raghavan, R.: "New Solutions for Well-Test-Analysis Problems: Part 1 Analytical Considerations," SPEFE (Sept. 1991) 359-65.

6. Chu,W., and Shank, G.D.: "A New Model for a Fractured Well in a Radial, Composite Reservoir," SPEFE (Sept. 1993) 225-32.

7. Beier, R.A.: "Pressure-Transient Model for a Vertically Fractured Well in a Fractal Reservoir," SPEFE (June 1994) 122-28.

8. Chen, C., and Raghavan, R.: "Modeling a Fractured Well in a Composite Reservoir," SPEFE (Dec. 1995) 241-46.

9. Karcher, B.J., Giger, F.M., and Combe, J.: "Some Practical Formulas to Predict Horizontal Well Behavior," paper SPE 15430, presented at the 1986 SPE Annual Technical Conference and Exhibition held in New Orleans, Louisiana, Oct. 5-8, 1986.

10. Economides, M.J., Delmbacher, F.X., Brand, C.W., and Heinemann, Z.E.: "Comprehensive Simulation of Horizontal-Well Performance," SPEFE (Dec. 1991) 418-26.

11. Van Poollen, H.K.: "Productivity vs. Permeability Damage in Hydraulically Produced Fractures," API, Drilling and Production Practice (1957), 103.

12. Dyes, A.B., Kemp, C.E., and Caudle, B.H.: "Effect of Fractures on Sweep-Out Pattern," Trans. AIME (1958), 213, 245.

13. McGuire, W.J. and Sikora, V.J.: "The Effect of Vertical Fractures on Well Productivity," Trans., AIME (1960), 219, 401.

14. Raymond, L.R. and Binder, G.G. Jr.: "Productivity of Wells in Vertically Fractured, Damaged Formations," J. of Pet. Tech. (January 1967), 121.

15. Giger, F.M., Reiss, L.H., and Jourdan, A.P.: "The Reservoir Engineering Aspect of Horizontal Drilling," paper SPE 13024 presented at the 1984 SPE Annual Technical Conference and Exhibition in Houston, Texas, Sept. 16-19, 1984.

16. Giger, F.M.: "Horizontal Well Production Techniques in Heterogeneous Reservoirs," paper SPE 13710, presented at the SPE 1985 Middle East Oil Technical Conference and Exhibition held in Bahrain, March 11-14, 1985.

17. Muskat, M.: The Flow of Homogeneous Fluids through Porous Media, I.H.R.D.C., Boston, 1982.

18. Houpeurt, A: Elements de mecanique des fluides dans les milieux poreux, Editions Technip, Paris, 1975.

19. Joshi, S.D.: "Augmentation of Well Productivity with Slant and Horizontal Wells," SPE 15375, 1986; JPT (June 1988) 729-39; Trans. AIME, 285.

20. Joshi, S.D.: "A Review of Horizontal Well and Drainhole Technology," paper SPE 16868, presented at the 1987 SPE Annual Technical Conference and Exhibition held in Dallas, Texas, Sept. 27-30, 1987.

21. Mukherjee, H., and Economides, M.J.: "A Parametric Comparison of Horizontal and Vertical Well Performance," SPEFE (June 1991) 209-16. 
22. Prats, M.: "Effect of Vertical Fractures on Reservoir Behavior -- Incompressible Fluid Case," SPEJ (June 1961) 105-16; Trans. AIME, 222.

23. Raghavan, R., and Joshi.,S.D.: "Productivity of Multiple Drainholes or Fractured Horizontal Wells," SPEFE (March 1993) 11-16.

24. Guo, G., and Evans, R.D.: "Inflow Performance of a Horizontal Well Intersecting Natural Fractures," paper SPE 25501, presented at the SPE Production Operations Symposium held in Oklahoma City, Oklahoma, March 21-23, 1993.

25. Li, H., Jia, Z., and Wei, Z.: "A New Method to Predict Performance of Fractured Horizontal Wells," paper SPE 37051, presented at the 1996 SPE International Conference on Horizontal Well Technology held in Calgary, Canada, November 18-20, 1996.

26. Guo, B. and Schechter, D.S.: "A Simple and Rigorous Mathematical Model for Estimating Inflow Performance of Wells Intersecting Long Fractures," paper SPE 38104 presented at the 1997 SPE Asia Pacific Oil and Gas Conference and Exhibition held in Kuala Lumpur, Malaysia, 14-16 April, 1997.

27. Elkins, L.F., and Skov, A.M.: "Cyclic Water Flooding the Spraberry Utilizes 'End Effects' to Increase Oil Production Rate," J. Pet. Tech. (Aug. 1963) 877-84.

28. Christie, R.S., and Blackwood, J.C.: "Production Performance in Spraberry," Oil \& Gas Journal (April 7, 1952) 107-15.

29. Elkins, L.F.: "Reservoir Performance and Well Spacing, Spraberry Trend Area Field of West Texas," Trans. AIME, 198, (1953) 177-96.

30. Schechter, D.S.: "Advanced Reservoir Characterization and Evaluation of $\mathrm{CO}_{2}$ Gravity Drainage in the Naturally Fractured Spraberry Trend Area," First Annual Technical Progress Report to DOE under Contract No. DE-FC22-95BC14942; PRRC Report 96-42, Dec. 17, 1996.

31. Elkins, L.F.: "Spraberry $\mathrm{CO}_{2}$-Gravity Drainage," Condensed Report, PRRC Spraberry Database, May 14, 1996.

32. Howell, W.D., Armstrong, F.E., and Watkins, J.W.: "Radioactive Gas Tracer Survey Aids Waterflood Planning," World Oil (Feb. 1961).

33. Lorenz, J.: "Summary of Observations and Interim Interpretations: Fractures in Horizontal Spraberry Cores, E.T. O’Daniel Well \#28," PRRC Spraberry Database, Dec. 12, 1996.

34. Beshry, M.: "Possible Fracture Orientation Based On Waterflood Surveillance for the O'Daniel Unit," PRRC Spraberry Database, August 26, 1996.

35. Browscombe, E.R. and Dyes, A.B.: "Water Imbibition Displacement - Can It Release Reluctant Spraberry Oil?" Oil \& Gas Journal (November 3 1952) 264-65.

36. Baker, R.: "Pressure Test Analysis for Midkiff 25-08," (April 1994) PRRC Spraberry Database.

37. Baker, R.: "Vertical Pulse Test Analysis of Shackelford 1-38A," (April 1994) PRRC Spraberry Database.

38. Van Golf-Racht, D.T.: Fundamentals of Fractured Reservoir Engineering, Elsevier Scientific Publishing Co., New York, 1982.

39. Warpinski, N.R., and Teufel, L.W.: "Effect of Stress and Pressure on Gas Flow Through Natural Fractures," paper SPE 22666, presented at the 1991 SPE Annual Technical Conference and Exhibition held in Dallas, Texas, Oct. 6-9, 1991.

40. Walsh, J.B.: "Effect of Pore Pressure and Confining Pressure on Fracture Permeability," Int. J. Rock Mech., Min. Sci. \& Geomech. Abstr., 18, 1981, 429-35. 
Table 3.1 - Parameters Used for Analyzing Performance of Spraberry Trend Area Reservoir Wells in the Driver Unit

Matrix permeability, md

0.80

Pay zone thickness, $\mathrm{ft}$

Initial water saturation

0.30

Water saturation during primary production

0.30

Average initial fracture porosity

0.70

Average initial fracture width, in

0.0025

Average fracture spacing, $\mathrm{ft}$

3.48

Average fracture half-length, $\mathrm{ft}$

600

Fracture height, $\mathrm{ft}$

Fracture conductivity exponent

0.33

Overall permeability anisotropy ratio

$13 / 1$

Number of fractures interconnected to wellbore

14.6

Oil viscosity, $\mathrm{cp}$

$0.9-1$

Formation volume factor 
Table 3.2 - Production Data of Six Shut-In Test Wells in the Driver Area, Spraberry Trend Area Field, Texas

\begin{tabular}{|c|c|c|c|c|}
\hline & \multicolumn{4}{|c|}{ Month during 1952} \\
\hline & March & April & May & June \\
\hline \multicolumn{5}{|l|}{ Davenport C-6: } \\
\hline Reservoir pressure, psig & 1850 & 1780 & 1700 & 1640 \\
\hline Bottom hole pressure, psig & 800 & 800 & 700 & 600 \\
\hline Gas oil ratio, $\mathrm{MCF} / \mathrm{BBL}$ & 0.8 & 0.8 & 1.0 & 1.5 \\
\hline Oil production rate, bopd & 190 & 250 & 180 & 175 \\
\hline \multicolumn{5}{|l|}{ Davenport C-8: } \\
\hline Reservoir pressure, psig & 1970 & 1930 & 1910 & 1860 \\
\hline Bottom hole pressure, psig & 1100 & 1250 & 800 & 740 \\
\hline Gas oil ratio, MCF/BBL & 0.85 & 0.65 & 0.65 & 0.75 \\
\hline Oil production rate, bopd & 195 & 220 & 255 & 245 \\
\hline \multicolumn{5}{|l|}{ Davenport B-5: } \\
\hline Reservoir pressure, psig & 1680 & 1600 & 1500 & 1400 \\
\hline Bottom hole pressure, psig & 1100 & 840 & 760 & 550 \\
\hline Gas oil ratio, $\mathrm{MCF} / \mathrm{BBL}$ & 2.8 & 1.2 & 1.3 & 2.1 \\
\hline Oil production rate, bopd & 140 & 150 & 90 & 85 \\
\hline \multicolumn{5}{|l|}{ Davenport B-7: } \\
\hline Reservoir pressure, psig & 1600 & 1470 & 1390 & 1060 \\
\hline Bottom hole pressure, psig & 600 & 570 & 510 & 510 \\
\hline Gas oil ratio, $\mathrm{MCF} / \mathrm{BBL}$ & 3.6 & 1.2 & 2.8 & 1.8 \\
\hline Oil production rate, bopd & 110 & 170 & 85 & 85 \\
\hline \multicolumn{5}{|l|}{ X.B. Cox A-4: } \\
\hline Reservoir pressure, psig & 1650 & 1600 & 1500 & 1400 \\
\hline Bottom hole pressure, psig & 1000 & 1000 & 800 & 750 \\
\hline Gas oil ratio, $\mathrm{MCF} / \mathrm{BBL}$ & 1.5 & 1.4 & 2.2 & 1.9 \\
\hline Oil production rate, bopd & 100 & 85 & 80 & 75 \\
\hline \multicolumn{5}{|l|}{ J.C. Bryans A-2: } \\
\hline Reservoir pressure, psig & 1830 & 1740 & 1640 & 1605 \\
\hline Bottom hole pressure, psig & 1560 & 1650 & 1010 & 1205 \\
\hline Gas oil ratio, $\mathrm{MCF} / \mathrm{BBL}$ & 1.35 & 1.2 & 1.5 & 1.0 \\
\hline Oil production rate, bopd & 180 & 110 & 205 & 160 \\
\hline
\end{tabular}


Table 3.3 - Production Data of Six Regularly Producing Wells in the Driver Area, Spraberry Trend Area Field, Texas

Davenport C-5:

Reservoir pressure, psig

Bottom hole pressure, psig

Gas oil ratio, $\mathrm{MCF} / \mathrm{BBL}$

Oil production rate, bopd

Davenport C-10:

Reservoir pressure, psig

Bottom hole pressure, psig

Gas oil ratio, MCF/BBL

Oil production rate, bopd

Davenport B-8:

Reservoir pressure, psig

Bottom hole pressure, psig

Gas oil ratio, MCF/BBL

Oil production rate, bopd

Davenport B-14:

Reservoir pressure, psig

Bottom hole pressure, psig

Gas oil ratio, MCF/BBL

Oil production rate, bopd

X.B. Cox A-5:

Reservoir pressure, psig

Bottom hole pressure, psig

Gas oil ratio, MCF/BBL

Oil production rate, bopd

J.C. Bryans A-2:

Reservoir pressure, psig

Bottom hole pressure, psig

Gas oil ratio, MCF/BBL

Oil production rate, bopd

Month during 1952

March April May

$\begin{array}{crc}1750 & 1600 & 1540 \\ 1250 & 740 & 600 \\ 2.0 & 3.9 & 12.2 \\ 80 & 60 & 40\end{array}$

$\begin{array}{lll}1860 & 1740 \quad 1730\end{array}$

$\begin{array}{lll}780 & 620 & 590\end{array}$

$\begin{array}{lll}1.0 & 1.75 \quad 2.4\end{array}$

$250 \quad 150 \quad 125$

$1600 \quad 1530 \quad 1430$

$640 \quad 850 \quad 660$

$\begin{array}{lll}5.0 & 9.7 & 10.0\end{array}$

$110 \quad 50 \quad 50$

$\begin{array}{lll}1600 & 1530 \quad 1430\end{array}$

$\begin{array}{lll}530 & 610 & 530\end{array}$

$3.8 \quad 5.1 \quad 7.1$

$60 \quad 40 \quad 35$

$\begin{array}{lll}1750 & 1620 & 1510\end{array}$

$\begin{array}{lll}1380 & 1010 \quad 820\end{array}$

$\begin{array}{lll}1.65 & 1.85 & 3.05\end{array}$

$145 \quad 130 \quad 105$

$\begin{array}{lll}1710 & 1620 \quad 1590\end{array}$

$1220 \quad 1400 \quad 1430$

$\begin{array}{lll}1.4 & 2.9 & 2.2\end{array}$

$250 \quad 85 \quad 70$ 


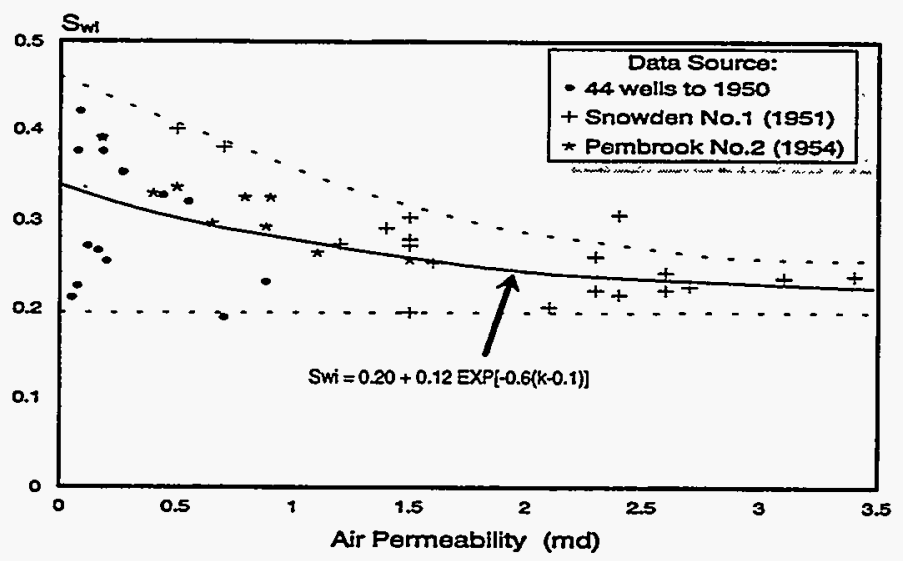

Fig. 3.1 - Initial water saturation in the Spraberry Trend Area as a function of rock permeability

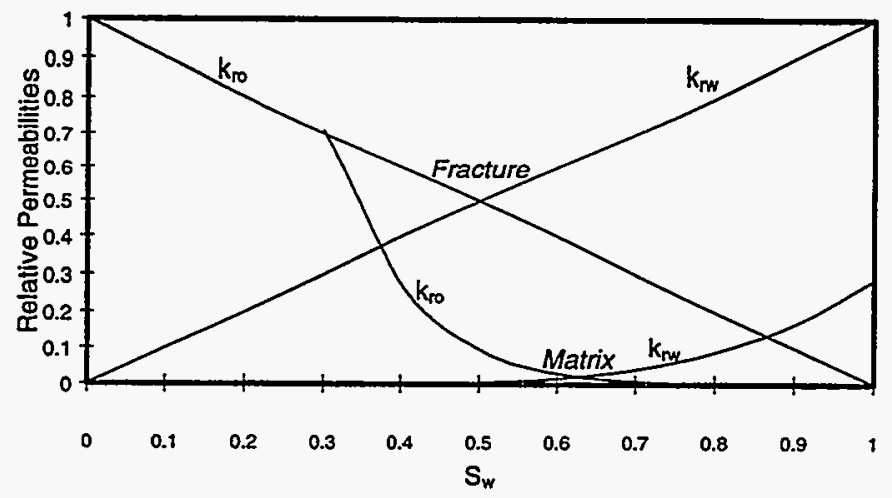

Fig. 3.2 - Water-oil relative permeability curves for the Spraberry Trend Area

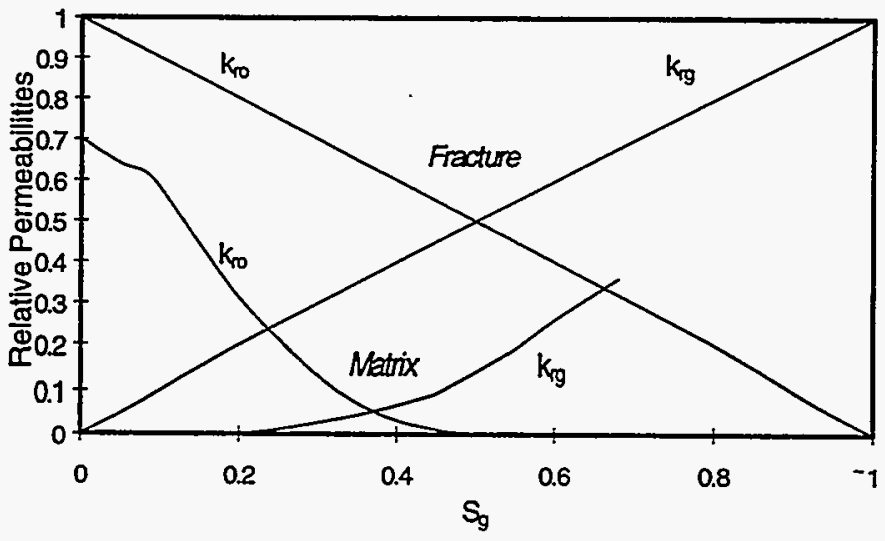

Fig. 3.3 - Oil-gas relative permeability curves for the Spraberry Trend Area 


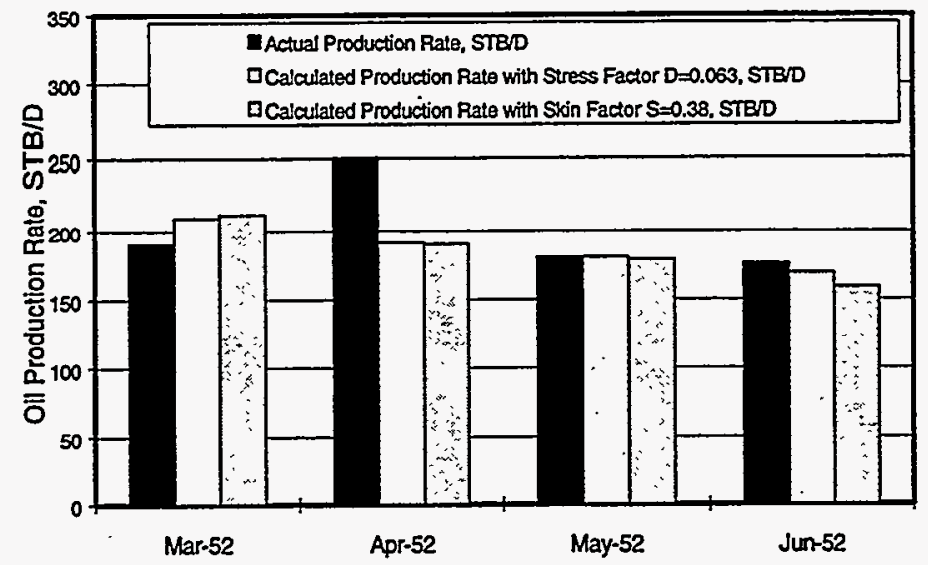

Fig. 3.4 - Comparison between calculated and actual oil production rates for Davenport C-6, Driver Unit, Spraberry Trend Area Field, west Texas.

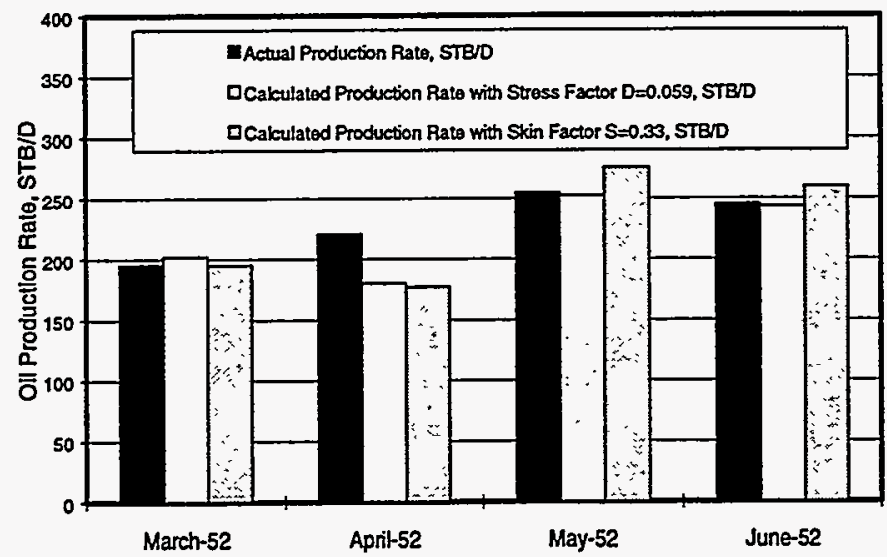

Fig. 3.5 - Comparison between calculated and actual oil production rates for Davenport C-8, Driver Unit, Spraberry Trend Area Field, west Texas.

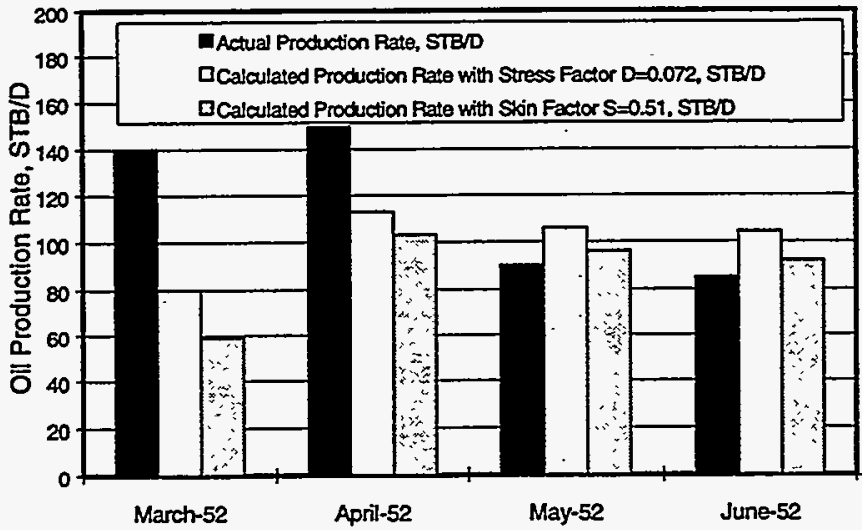

Fig. 3.6 - Comparison between calculated and actual oil production rates for Davenport B-5, Driver Unit, Spraberry Trend Area Field, west Texas. 


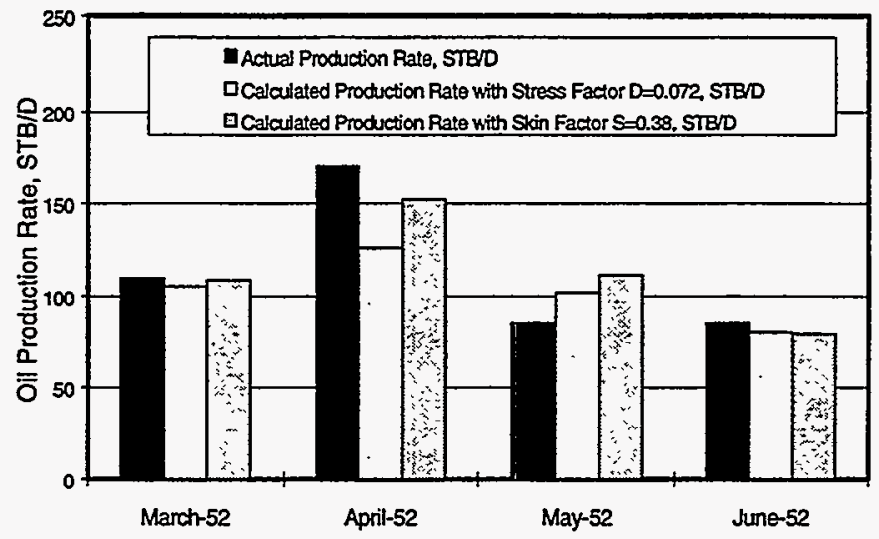

Fig. 3.7 - Comparison between calculated and actual oil production rates for Davenport B-7, Driver Unit, Spraberny Trend Area Field, west Texas.

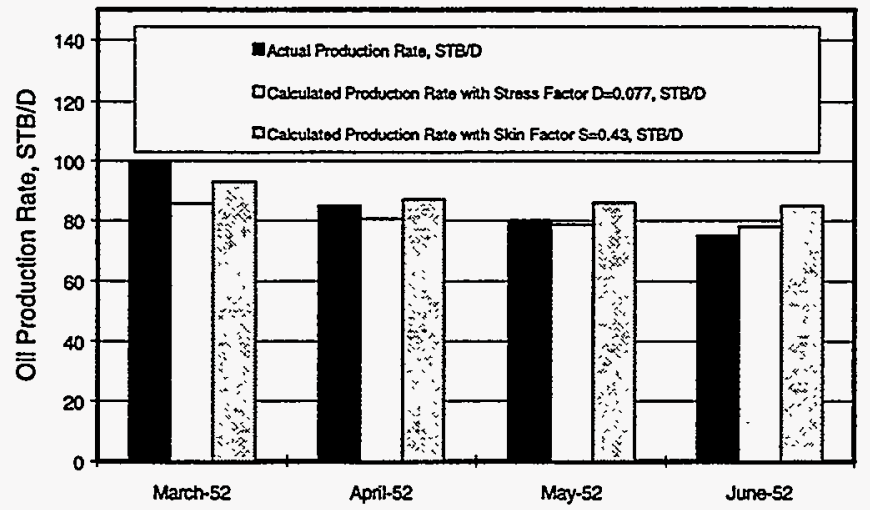

Fig. 3.8 - Comparison between calculated and actual oil production rates for X.B. Cox A-4, Driver Unit, Spraberry Trend Area Field, west Texas.

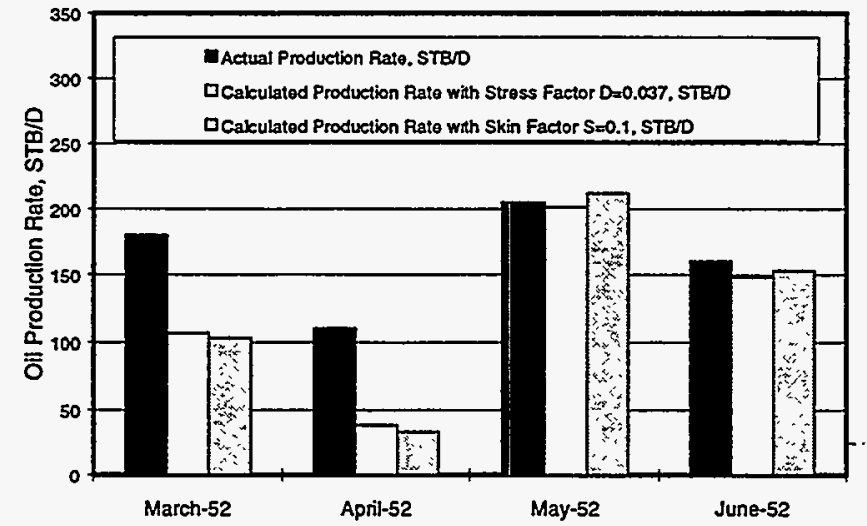

Fig. 3.9 - Comparison between calculated and actual oil production rates for J.C. Bryans A-2, Driver Unit, Spraberry Trend Area Field, west Texas. 


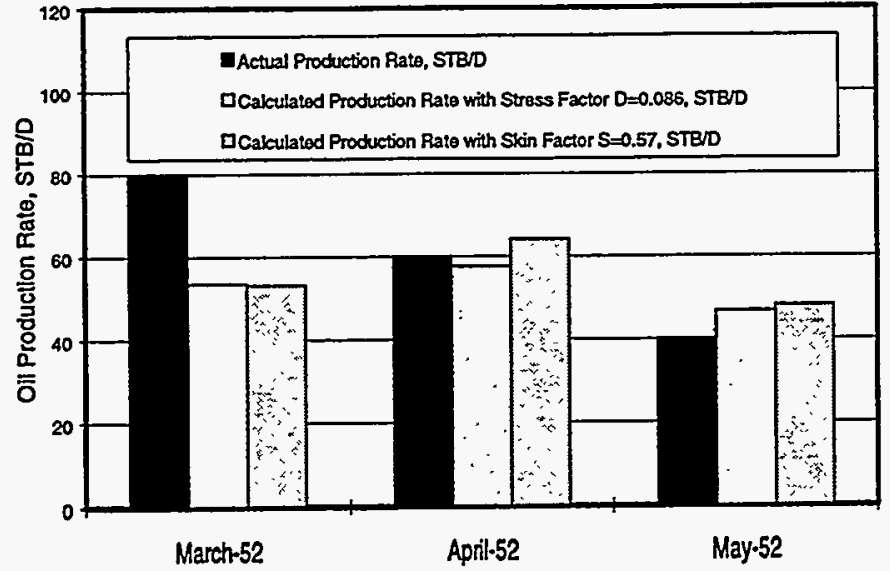

Fig. 3.10 - Comparison between calculated and actual oil production rates for Davenport C-5, Driver Unit, Spraberry Trend Area Field, west Texas.

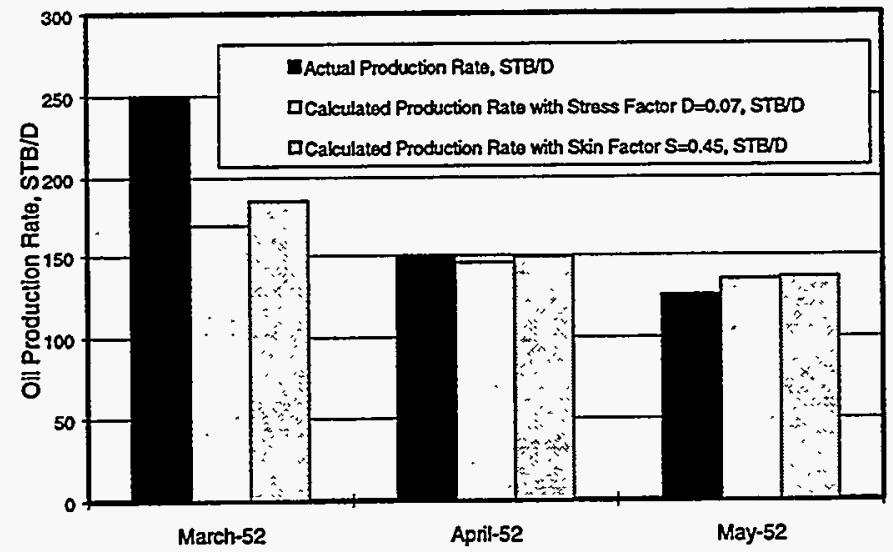

Fig. 3.11 - Comparison between calculated and actual oil production rates for Davenport C-10, Driver Unit, Spraberry Trend Area Field, west Texas.

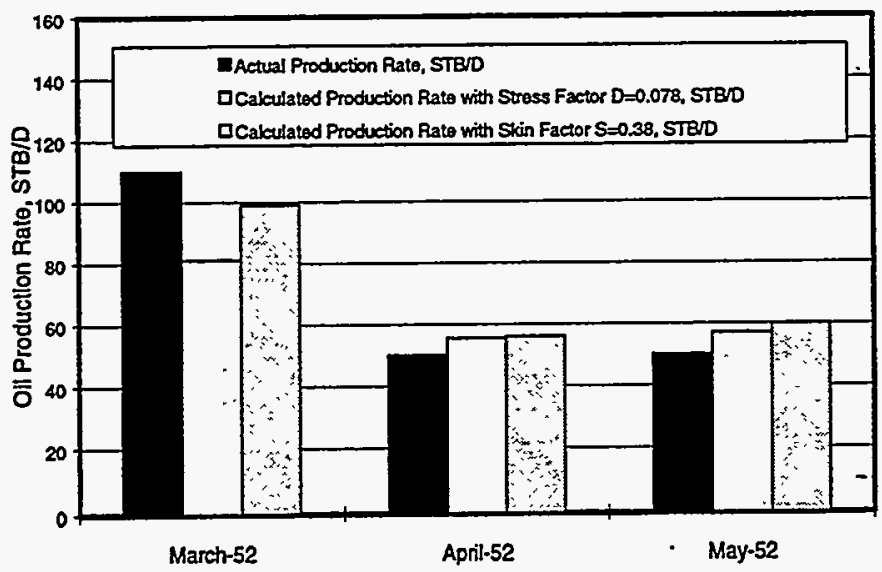

Fig. 3.12 - Comparison between calculated and actual oil production rates for Davenport B-8, Driver Unit, Spraberry Trend Area Field, west Texas. 


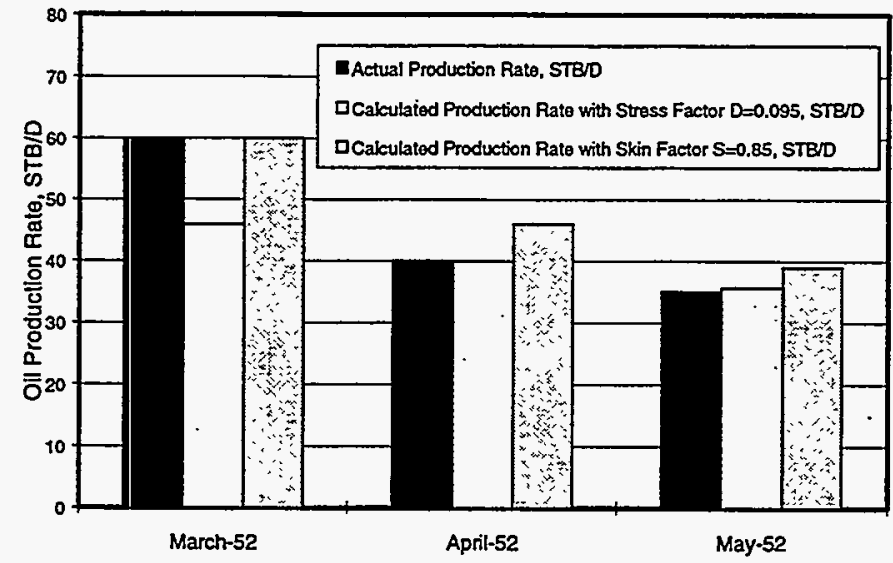

Fig. 3.13 - Comparison between calculated and actual oil production rates for Davenport B-14, Driver Unit, Spraberry Trend Area Field, west Texas.

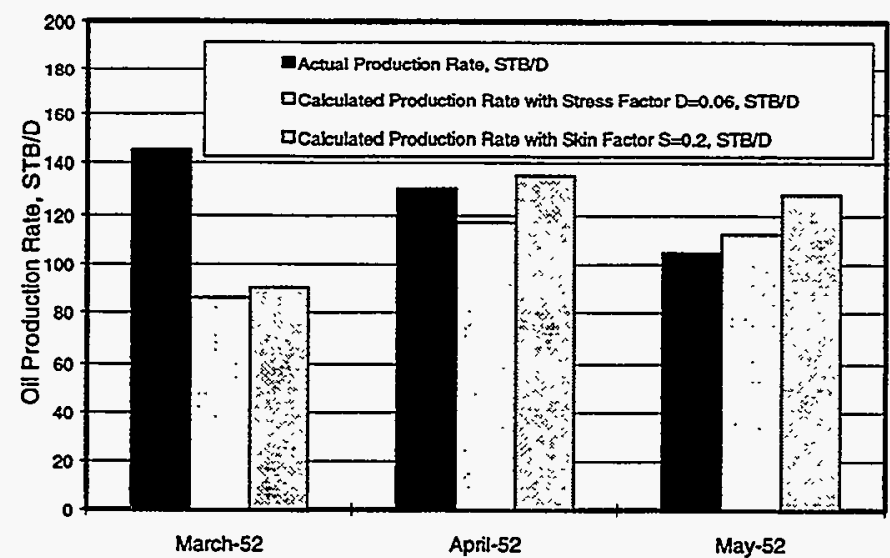

Fig. 3.14 - Comparison between calculated and actual oil production rates for X.B. Cox A-5, Driver Unit, Spraberry Trend Area Field, west Texas.

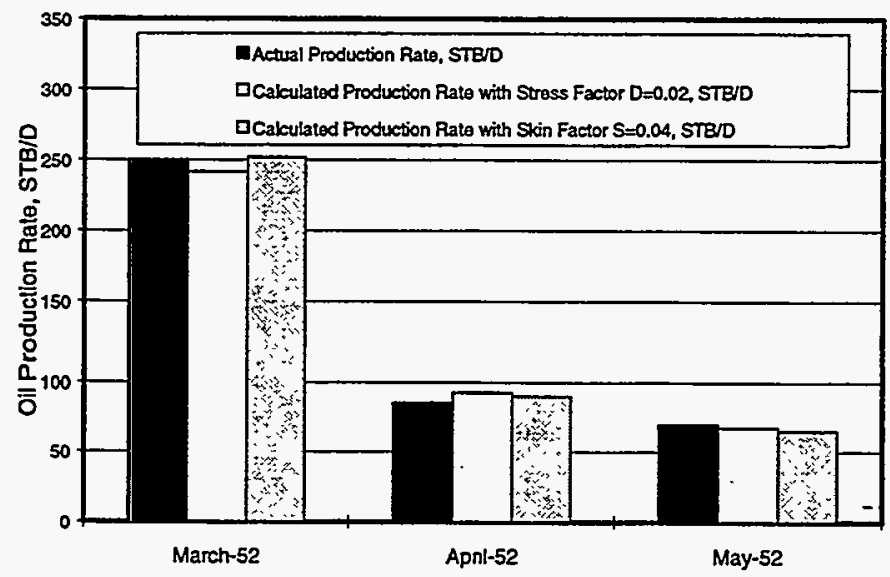

Fig. 3.15 - Comparison between calculated and actual oil production rates for J.C. Bryans A-1, Driver Unit, Spraberry Trend Area Field, west Texas. 


\subsection{Permeability Anisotropy Analysis}

\section{Introduction}

The Spraberry Trend Area reservoirs are low permeability, naturally fractured siltstones which present unusual problems for both primary production and waterflooding. After more than $\mathbf{4 0}$ years of waterflooding, the current oil recovery in most areas is still less than 15 per cent. The reasons for the low waterflood recovery have never been thoroughly understood. Various hypotheses have been proposed to explain the poor performance of wide-scale waterflooding. ${ }^{1-3}$ These hypotheses include: lack of pattern confinement and injection well density, incorrect well pattern alignment, fracture mineralization which could restrict crossflow, ${ }^{1}$ low permeability to oil after waterflooding of the gas-saturated reservoir, ${ }^{2}$ stress-sensitive fracture conductivity, ${ }^{3}$ and slow imbibition of water into the tight, weakly water-wet rock matrix during waterflooding. ${ }^{4}$ In order to fully understand the performance of waterflooding in the reservoir and optimize the design of the $\mathrm{CO}_{2}$ pilot, large scale reservoir simulation using a dual-porosity simulator is necessary.

The most important input data required by the simulator is the directional fracture permeability. The information about permeability anisotropy can usually be obtained by interpretation of interference well test data. However, due to the unusual behavior of the reservoir, a recent interference test conducted near the pilot area failed to provide meaningful information about the permeability anisotropy. This document reports directional fracture permeabilities estimated from pressure data recorded during single-well tests using a newly developed mathematical model.

A literature survey indicates that two types of analytical solutions have been used for determination of directional permeabilities in ansotropic oil reservoirs. The first type is the traditional single-porosity model, while the second type is referred to as dual-porosity model. Elkins ${ }^{5}$ appears to have used the line-source type curve first in a study in 1946 for analysis of an anisotropic reservoir. The interpretation method that he used was proposed by Theis ${ }^{6}$ for singleporosity media. The pioneering work on the analysis of permeability anisotropy of the naturally fractured Spraberry reservoir was performed by Elkins and Skov. ${ }^{7}$ They interpreted pressure data recorded during interference tests using a single-porosity mathematical model presented by Collins $^{8}$ to obtain information about effective directional permeabilities in the Midkiff and Driver areas. Ramey ${ }^{9}$ utilized Collins ${ }^{8}$ solution for determining orientation of fractures in a different reservoir from interference tests. Among many applications, similar analyses were performed by Swift and Brown ${ }^{10}$ and Beliveau. ${ }^{11}$ The single-potosity models are generally not considered adequate to capture the behavior of naturally fractured reservoirs. ${ }^{12}$

Warren and Root ${ }^{12}$ are recognized to be the pioneers in developing dual-porosity models. They presented a model based on the mathematical concept of superposition of two media as previously introduced by Barenblatt et al. ${ }^{13}$ The effect of fracture spacing on the rate of matrix flow was not considered in Warren and Root's model. Consequently, this model predicts the same pressure response for different reservoirs where equal fracture porosities result from different combinations of fracture width and spacing. Odeh ${ }^{14}$ presented a model for the interpretation of pressure-transient data taken in wells completed in naturally fractured formations. The effect of fracture spacing on the rate of matrix flow was not considered in Odeh's model either. Kazemi ${ }^{15}$ presented a model for pressure-transient analysis of naturally 
fractured reservoirs assuming the matrix is a continuum medium. The solution was obtained for finite systems. Although the Kazemi model and the Warren and Root model are conceptually different, the wellbore pressure solutions are very similar in the two models. De Swaan ${ }^{16}$ presented early and long time solutions for determination of properties of naturally fractured reservoirs from well testing data. The solutions were derived based on spherical matrix blocks, which probably do not occur in nature. Following De Swaan's theory, Najurieta ${ }^{17}$ provided solutions for a full time range. However, the model requires four parameters to characterize the pressure behavior.

Da Prat ${ }^{18}$ performed a comparison of the more relevant models for well-test interpretation. In answering the question of the best model to use, he concluded that the tendency is to apply all of them and to choose the one that best fits the data. Schechter and Banik ${ }^{19}$ tried.various models to fit a set of well-test data obtained before and after fracturing treatment of a well penetrating a naturally fractured Spraberry Trend Area reservoir. They found that none of the existing models consistently fit the data set. Plotted in Fig. 3.16 and Fig. 3.17 are type curve matching between the Warren and Root ${ }^{12}$ model and recorded data obtained from E.T. O'Daniel \#37 before and after hydraulic fracturing, respectively. The model generated curves do not fit recorded data, especially for the post-fracture case in Fig. 3.17. In addition, they found that no model gives information about the directional fracture permeabilities from single-well tests. The objective of this study was to develop a new model that better fits the single-well test data and also provides a tool for estimation of the directional fracture permeabilities in naturally fractured reservoirs.

In this study, a new, dual-porosity, dual-permeability, mathematical model has been developed for single phase flow in reservoirs that have vertical natural fractures. Fracture spacing is explicitly considered in the model. With interference test data unavailable, the model consistently fits a set of single-well-test data obtained before and after hydraulic fracturing in the naturally fractured Spraberry Trend Area. Meaningful directional fracture permeabilities were estimated for the reservoir based on the arithmetic and geometric means of the principal horizontal permeabilities. This report provides reservoir engineers with a useful tool for estimating fracture permeability anisotropy and other properties of naturally fractured reservoirs from single-well tests.

\section{Mathematical Model}

Derivation of the mathematical model is presented in detail in a separate document. ${ }^{20}$ Resultant equations are summarized in this section.

Single rate drawdown test

Flowing bottom hole pressure $\left(p_{w f}\right)$ during a drawdown test can be expressed as follows: 


$$
p_{w f}=p_{i}-\frac{141.2 B_{o} q \mu}{h \overline{k_{g}}}\left[p_{D}\left(r_{w}, t\right)+S\right]
$$

where

$$
\begin{array}{lll}
p_{i} & = & \text { initial reservoir pressure, } \mathrm{psig}, \\
B_{o} & = & \text { formation volume factor of oil, } \mathrm{rb} / \mathrm{STB}, \\
q & = & \text { oil production rate, } \mathrm{STB} / \mathrm{D}, \\
\mu & = & \text { oil viscosity, } \mathrm{cp}, \\
h & = & \text { net thickness of pay zone, } \mathrm{ft}, \\
\overline{k_{g}} & =\quad \text { geometric mean of principal fracture permeabilities, } \mathrm{md}, \\
r_{w} & =\quad \text { wellbore radius, } \mathrm{ft}, \\
t & =\quad \text { production time, hour. }
\end{array}
$$

The dimensionless drawdown $p_{D}\left(r_{w}, t\right)$ in Eq. (1) is given by

$$
\begin{aligned}
p_{D}\left(r_{w}, t\right)= & K_{o}\left(\frac{r_{w}}{B}\right)-\frac{1}{2} I_{o}\left(\frac{r_{w}}{B}\right) E i\left(\frac{t}{C B^{2}}\right)+\frac{1}{2} e^{-\frac{t}{C B^{2}}} . \\
& {\left[0.5772+\ln \left(\frac{C r_{w}{ }^{2}}{4 t}\right)+E i\left(\frac{C r_{w}{ }^{2}}{4 t}\right)-\frac{C r_{w}{ }^{2}}{4 t}+\frac{C r_{w}{ }^{2}\left[I_{o}\left(r_{w} / B\right)-1\right]}{4 t\left(r_{w} / 2 B\right)^{2}}\right] }
\end{aligned}
$$

where

$$
\begin{aligned}
& K_{o}=\text { modified Bessel function of the second kind of zero order, } \\
& I_{o}=\text { modified Bessel function of the first kind of zero order, } \\
& E i=\text { exponential integral, } \\
& S \quad=\quad \text { skin factor. }
\end{aligned}
$$

The constants $B$ and $C$ are called matrix bond and fracture capacitance respectively, and are defined as

$$
B=\frac{S_{f}}{\sqrt{2}} \sqrt{\frac{k_{a}}{k_{m}}}
$$


and

$$
C=\frac{\phi_{f} c_{t} \mu}{\overline{k_{a}}}
$$

where

$$
\begin{array}{lll}
S_{f} & = & \text { fracture spacing, } \mathrm{ft}, \\
\overline{k_{a}} & = & \text { arithmetic mean of principal fracture permeabilities, md, } \\
k_{m} & = & \text { matrix permeability, md, } \\
\phi_{f} & = & \text { fracture porosity, bulk volume of formation rock, } \\
c_{t} & = & \text { total compressibility of the fracture system, } \mathrm{psi}^{-1} .
\end{array}
$$

Pressure buildup testing

On the basis of superposition principle, bottom hole pressure $\left(p_{w s}\right)$ during a pressure buildup test can be readily formulated using Eq. (1):

$$
p_{w s}=\bar{p}-\frac{141.2 B_{o} q \mu}{h \bar{k}_{g}}\left[p_{D}\left(r_{w}, t_{c}+\Delta t\right)-p_{D}\left(r_{w}, \Delta t\right)+S\right]
$$

where

$$
\begin{array}{lll}
\bar{p} & = & \text { average reservoir pressure, } \mathrm{psig}, \\
t_{c} & =\quad \text { corrected production time, hour, } \\
\Delta t & =\text { shut-in time, hour. }
\end{array}
$$

Data interpretation

Equations (1) and (5) can be used for matching bottom hole pressure data obtained from drawdown and buildup tests. Basic parameters for trend matching are $\bar{B}, C$, and $\overline{k_{g}}$. Changes in parameters $S$ and $p_{i}$ or $\bar{p}$ will only affect intersection of the matching curve on the pressure axis. 
Once curve matching is achieved by tuning parameters $B, C, \overline{k_{g}}, S$, and $p_{i}$ or $\bar{p}$, reservoir properties may be extracted using Eqs. (3) and (4). For instance, if fracture spacing and matrix permeability are known, arithmetic mean of principal fracture permeabilities $\overline{k_{a}}$ can be calculated from Eq. (3). Then, $\phi_{f} c_{t}$ can be estimated using Eq. (4).

The most important parameters in reservoir simulation with a dual-porosity simulator are ontrend and off-trend fracture permeabilities $k_{x}$ and $k_{y}$. These two parameters may be calculated based on $\overline{k_{g}}$ and $\overline{k_{a}}$ :

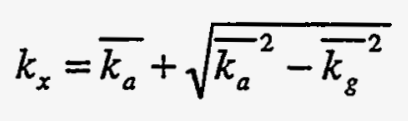

and

$$
k_{y}=\overline{k_{a}}-\sqrt{{\overline{k_{a}}}^{2}-{\overline{k_{g}}}^{2}} .
$$

\section{Reservoir Response in E.T. O’Daniel \#37}

The newly developed mathematical model has been utilized for analyzing the pre-frac and postfrac pressure buildup tests performed in the Upper Spraberry on well \#37 in the E.T. O'Daniel Unit. Examination of the pressure data indicated that the subsurface pressure was calculated from the casing head pressure by assuming that the wellbore was full of water. However, depending on the actual oil level in the wellbore, the subsurface pressures could be up to $200 \mathrm{psi}$ lower than the calculated values. $^{21}$

\section{Pre-frac test}

Shown in Fig. 3.18 is the match between the reported pressure data and model calculated data for the pre-frac test. The mismatch during the early time may be due to wellbore storage. This match was achieved by using the following parameters:

$$
\begin{aligned}
& \mathrm{B}=55.38 \mathrm{ft} \\
& \mathrm{C}=228.2 \mathrm{~s}^{2} \mathrm{ft}^{2} \\
& \overline{k_{g}}=1.67 \mathrm{md} \\
& \bar{p}=1,740 \mathrm{psig} \\
& S=4.6
\end{aligned}
$$


If the average fracture spacing ${ }^{22}$ of $2.86 \mathrm{ft}$ is used, the permeability ratio $\overline{k_{a}} / k_{m}$ can be determined from Eq. (3) to be 750. If the effective matrix permeability is $k_{m}=0.02 \mathrm{md},{ }^{20} \overline{k_{a}}$ can be estimated to be about $15 \mathrm{md}$. Then, using Eqs. (6) and (7), the on-trend and off-trend fracture permeabilities can be estimated to be $k_{x}=30 \mathrm{md}$ and $k_{y}=0.09 \mathrm{md}$, respectively. The ratio of the two fracture permeabilities is $k_{x} / k_{y}=322$.

If the average oil viscosity is taken as $5 \mathrm{cp}$, the fracture capacity $\phi_{f} c_{t}$ can be estimated using Eq. (4) to be $5 \times 10^{-5} \mathrm{psi}^{-1}$. If fracture porosity is assumed to be $\phi_{f}=0.01$, the total compressibility of the fracture system is estimated to be $c_{t}=5 \times 10^{-3} \mathrm{psi}^{-1}$.

It must be noted that the curve matching on the Cartesian scale is not unique. For example, instead of using $\bar{p}=1,740 \mathrm{psig}$ and $S=4.6$, other combinations of these two parameters can also be used to achieve the same quality of curve matching. Therefore, reliability of the derived skin factor depends upon the interpreter's knowledge of the reservoir pressure. More research work on the matching uniqueness with this model is being conducted.

\section{Post-frac test}

Figure 3.19 demonstrates the match between the reported pressure data and model calculated data for the post-frac test. Again the mismatch during the early time may be due to wellbore storage. This match was achieved by using the following parameters:

$$
\begin{aligned}
& \mathrm{B}=63.95 \mathrm{ft} \\
& \mathrm{C}=342.3 \mathrm{~s} / \mathrm{ft}^{2} \\
& \overline{k_{g}}=6 \mathrm{md} \\
& \bar{p}=1,740 \mathrm{psig} \\
& S=4.6
\end{aligned}
$$

If the average fracture spacing 22 of $2.86 \mathrm{ft}$ is used, the permeability ratio $\overline{k_{a}} / k_{m}$ can be determined from Eq. (3) to be 1000. If the effective matrix permeability is $k_{m}=0.02 \mathrm{md}^{20}$ $\overline{k_{a}}$ can be estimated to be about $20 \mathrm{md}$. Then, using Eqs. (6) and (7), the on-trend and off-trend fracture permeabilities can be estimated to be $k_{x}=39 \mathrm{md}$ and $k_{y}=0.9 \mathrm{md}$, respectively. The ratio of the two fracture permeabilities is $k_{x} / k_{y}=43$.

If the average oil viscosity is taken as $5 \mathrm{cp}$, the fracture capacity $\phi_{f} c_{t}$ can be estimated using Eq. (4) to be $1 \times 10^{-4} \mathrm{psi}^{-1}$. If the total compressibility of the fracture system remained the same as after hydraulic treatment $\left(c_{t}=5 \times 10^{-3} \mathrm{psi}^{-1}\right)$, fracture porosity should be doubled to be $\phi_{f}=0.02$ due to sand placement in the fractures. 
Again, it should be noted that other combinations of $\bar{p}$ and $S$ can also be used to achieve the same quality of curve matching. Therefore, reliability of the derived skin factor depends upon the interpreter's knowledge of the reservoir pressure.

\section{Discussion}

Traditionally the directional permeabilities have been estimated based on interpretation of data obtained from interference well tests. Both permeability ratio and fracture orientation have been estimated in some fractured reservoirs. Our first concern in this investigation was to answer a basic question: Can we estimate permeability ratio using pressure data from single-well tests? Elkins and Skov ${ }^{7}$ interpreted pressure data recorded during interference tests using a singleporosity mathematical model presented by Collins ${ }^{8}$ to obtain information about effective directional permeabilities in several areas in the same oil field. Depending upon the area where the tests were performed, the effective permeability ratio varies between 6 and 1000 . According to their study, the ratio is between 6 and 36 in the Driver unit, 9 in the North Driver Unit, 49 in the Pembrook Area, 16 in the Aldwell Area, and between 100 and 1000 in the Midkiff Area where a waterflooding pilot was matched by a reservoir simulator using a permeability ratio of 144. These results are consistent with our interpretation of data from single-well tests in the E.T. O'Daniel Unit. This indicates that it is possible to estimate permeability anisotropy from singlewell test if an appropriate mathematical model is employed.

Ideally the permeability ratio should be fairly constant within a reasonably large region. It is our opinion that the permeability ratio in the Spraberry Trend Area reservoirs were altered locally during hydraulic fracture treatments. It is seen from our interpretation that hydraulic fracturing changed reservoir properties. The fracture permeability ratio dropped from 322 to 42 after hydraulic treatment in the well E.T. O'Daniel \#37. While the on-trend fracture permeability increased slightly (from $30 \mathrm{md}$ to $39 \mathrm{md}$ ), the off-trend fracture permeability increased by 10 fold (from $0.09 \mathrm{md}$ to $0.9 \mathrm{md}$ ). This is expected to occur if the treatment creates fractures that have non-zero components in the off-trend direction. These hydraulically induced fractures should connect the wellbore to the naturally occurring fractures near the wellbore.

\section{Conclusions}

A mathematical model has been developed for estimating permeability anisotropy in naturally fractured reservoirs using pressure data from well tests. Although this model is general and can be used for interpretation of data from interference tests for directional permeability determination, with limited data from single-well tests we have shown that permeability anisotropy can be estimated from pressure data obtained from single-well tests.

Application of the new model to analysis of pressure data obtained from the E.T. O'Daniel \#37 indicates that the fracture permeability ratio in the test area was 322 before stimulation. Hydraulic fracturing reduced this ratio to 42 . 


\section{Nomenclature}

\begin{tabular}{|c|c|c|}
\hline$A$ & $=$ & integration constant \\
\hline$B$ & $=$ & matrix bond constant defined by Eq. (3), $\mathrm{ft}$ \\
\hline$B_{o}$ & $=$ & formation volume factor of oil, rb/STB \\
\hline$C$ & $=$ & fracture capacitance defined by Eq. (4), s/ft ${ }^{2}$ \\
\hline$c_{t}$ & $=$ & total compressibility of the fracture system, $\mathrm{psi}^{-1}$ \\
\hline$E i$ & $=$ & exponential integral \\
\hline$h$ & $=$ & net thickness of pay zone, $\mathrm{ft}$ \\
\hline$I_{o}$ & $=$ & modified Bessel function of the first kind of zero order \\
\hline$J_{o}$ & $=$ & Bessel function of the first kind of zero order \\
\hline$\overline{k_{a}}$ & $=$ & arithmetic mean of principal fracture permeabilities, md \\
\hline$\overline{k_{g}}$ & $=$ & geometric mean of principal fracture permeabilities, md \\
\hline$k_{m}$ & $=$ & matrix permeability, md \\
\hline$K_{o}$ & $=$ & modified Bessel function of the second kind of zero order \\
\hline$\overline{k_{r}}$ & $=$ & fracture permeability in the radial direction, md \\
\hline$\overline{k_{\theta}}$ & $=$ & fracture permeability in the angular direction, $m d$ \\
\hline$k_{x}$ & $=$ & on-trend fracture permeability, md \\
\hline$k_{y}$ & $=$ & off-trend fracture permeability, md \\
\hline $\bar{p}$ & $=$ & average reservoir pressure, psig \\
\hline$p_{i}$ & $=$ & initial reservoir pressure, psig \\
\hline$q$ & $=$ & oil production rate, STB/D \\
\hline$r$ & $=$ & distance from wellbore, $\mathrm{ft}$ \\
\hline$r_{w}$ & $=$ & wellbore radius, $\mathrm{ft}$ \\
\hline$S$ & $=$ & skin factor \\
\hline$S_{f}$ & $=$ & fracture spacing, $\mathrm{ft}$ \\
\hline$t$ & $=$ & production time, hour \\
\hline$t_{c}$ & $=$ & corrected production time, hour \\
\hline$\Delta t$ & $=$ & shut-in time, hour \\
\hline$\theta$ & $=$ & orientation angle \\
\hline$\mu$ & $=$ & oil viscosity, $\mathrm{cp}$ \\
\hline$\phi_{f}=$ & & porosity, bulk volume of \\
\hline
\end{tabular}

\section{References}

1. Schechter, D.S., McDonald, P., Sheffield, T., and Baker, R.: "Reservoir Characterization and $\mathrm{CO}_{2}$ Pilot Design in the Naturally Fractured Spraberry Trend Area," paper SPE 35469, presented at the SPE Permian Basin Oil \& Gas Recovery Conference held in Midland, Texas, 27-29, March 1996. 
2. Baker, R.: "Reasons for the Relatively Low Recovery of the Spraberry Waterfloods," PRRC Spraberry Database, June, 1996.

3. Guo, B. and Schechter, D.S: "Use of a Simple Mathematical Model for Estimating Formation Damage in Wells Intersecting Long Fractures," paper SPE 38178 presented at the 1997 SPE European Formation Damage Conference held in The Hague, The Netherlands, 2-3 June 1997.

4. Schechter, D.S.: "Advanced Reservoir Characterization and Evaluation of $\mathrm{CO}_{2}$ Gravity Drainage in the Naturally Fractured Spraberry Trend Area," Quarterly Technical Progress Report to DOE under Contract No. DE-FC22-95BC14942, PRRC. Report 97-11, Dec. 31, 1996.

5. Elkins, L.F.: "Reservoir Performance and Well Spacing --- Silica Arbuckle Pool," Drill. and Prod. Prac., API (1946), 109.

6. Theis, C.V.: "The Relation between the Lowering of the Peizometric Surface and the Rate and Duration of Discharge of a Well Using Groundwater Storage," Trans., AGU (1935) 16, 519.

7. Elkins, L.F. and Skov, A.M.: "Determination of Fracture Orientation from Pressure Interference," Trans. AIME (1960) 219, 301-304.

8. Collins, R.E.: Flow of Fluids Through Porous Materials, Reinhold Publishing Corp., New York (1961).

9. Ramey, H.J: "Interference Analysis for Anisotropic Formations --- A Case History," JPT (Oct. 1975), 1290-1298.

10. Swift, S.C. and Brown, L.P.: "Interference Testing for reservoir definition -- The State of the Art," paper SPE 5809 presented at the SPE Improved Oil Recovery Symposium held in Tulsa, Oklahoma, March 22-24, 1976.

11. Beliveau, D.: "Pressure Transients Characterize Fractured Midale Unit," JPT (Dec. 1989), 1354-1362.

12. Warren, J.E. and Root, P.J.: "The Behavior of Naturally Fractured Reservoirs," SPEJ (Sept. 1963), 245-255.

13. Barenblatt, G.I., Zheltov, Iu.P. and Kochina, I.N.: "Basic Concept in the Theory of Homogeneous Liquids in Fissured Rocks," J. Appl. Math. Mech. (1960) 24, 1286-1303.

14. Odeh, A.A.: "Unsteady-State Behavior of Naturally Fractured Reservoirs," SPEJ (March 1965) 60-66.

15. Kazemi, H.: "Pressure Transient Analysis of Naturally Fractured Reservoirs with Uniform Fracture Distribution," Trans. AIME (1969) 246, 451-461.

16. De Swaan, O.A.: "Analytical Solutions for Determining Naturally Fractured Reservoir Properties by Well Testing," SPEJ (June 1976), 117-122.

17. Najurieta, H.L.: "A Theory for the Pressure Transient Analysis in Naturally Fractured Reservoirs," JPT (1976), 1241-1250.

18. Da Prat, G.: Well Test Analysis for Fractured Reservoir Evaluation, Elsevier Science Publishing Company Inc., New York (1990).

19. Schechter, D.S. and Banik, A.K.: "Modern Computer-Aided Transient Pressure Test Interpretation for Characterization of the Naturally Fractured Spraberry Trend Area," PRRC Spraberry Database, 1997, PRRC Report No. 97-4. 
20. Guo, B. and Schechter, D.S.: "Estimate of Anisotropic Fracture Permeabilities from SingleWell Pressure Transient Tests," paper to be presented at the SPE 1998 Permian Basin Oil and Gas Recovery Conference to be held 23-27 March 1998 in Midland, Texas.

21. Epic Consulting Services Limited: "Pre and Post Hydraulic Fracture Buildup Tests on E.T. O’Daniel \#37," PRRC Spraberry Database, December 17, 1997.

22. Lorenz, J.: "Summary of Observations and Interim Interpretations: Fractures in Horizontal Spraberry Cores, E.T. O’Daniel Well \#28," PRRC Spraberry Database, Dec. 12, 1996. 


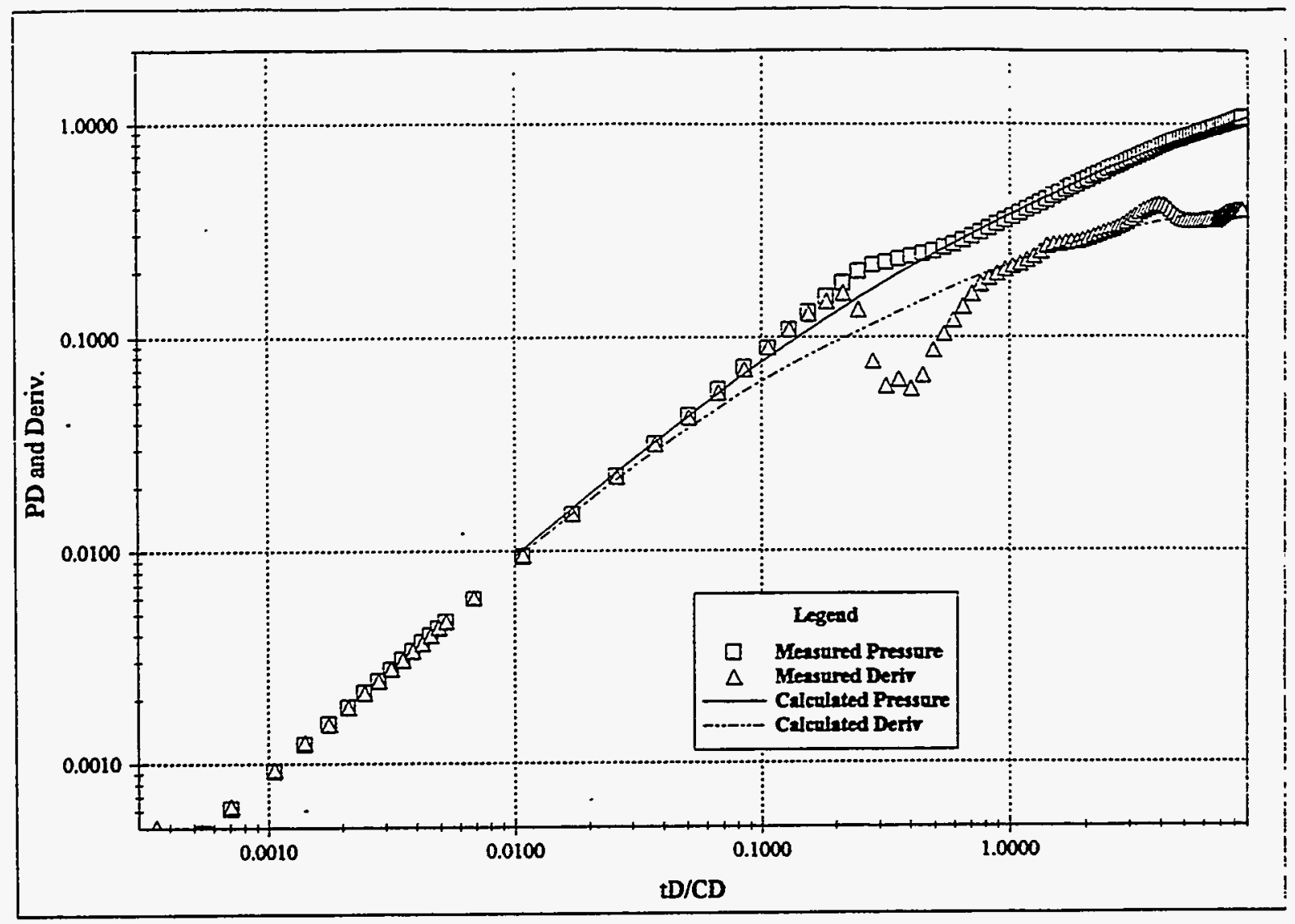

Fig. 3.16 - Type curve matching between recorded pressure and pressure calculated by the Warren and Root model for a pre-frac buildup test. 


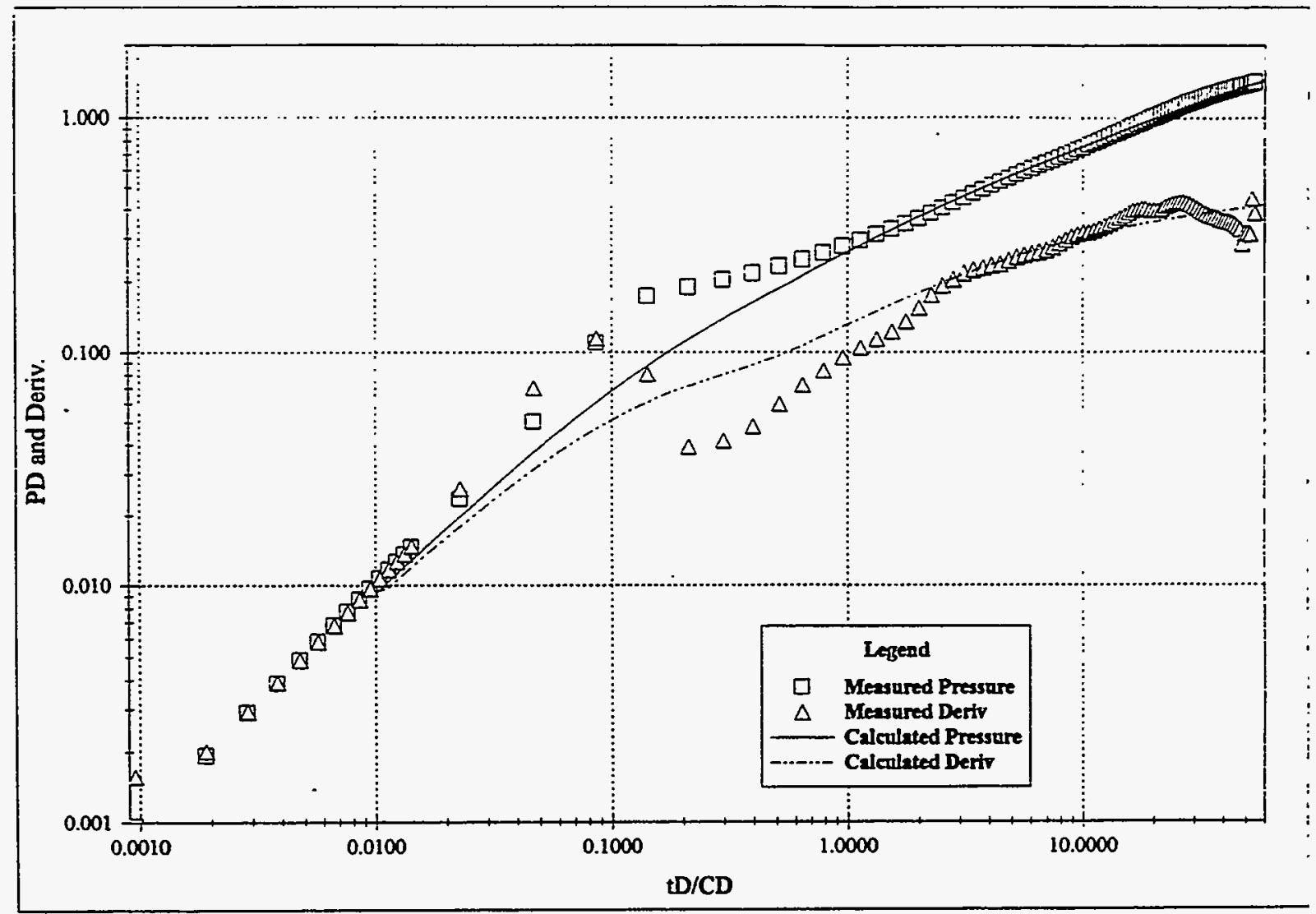

Fig. 3.17 - Type curve matching between recorded pressure and pressure calculated by the Warren and Root model for a post-frac buildup test. 


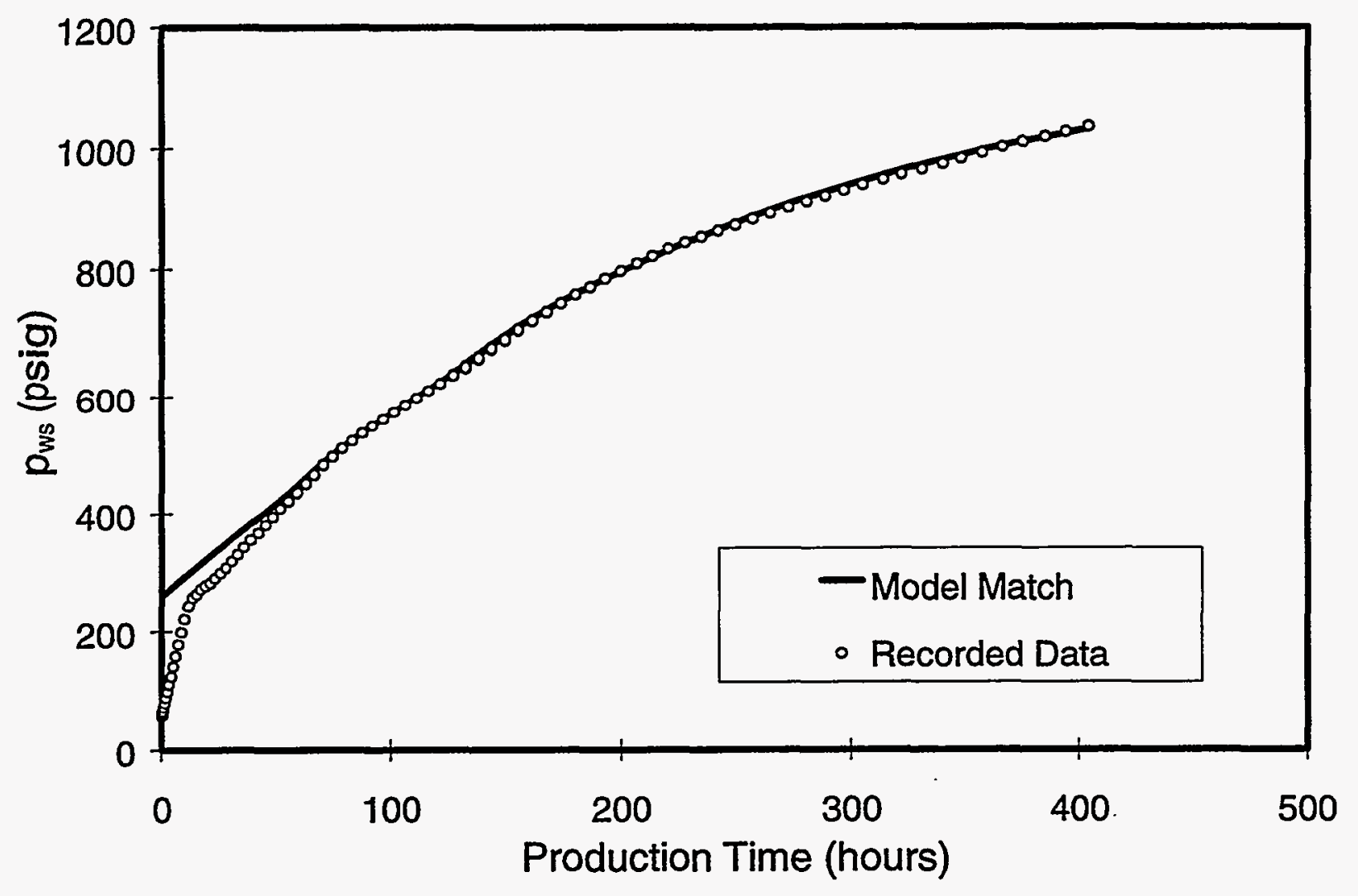

Fig. 3.18 - Matching between recorded and calculated bottom hole pressures for a pre-frac buildup test. 


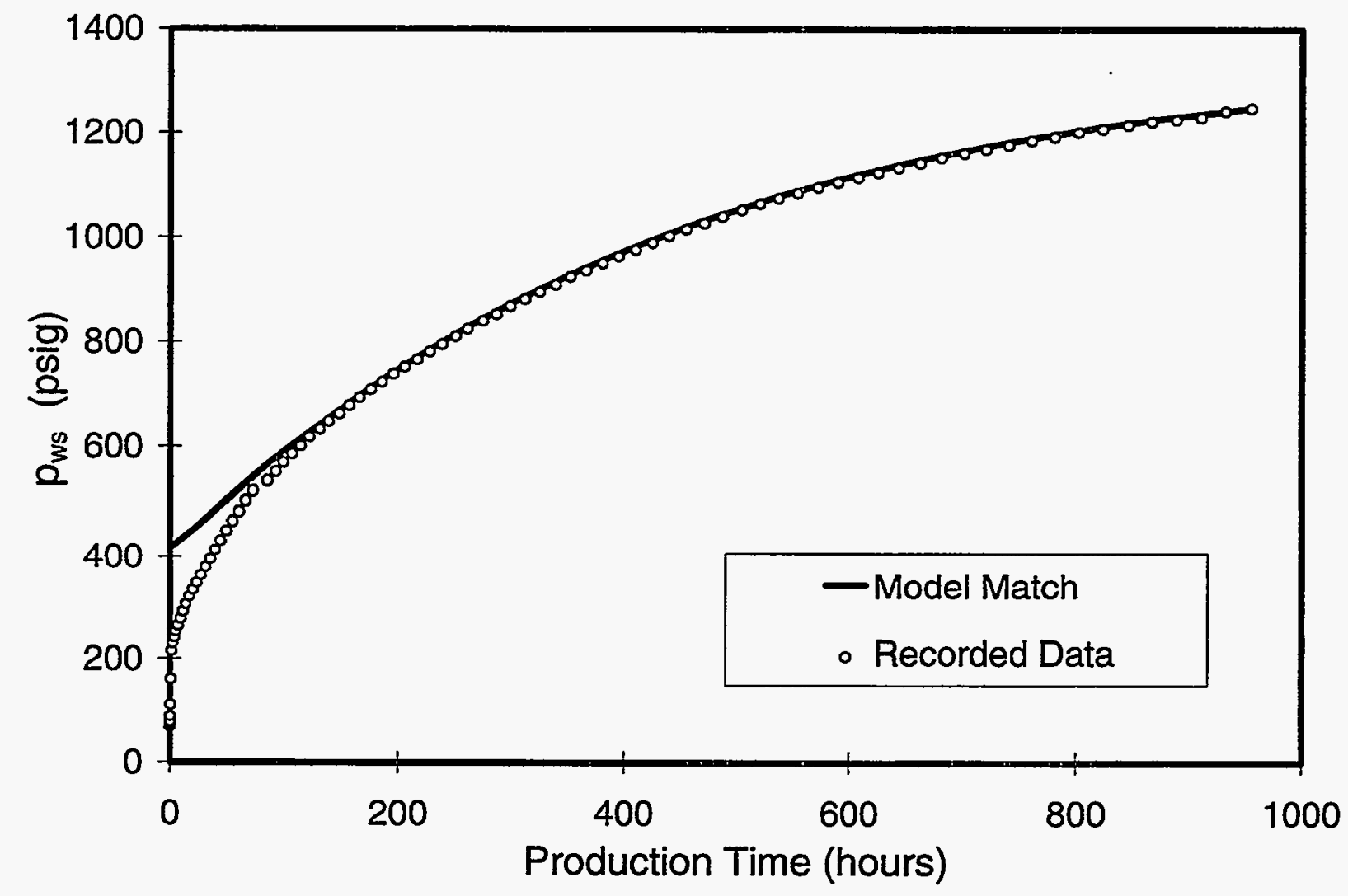

Fig. 3.19 - Matching between recorded and calculated bottom hole pressures for a post-frac buildup test. 


\subsection{Numerical Simulation of a Water Flood Pilot in the Naturally Fractured Spraberry Trend}

During the first year of the project, efforts were made in numerical simulation of the Humble Waterflood Pilot using the VIP simulator. A good quality history match was achieved for oil, gas and water production data but not for pressure data. In the second year of the project, simulation efforts concentrated on matching pressure data. A pilot model was constructed using the threephase, three-dimensional, dual porosity simulator ECLIPSE. The effect of varying the fracture and matrix parameters such as fracture spacing, permeability and relative permeability, and capillary pressure to history match the pilot response was simulated in detail. The analysis may be helpful for understanding the reservoir behavior and reducing uncertain parameters in future process options such as horizontal wells and $\mathrm{CO}_{2}$ injection. This section presents our simulation results obtained using the commercial simulator ECLIPSE. Background for this simulation was presented in the first annual report ${ }^{1}$ and will not be repeated here.

\section{Humble Pilot Waterflood Model}

A dual porosity model was used as the Spraberry formation is very tight and no significant fluid flow in the matrix can be assumed. The main flow in the reservoir occurs through exchange of fluid from the matrix to the fractures and the fractures towards the production wells. In order to understand the physical meaning behind the dual porosity/single permeability simulation, the equation describing two phase, 3-D flow in the fracture system is presented in finite difference form.

Fracture Flow Equation:

$$
\begin{aligned}
& \Delta\left[T_{\alpha f}\left(\Delta p_{\alpha f}-\gamma_{\alpha f} \Delta D_{f}\right)\right]-T_{\alpha m a}\left[\left(p_{\alpha f}-\gamma_{\alpha f} \Delta D_{f}\right)-\left(p_{\alpha m a}-\gamma_{\alpha m a} \Delta D_{m a}\right)\right] \\
& +q_{\alpha}=\frac{V R}{\Delta t} \Delta_{t}\left(\frac{\phi S_{\alpha}}{B_{\alpha}}\right)_{f}
\end{aligned}
$$

where $\alpha$ refers to oil or water. The $-\mathrm{T}_{\alpha \mathrm{ma}}\left[\left(\mathrm{p}_{\alpha \mathrm{f}}-\gamma_{\alpha f} \Delta \mathrm{D}_{\mathrm{f}}\right)-\left(\mathrm{p}_{\alpha \mathrm{ma}}-\gamma_{\alpha \mathrm{ma}} \Delta \mathrm{D}_{\mathrm{ma}}\right)\right]$ terms represent matrix/fracture fluid exchange. The fracture equations are identical to those for a single porosity system if the matrix/fracture transfer terms are omitted.

Matrix Flow Equation:

$$
\mathrm{T}_{\alpha \mathrm{ma}}\left[\left(\mathrm{p}_{\alpha \mathrm{f}}-\gamma_{\alpha \mathrm{f}} \Delta \mathrm{D}_{\mathrm{f}}\right)-\left(\mathrm{p}_{\alpha \mathrm{ma}}-\gamma_{\alpha \mathrm{ma}} \Delta \mathrm{D}_{\mathrm{ma}}\right)\right]=\frac{\mathrm{VR}}{\Delta \mathrm{t}} \Delta_{\mathrm{t}}\left(\frac{\phi \mathrm{S}_{\alpha}}{\mathrm{B}_{\alpha}}\right)_{\mathrm{ma}}
$$

Flow rate is not included in the matrix equations because the matrix permeability and flow rate is insignificant compared to fracture flow rate and permeabilities.

The saturation and capillary pressure terms have the following relationships: 


$$
\begin{aligned}
& S_{o f}=1-S_{w f} \\
& S_{o m a}=1-S_{w m a} \\
& p_{o f}=p_{w f}+P_{c f} \\
& p_{o m a}=p_{w m a}+P_{c m a}
\end{aligned}
$$

Initial saturations and pressures are calculated based on capillary pressure data, water-oil contact data, and fluid pressure gradients. This initialization ensures that the system is at capillary-gravity equilibrium at zero time. For time greater than zero, boundary conditions must be specified. There are two boundary conditions: inner boundary and outer boundary condition. For the inner boundary, two conditions can be specified, either constant total wellbore rate or constant wellbore pressure. In our simulation, only constant total wellbore rate are applied. For the outer boundary, the simulator allows for four conditions, constant influx, constant pressure, no flow or aquifer boundaries. No flow boundary is specified in the model.

Equation (7) is the $\mathrm{x}$-direction transmissibility for Cartesian coordinates. The $\mathrm{y}$ and $\mathrm{z}$ directional transmissibilities are similarly defined. The transmissibilities between the matrix and fracture blocks are calculated as follows

$$
\begin{aligned}
& \mathrm{T}_{\alpha \mathrm{fx}}=0.001127\left(\frac{\mathrm{k} \mathrm{k}_{\mathrm{r} \alpha}}{\mu_{\alpha} \mathrm{B}_{\alpha}}\right)_{\mathrm{f}}\left(\frac{\Delta \mathrm{y} \Delta \mathrm{z}}{\Delta \mathrm{x}}\right) \\
& \mathrm{T}_{\alpha \mathrm{ma}}=0.001127\left(\frac{\mathrm{k} \mathrm{k}_{\mathrm{r} \alpha}}{\mu_{\alpha} \mathrm{B}_{\alpha}}\right)_{\mathrm{ma}}(\Delta \mathrm{x} \Delta \mathrm{y} \Delta z) \sigma
\end{aligned}
$$

The coefficient $\sigma$ is a function of block geometry that measures the conductivity between the matrix block and surrounding fractures. Gilman and $\mathrm{Kazemi}^{2}$ introduced a shape factor, $\sigma$, to relate matrix-fracture pressure difference and flow rate as

$$
\sigma=4\left(\frac{1}{\mathrm{~L}_{\mathrm{x}}^{2}}+\frac{1}{\mathrm{~L}_{\mathrm{y}}{ }^{2}}+\frac{1}{\mathrm{~L}_{\mathrm{z}}{ }^{2}}\right)
$$

where $\mathrm{Lx}, \mathrm{Ly}$, and $\mathrm{Lz}$ are dimensions of matrix blocks which correspond to fracture spacing in the $\mathrm{x}-, \mathrm{y}$ - and the $\mathrm{z}$ - direction respectively.

This shape factor was calculated from a first-order conservative finite difference approximation of flow between fractures and matrix blocks. Equation (9) assumes that the matrix properties are uniform and the matrix block size is rectangular, known as the sheet model. In practice, matrix block size and shape varies considerably depending on the fracture system, thus making the network difficult to characterize. The shape factor may be much different from that predicted by Eq. (9). Consequently, the shape factor normally must be evaluated as a history-match parameter. 
In the simulation, the shape factor is taken as a constant parameter of 1.47 with $2.86 \mathrm{ft}$ fracture spacing.

In this model, each grid block may contain many matrix blocks. The matrix block acts as a source to the fractures with fluid exchange mechanisms. There is no direct flow from matrix block to matrix block within the grid block; nor is there any direct flow from matrix blocks in a grid block to those in an adjacent grid block.

Since regional fractures in the Spraberry are primarily oriented in one direction, the on-trend fracture permeability is greater than the off-trend fracture permeabilty. The ratio of fracture permeability is $15: 0.25$. The matrix permeability is set to be $0.02 \mathrm{mD}$. The different between offtrend fracture permeability and matrix permeability accounts for cross fractures in the model.

The grid dimension is $22 \times 18$ with 396 grid blocks in the horizontal direction and 3 grid blocks in the vertical direction. A total number of 1188 grid blocks were used to simulate the pilot. The total number of grid blocks becomes twice that of a single porosity realization since the simulator generates one set of grid blocks for matrix parameters and one set for the fracture parameters. The wells and all layers were aligned parallel with the major fracture system with an orientation of $\mathrm{N} 50^{\circ} \mathrm{E}$.

Figure 3.20 shows the grid model for the five spot pattern after orientation with the major fracture system. The virgin reservoir properties are shown in Table 3.4. The reservoir fluid analysis (PVT analysis) was conducted by Magnolia Petroleum Co. ${ }^{3}$ and results are displayed in Table 3.5. The fluid samples were recombined and flashed to reservoir conditions at a temperature of $140^{\circ} \mathrm{F}$. It was found that the saturation pressure was 1840 psia, 460 psia below the estimated original reservoir pressure of $2300 \mathrm{psi}$.

The two main Spraberry pay zones, the $1 \mathrm{U}$ and $5 \mathrm{U}$, were modeled with one large intervening shale layer. An assumption was made that there is no vertical communication in matrix or fracture between the two different sand zones, so the transmissibilities of matrix and fracture in the intervening shale were set to zero. This assumption agrees with recent horizontal core results.

The five spot pattern with one producer (Sh. B-9) and four injectors (Sh. B-2, Sh. B-4, Sh. B-6 and Sh. B-10) was modeled in the simulation. The 80 -acre drainage area of the pilot were confined by straight lines connecting the four injection wells.

In addition to the five spot pattern wells, five observation wells; Sh. B-1, Sh. B-5, Sh. B-7, Sh. B11, T-1, A-4 and Sh. B-8 were included to provide information on the changes in reservoir pressure and production rates which helps in tracing the response of the flood outside the pattern.

\section{Sensitivity Parameters}


The sensitivity cases were performed to evaluate ranges of behavior for different values to help assess the impact of major uncertainties on predicted performance.

In order to reduce the number of parameters that effect well performance in this study, the unknown parameters were altered to match the observed data. The known properties were input in the model as fixed parameters.

These are the sensitivity parameters we need to simulate :
a. Fracture spacing
b. Matrix and fracture permeability
c. Matrix and fracture relative permeability
d. Capillary pressure
e. Matrix and fracture porosity
f. Dual porosity/dual permeability

\section{a. Fracture Spacing}

The pilot model was set up with extensive vertical fractures having the same spacing in 1U and 5U. An assumption was made that there is no vertical communication between the two sand units (1U and 5U). This was accounted for by setting the matrix and fracture transmissibilities in the shale to be zero. Both on-trend (x-direction in Fig. 3.20) and off-trend (y-direction) fractures were input in the model.

A recent outcrop study in the Bone Springs formation, a Spraberry equivalent outcrop, showed that a 3-ft fracture spacing dominates in the outcrop. The horizontal cores obtained from the E.T O'Daniel \#28 well also show the 3 to $5 \mathrm{ft}$ fracture spacing dominates in field. ${ }^{4} \mathrm{~A}$ fracture spacing of $2.86 \mathrm{ft}$ was used to history match the observed field data performance. As can be seen in Eqs. (8) and (9), lowering the fracture spacing will increase the shape factor value, then the transmissibility from matrix to fracture will increase. This change will increase oil and gas production, decrease water rate, and increase bottom hole pressure.

\section{b. Matrix and Fracture Permeability}

The reservoir permeability was much greater in the direction of the major fracture trend than in the minor trend direction. A fracture permeability ratio between major $\left(\mathrm{K}_{\mathrm{xf}}\right)$ and minor permeability $\left(\mathrm{K}_{\mathrm{yf}}\right)$ of $15: 0.25$ and the matrix permeability of $0.02 \mathrm{mD}$ were used. We input a different value for matrix and minor fracture permeability to account for cross fractures. Water production is increased with increase in the minor fracture permeability, while increasing the major permeability will increase the oil rate. The fracture permeability ratio used in this study was started from the $144: 1$ ratio used by Wolff ${ }^{5}$ for the Humble Piłot Waterflood and from anisotropic fracture permeabilities obtained from the single well test on the E.T. O'Daniel \#37 before and after hydraulic fracturing, 30:0.09 and 39:0.9 respectively (see section 3.2), until the 
best matches were achieved. Besides constraining the production rate and bottom hole pressure, cumulative water injection was also used as one of the constraints for these matches.

Stress-sensitivity has been used to match the performance since the fracture permeability of this pilot may be stress-sensitive. Similar behavior has been observed in the Spraberry Midkiff Unit. A series of pulse tests for 80 acre spacing were conducted before and after high pressure water injection into injection wells. Pulse tests demonstrated that the fracture permeability changed as the injection pressure and reservoir pressure increased. Cross fracturing also occurs as a result of high pressure injection. Further evidence of fracture sensitivity was observed during a recent tracer survey in the Midkiff Unit. ${ }^{6}$

To model stress-sensitive behavior, Eclipse has a compaction option. This option is a table of multiplication factors for porosities and permeabilities. The compaction has two options, either reversible or irreversible. Reversible means that the current grid block pressure is used in compaction calculations while irreversible means that the minimum pressure achieved in the grid block is used in the compaction calculation.

Stress sensitivity data is not available from laboratory experiments; therefore, this data has to be found from history matches. The compaction with reversible option is used since the fractures may be pressure sensitive.

\section{c. Matrix and Fracture Relative Permeability}

Relative permeability curves for the matrix were obtained from several unfractured core reports. The curves used in this study are shown in Figs. 3.2 and 3.3. The permeability in the matrix for water-oil was restricted to the mobile saturation range from $\mathrm{Sw}=0.3$ to $\mathrm{Sw}=0.7$.

It is very difficult to measure accurately fracture permeability curves for a reservoir. Assumptions for this curve are that both phases are equally mobile for the entire range of saturations for the fractures. Several curves were used to try match the observed data, however, alteration of relative permeability curves in the fracture system does not significantly change the results.

\section{d. Capillary Pressure}

The capillary pressure is an important parameter in the water imbibition process. When water comes in contact with the oil zone via the fractures, water may imbibe into the matrix blocks to displace oil. Imbibition capillary pressure curves presented in Section 2.1 are used in this simulation. Reproduction of the curve is shown in Fig. 3.21.

Based on Eqs. (5) and (6), increasing the matrix capillary pressure will either increase the oil pressure in the matrix and allow easier oil movement from matrix to fractures, or decrease the water pressure in the matrix and allow easier water movement from fractures to the matrix block. 
The simulation results show similar behavior, thus lowering the capillary pressure causes an increase in water production results and a decrease in oil and gas production and bottom hole pressure.

\section{e. Matrix and Fracture Porosity}

A fracture porosity of $0.1 \%$ was used in the model. This value will be dependent on the fracture spacing and width of the fractures. Width is not an input parameter in this model, however the fracture spacing is given independent of the fracture porosity. Fracture permeability could be dependent on spacing, since a more dense system of fractures should give better overall permeability. The fact that these various parameters are given individually in the model, although they are dependent on each other, might cause some confusion. However, if the width is not a constant parameter, the fracture porosity will be an indicator of fluid storage. The fracture spacing will account for matrix surface area in contact with the injected water and would then alter the effectiveness of the imbibition process. The fracture permeability should be a value that represents the productivity of the field. Using a fracture porosity of $1.0 \%$, water will not be produced at all because the water fills the fractures instead of flowing to the well. Thus, it can be concluded that increasing fracture porosity will decrease water production. The matrix porosity was kept constant at $10 \%$. Increasing the matrix porosity will increase oil in the matrix block, therefore it will increase the oil recovery. A fracture porosity of $0.1 \%$ matches with Elkins estimation? ${ }^{7}$.

\section{f. Orientation of the Major Fracture Trend}

Several sources of data, such as interference tests, core analysis, etc., have been used to determine the orientation of the major fracture system. The recent advances in fracture characterization from horizontal coring indicate that there is a distinct fracture permeability direction that is oriented approximately $\mathrm{N}^{\circ} 0^{\circ} \mathrm{E}^{4}$ and this was used for most simulations. Two additional simulations were conducted to investigate the effects of rotation of the major fracture orientation. The orientations simulated were $\mathrm{N} 60^{\circ} \mathrm{E}$ and $\mathrm{N} 85^{\circ} \mathrm{E}$. Both these simulations resulted in too high water production in the middle producer, since the well at these orientations was aligned with east and west water injectors.

\section{g. Dual Porosity/Dual Permeability}

A simulation was performed with the dual porosity/dual permeability option, but no significant differences in the results were observed between this and the dual porosity/single permeability option. Since the Spraberry formation is very tight, we can assume no significant fluid flow occurs in the matrix rock. The main flow occurs through exchange of fluid from the matrix to the fractures.

\section{Matched Parameters}

Production rates for the five observations wells around the pilot area were input in the model in addition to the middle producer. The results showed that Sh. B-7 and Sh. B-11 did not produce any water after water injection. It appears water did not flow off-trend to these wells. 
From observed data and the simulation, it can be noted that the Sh. B-9 was the first well to experience water breakthrough, closely followed by Sh. B-1, Sh. B-5 and T-1 . A total of 3.7 MMbbls of water was injected into the model and matched with observed injection data.

From the parameters listed in Table 3.6 and Table 3.7, an attempt was made to match the observed data for the middle producer, Sh. B-9.

The simulation of oil production rate matches the observed data (Fig 3:22). Gas production has approximately the same trend as the observed data, but the first peak in gas production observed in the field upon initiation of water injection is not obtained in the simulated results (Fig. 3.23). The trend of oil and gas rates should be the same since a straight line relative permeability curve in the fracture was used. Because the first peak in gas production cannot be matched, the first peak in gas-oil ratio also can not be matched with the observed data (Fig. 3.24).

The water production and water cut also were influenced by the first peak in gas production, so the performance cannot be matched during the initial phases of water production (Fig. 3.25 and 3.26).

The bottom hole pressure for the middle producer is strongly dependent on the rates of surrounding observation wells and the ratio of fracture permeability. The permeability sensitivity is also performed to match the simulated bottom hole pressure as can be seen in Fig. 3.27.

\section{Conclusions}

From the interpretation of the Humble pilot using a dual porosity simulator, the following conclusions can be drawn :

1. A dual porosity model was used for this simulation since this method gave the same results as dual porosity/dual permeability model. This indicates that there is negligible fluid flow in tight matrix rock, and that main flow occurs within the fractures with local exchange of fluids between the fracture system and matrix blocks.

2. A capillary pressure curve from imbibition experiments was used in the history match of the observed water production and bottom hole pressure data from the Humble Pilot waterflood.

3. The constant fracture spacing of the major fracture trend is set at $2.86 \mathrm{ft}$ which is the value measured in recently obtained horizontal cores.

4. A fracture orientation of $\mathrm{N} 50^{\circ} \mathrm{E}$ best matches the flood pattern observed during the Humble Pilot test, which is also consistent with horizontal core.

5. A ratio of permeability parallel and perpendicular to the major fracture trend of $15: 0.25$ was one of the parameters that gave the best match of observed data. 
6. Beside the constraints in matching production rate and bottom hole pressure, cumulative water injection was also used as one of the parameters constrained for matching the performance of pilot response.

7. The compaction option has been used to simulate the stress sensitive behavior of the fracture system.

\section{Nomenclature}

$\begin{array}{lll}\mathrm{B} & = & \text { formation volume factor, reservoir bbl/STB } \\ \mathrm{D} & = & \text { depth of grid block, } \mathrm{ft} \\ \mathrm{k} & = & \text { permeability, md } \\ \mathrm{kr} & = & \text { relative permeability, fraction } \\ \mathrm{L} & = & \text { ength of matrix block edges, } \mathrm{ft} \\ \mathrm{p} & = & \text { fluid pressure, psia } \\ \mathrm{Pc} & = & \text { oil-water system capillary pressure, psia } \\ \mathrm{q} & = & \text { producing interval flow rate, STB/D } \\ \mathrm{t} & = & \text { time, days } \\ \mathrm{T} & = & \text { fluid transmissibility } \\ \mathrm{VR} & = & \text { bulk rock volume, STB }\end{array}$

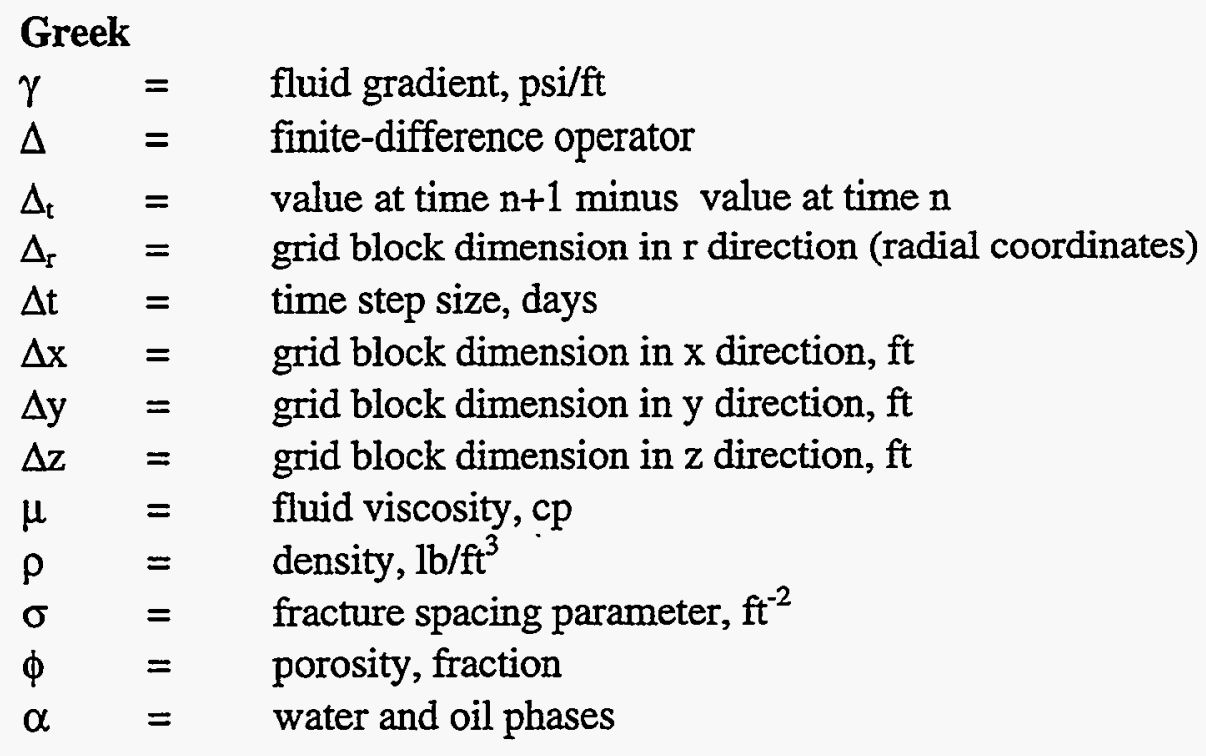

\section{Subscripts}

$\begin{array}{lll}\mathrm{f} & = & \text { fracture } \\ \mathrm{ma} & = & \text { matrix } \\ \mathrm{o} & = & \text { oil phase } \\ \mathrm{t} & = & \text { time } \\ \mathrm{w} & = & \text { water phase } \\ \mathrm{x} & = & \mathrm{x} \text {-direction flow property } \\ \mathrm{y} & = & \mathrm{y} \text {-direction flow property }\end{array}$


$\mathrm{z} \quad \mathrm{z}$-direction flow property

\section{References}

1. Schechter, D.S.: "Advanced Reservoir Characterization and Evaluation of $\mathrm{CO}_{2}$ Gravity Drainage in the Naturally Fractured Spraberry Trend Area," First Annual Technical Progress Report to DOE under Contract No. DE-FC22-95BC14942, PRRC Report 96-42, Dec. 17, 1996.

2. Gilman, J.R., Kazemi, H, "Improvements in Simulation of Naturally Fractured Reservoirs," SPE, Aug. 1983.

3. Petroleum Production Laboratories Inc.: "PVT Analysis Report, Louise Schackelford No. 1, Spraberry Reservoir, Tex Harvey Field," PRRC Spraberry Database, May 30, 1952.

4. Lorenz, J. "Summary of Observations and Interim Interpretations: Fractures in Horizontal Spraberry Cores, E.T. O’ Daniel Well \#28," PRRC Spraberry Database, Dec. 12, 1966.

5. Wolff, M., Miller, M.A., and Lake, L.W., "Oil Recovery From Geologically Based Fracture Networks," Insitu, Austin, TX, 1990.

6. Baker, R., and Spencely, N., "Analysis of Tracer Study at The Midkiff Unit Upper Spraberry Formation,"'Epic Consulting Ltd .,Calgary, Canada, PRRC Spraberry Database, Aug. 1996.

7. Elkins, L.F., "Reservoir Performance and Well Spacing, Spraberry Trend Area Field of West Texas," Trans., AIME, Vol. 198, Feb. 1953. 


\section{Table 3.4. Reservoir Properties for the Humble Pilot Flood ${ }^{2}$}

\begin{tabular}{|l|l|}
\hline Original Reservoir Pressure, psia & 2300 \\
\hline Saturation Pressure, Psia & 1840 \\
\hline Reservoir Temperature, ${ }^{\circ} \mathrm{F}$ & 140 \\
\hline Initial Water Saturation, $\%$ & $30-35$ \\
\hline Initial Oil Saturation, $\%$ & $65-70$ \\
\hline Matrix Porosity, $\%$ & $6-18$ \\
\hline Effective Permeability, $\mathrm{mD}$ & $2.0-183.0$ \\
\hline Matrix Permeability; $\mathrm{mD} ;$ & \\
Area & $0.1-0.5$ \\
Vertical & $0.05-0.25$ \\
\hline${\text { Pore Compressibility, } \text { psi }^{-1}}^{-1}$ & $4.00 \mathrm{E}-6$ \\
\hline
\end{tabular}

Table 3.5. Reservoir Fluid Properties ${ }^{2}$

\begin{tabular}{|l|l|}
\hline Oil Formation Volume Factor, gm/cc & 1.385 \\
\hline Density of Residual Oil, gr/cc & 0.851 \\
\hline Molecular Weight of Residual oil & 217 \\
\hline Stock Tank Oil Gravity, ${ }^{\circ}$ API & 37.8 \\
\hline Gas Specific Gravity & 0.932 \\
\hline Density of Stock Tank Water, gr/cc & 1.010 \\
\hline Water Formation Volume Factor, bbl/STB & 1.003 \\
\hline Water Viscosity, cp & 1.2486 \\
\hline Water Compressibility, psi $^{-1}$ & $3.00 \mathrm{E}-6$ \\
\hline
\end{tabular}


Table 3.6 - Matched Parameters for Rock Matrix

\begin{tabular}{|l|c|c|}
\hline \multicolumn{1}{|c|}{ Property } & Symbol & Value \\
\hline Porosity & $\phi \mathrm{m}$ & $10.0 \%$ \\
\hline Permeability in the x-direction & $\mathrm{Kx}$ & $0.02 \mathrm{md}$ \\
\hline Permeability in the y-direction & $\mathrm{Ky}$ & $0.02 \mathrm{md}$ \\
\hline Permeability in the z-direction & $\mathrm{Kz}$ & $0.02 \mathrm{md}$ \\
\hline
\end{tabular}

Table 3.7 - Matched Parameters for Fractures

\begin{tabular}{|l|c|c|}
\hline \multicolumn{1}{|c|}{ Property } & Symbol & Value \\
\hline Porosity & $\phi \mathrm{f}$ & $0.1 \%$ \\
\hline Fracture Permeability Ratio & $\mathrm{kxf} / \mathrm{kyf}$ & $15 / 0.25$ \\
\hline & $\sigma$ & 1.47 \\
Shape factor & & \\
\hline Major Fracture Orientation & - & $\mathrm{N} 50^{\circ} \mathrm{E}$ \\
\hline
\end{tabular}




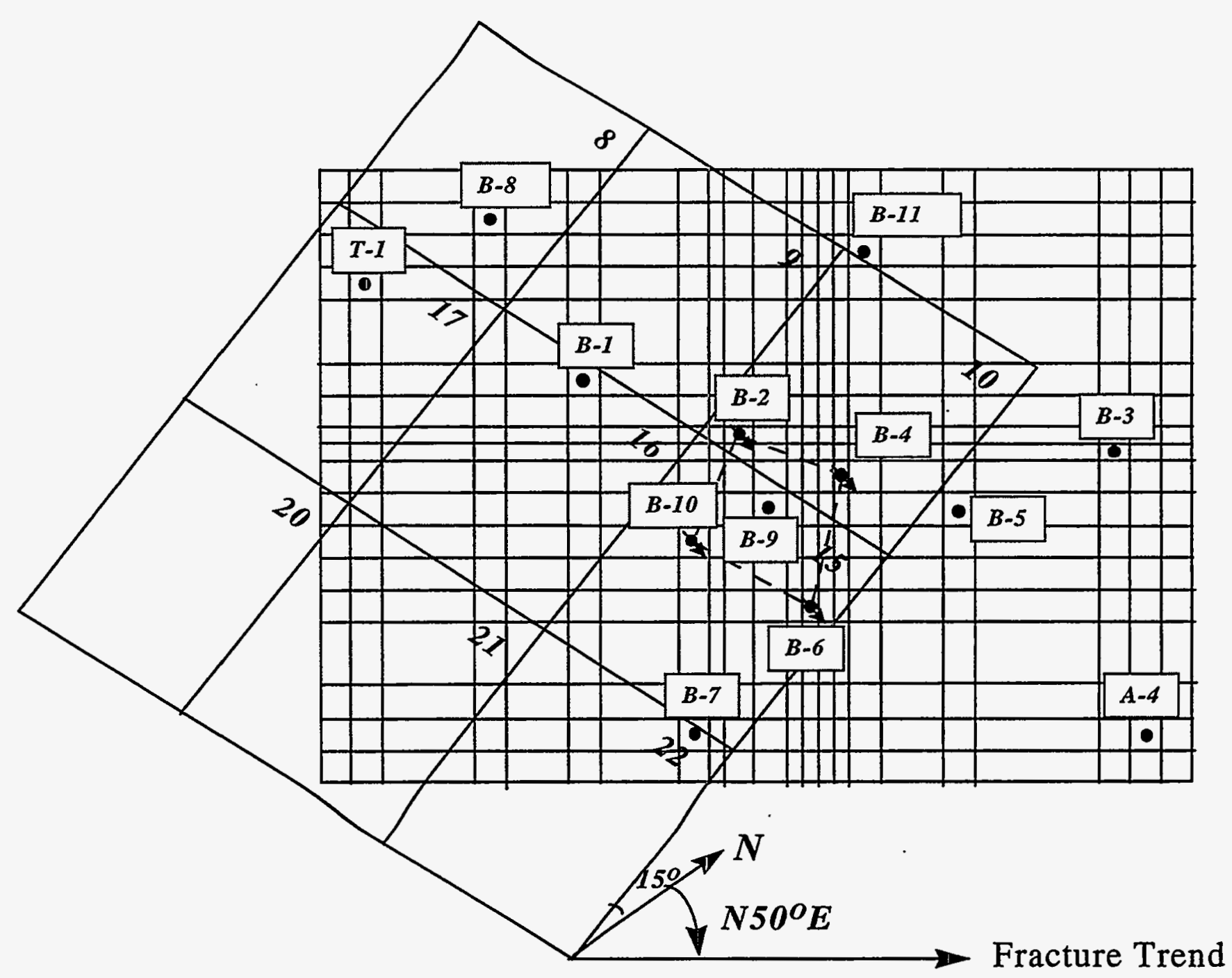

Fig. 3.20 - Grid model after orientation to $\mathrm{N}^{\circ} 0^{\circ} \mathrm{E}$ along the major fracture system. 
Imbibition Capillary Pressure Curve

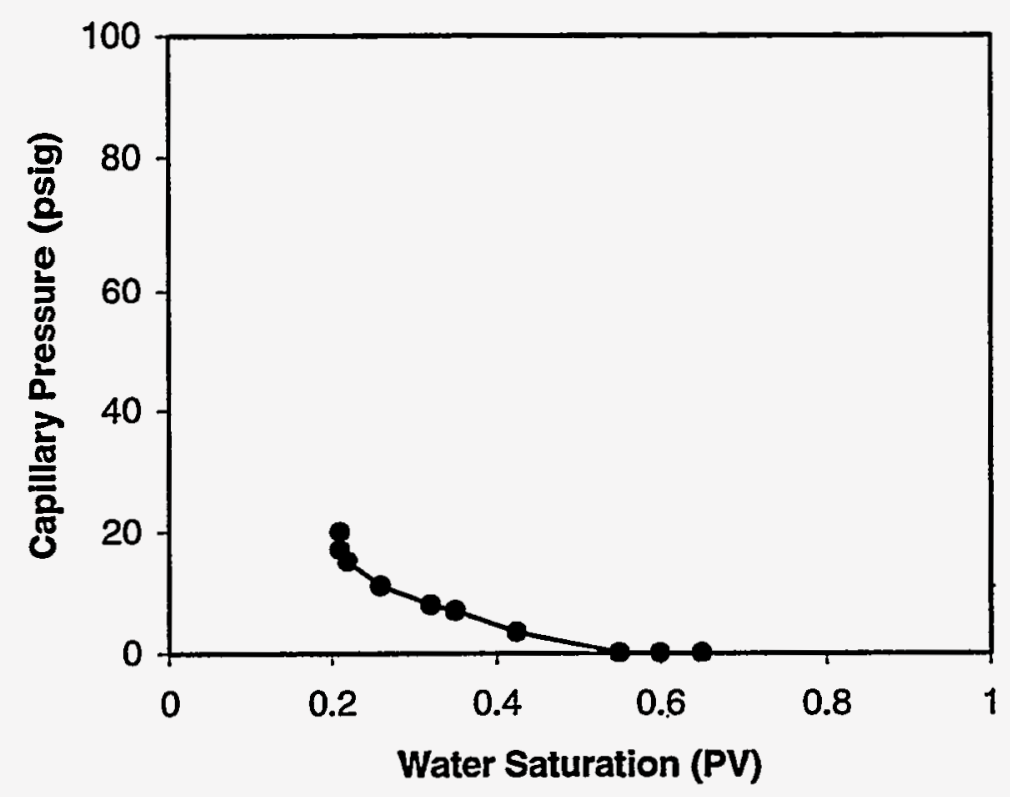

Fig. 3.21 - Plot of imbibition capillary pressure curve for core samples from the Spraberry Trend Area.

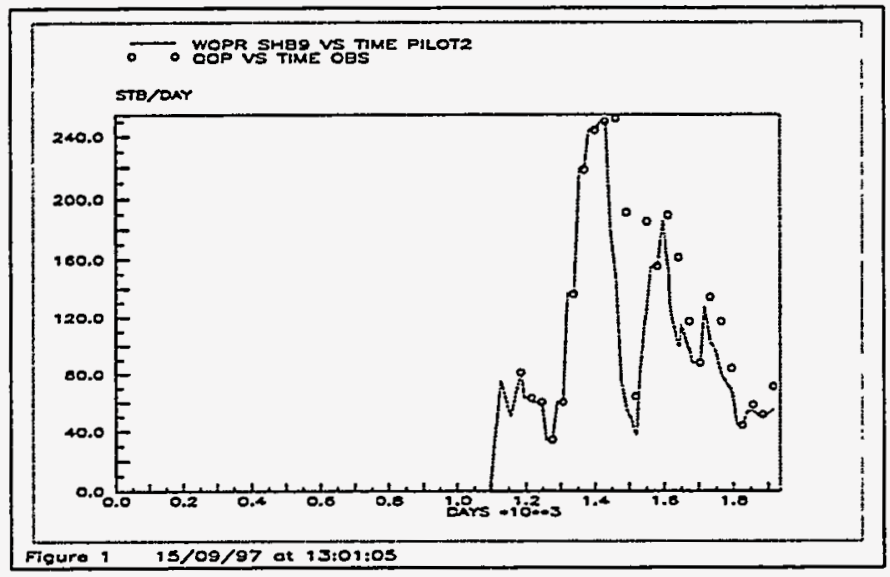

Fig. 3.22 - Match of observed and simulated data for oil production rate in central production well (Sh. B-9). 


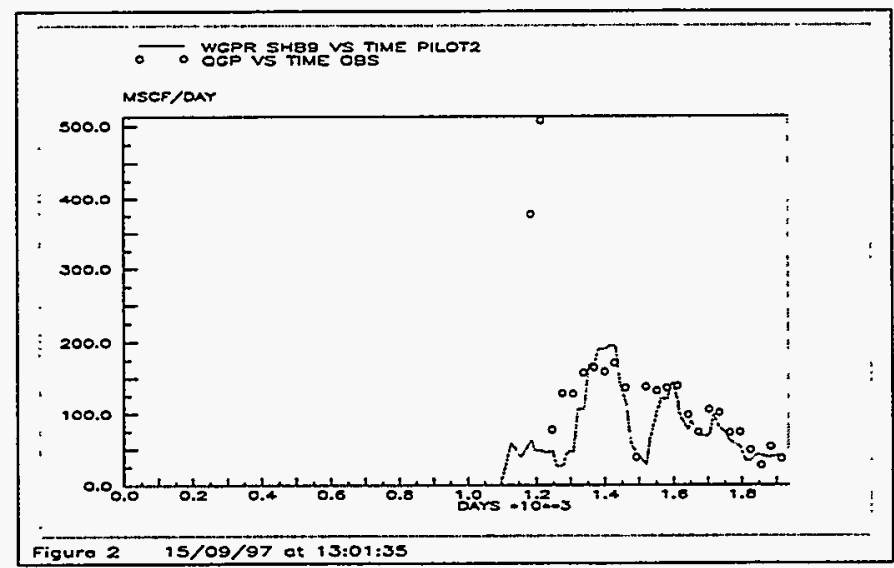

Fig. 3.23 - Match of observed and simulated data for gas production rate.

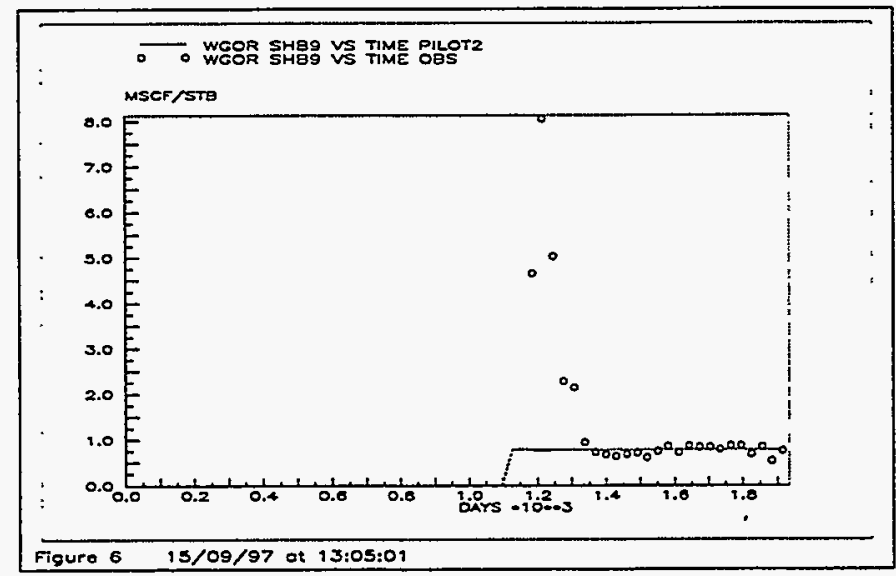

Fig. 3.24 - Match of observed and simulated data for gas-oil ratio. 


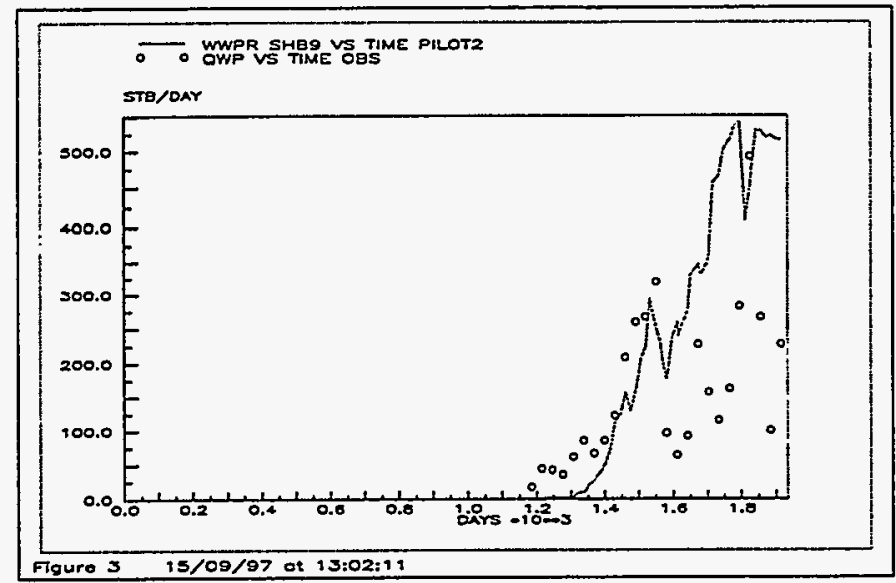

Fig. 3.25 - Match of observed and simulated data for water production rate.

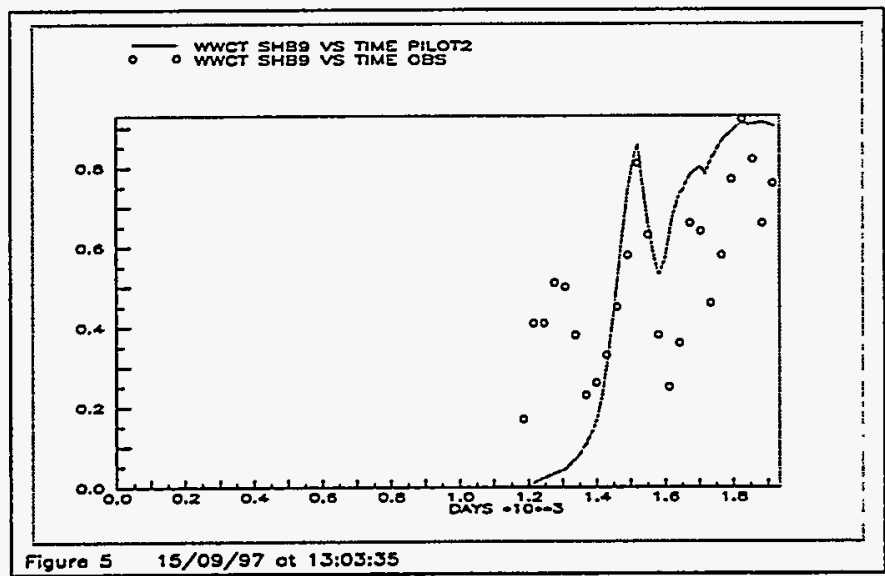

Fig. 3.26 - Match of observed and simulated data for water cut. 


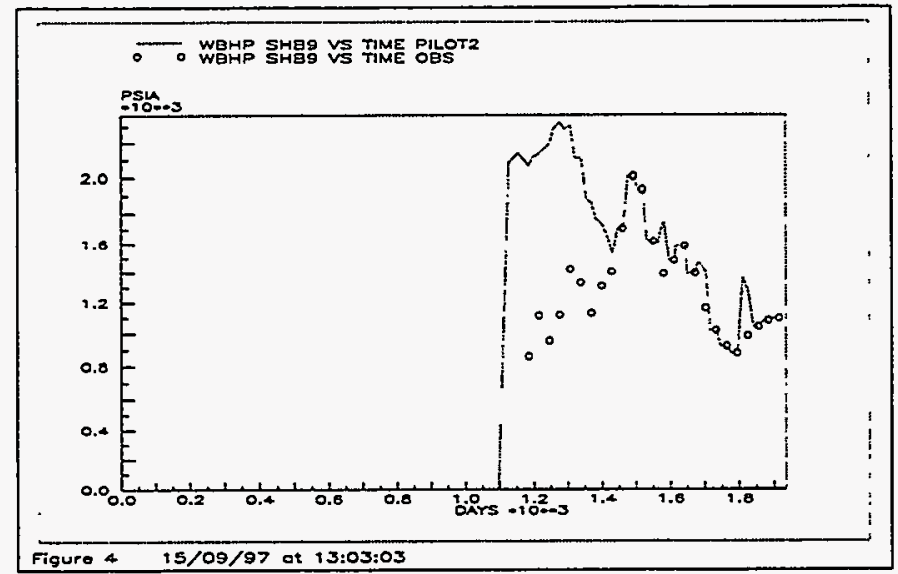

Fig. 3.27 - Match of observed and simulated data for bottom hole pressure. 


\section{INVESTIGATION OF RECOVERY MECHANISMS BY $\mathrm{CO}_{2}$ INJECTION IN FRACTURED SYSTEMS}

During the first year of the project, three experiments were performed using a $500 \mathrm{md}$ Berea core, a $50 \mathrm{md}$ Berea core, and a $0.01 \mathrm{md}$ reservoir core from the Spraberry Trend Area. Table 4.1 summarizes physical properties of these whole cores. Experimental details were presented in the First Annual Technical Progress Report. Oil recovery curves are presented in Fig. 4.1. It is clearly seen from Fig. 4.1 that the efficiency of the $\mathrm{CO}_{2}$ injection decreases with decreased rock permeability.

During the second year of the project, two experiments were conducted using two whole cores from Spraberry reservoirs. The first core has a permeability of $0.38 \mathrm{md}$, while second core consists of two stacks and has a permeability of $0.05 \mathrm{md}$. The purpose of the experiment with the first core was to investigate the effect of water saturation on the $\mathrm{CO}_{2}$ flood efficiency, while that with the second core was to investigate the effects of core discontinuity and impermeable layers at the top and bottom of the pay zone on $\mathrm{CO}_{2}$ flood efficiency. Physical properties of the two cores are also included in Table 4.1. As the second experiment is not yet completed, only the results from the first experiment are presented in this document.

\section{Core Sample}

The whole core was taken from E.T. O'Daniel \#37. It is 3-1/2" in diameter and 21-3/4" in length. The core has a porosity of $11 \%$ and a permeability to brine of $0.38 \mathrm{md}$. The core was first saturated with synthetic Spraberry brine. Spraberry oil was then injected into the core to establish an initial water saturation of $30 \%$. After establishment of the initial water and oil saturations, brine was injected into the core again to reduce oil saturation in the core. The purpose of the second water injection was to simulate waterflooding in the real reservoirs. Water injection was terminated when a water saturation of $45 \%$ was achieved in the core.

\section{Oil}

A separator oil was used in the experiments. Composition of the oil was obtained from GC analysis. The average molecular weight of the oil is 219.39 . The oil sample was tested at $100^{\circ} \mathrm{F}$ and $1000 \mathrm{psig}$. The density was $0.8329 \mathrm{~g} / \mathrm{cc}$ and the viscosity was equal to $2.956 \mathrm{cp}$. The MMP of the oil was measured and found to be 1550 psig using slim tube at the reservoir temperature of $138^{\circ} \mathrm{F}$. Details were presented in the First Annual Technical Progress Report.

\section{Experimental Result}

Experimental apparatus and procedure were described in our First Annual Technical Progress Report. The brine/oil-saturated core was placed vertically in a drainage cell and $\mathrm{CO}_{2}$ was introduced into the drainage cell. Cell pressure was maintained between 1,900 psia and 2,000 psia. The cell temperature was $138^{\circ} \mathrm{F}$. Oil recovered during the experiment was collected through a condenser to minimize vaporization. Early in the experiment, both water and oil were produced 
from the core. Water production ceased at day 55 of the experiment when water saturation dropped by 0.06 . The oil recovery rate increased after water production stopped. After 167 days, oil recovery reached 0.24 OOIP. Figure 4.2 presents the results of oil recovery and backcalculated water saturation in the core versus time.

\section{Discussion}

Figure 4.3 compares the newly obtained oil recovery curve with those previously obtained. Although the new reservoir core has a permeability $0.38 \mathrm{md}$, significantly higher than the permeability of the previous reservoir core $(0.01 \mathrm{md})$, the oil recovery rate in the $0.38 \mathrm{md}$ core is lower than that in the $0.01 \mathrm{md}$ core. The reason may be attributed to the effect of water saturation. Significant amount of water was produced from the core early in the experiment. Water production ceased after 55 days when water saturation dropped by 0.06 . The produced water may be the free water above the initial water saturation in the reservoir rock. In fact, when the water production ceased, the residual water saturation in the core was estimated to be about 0.39. Based on the initial water saturation data shown in Fig. 3.1, the initial water saturation in a 0.38 -md reservoir sand should be about 0.35 which is not much different from 0.39 . It is therefore believed that the excessive free water in the core had hindered oil recovery during the early parts of the experiment due to competing two-phase flow relative permeabilities.

\section{Summary}

Four experiments on $\mathrm{CO}_{2}$ gravity drainage have been completed using Berea and Spraberry reservoir cores. Rock permeability and water saturation have been identified to be two major factors affecting the efficiency of oil recovery during $\mathrm{CO}_{2}$ injection into naturally fractured systems. 
Table 4.1 - Physical Properties of Core Samples Used in the Experiments

Core No.

1

2

3

4

5

Core Type

Berea

Bere

Porosity, \%

18.1

13

Spraberry

Spraberry Spraberry

Permeability, md

500

50

10

11.1

10.7

Water Saturation, \%PV

35

29.3

0.01

0.38

0.05

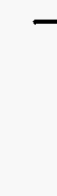

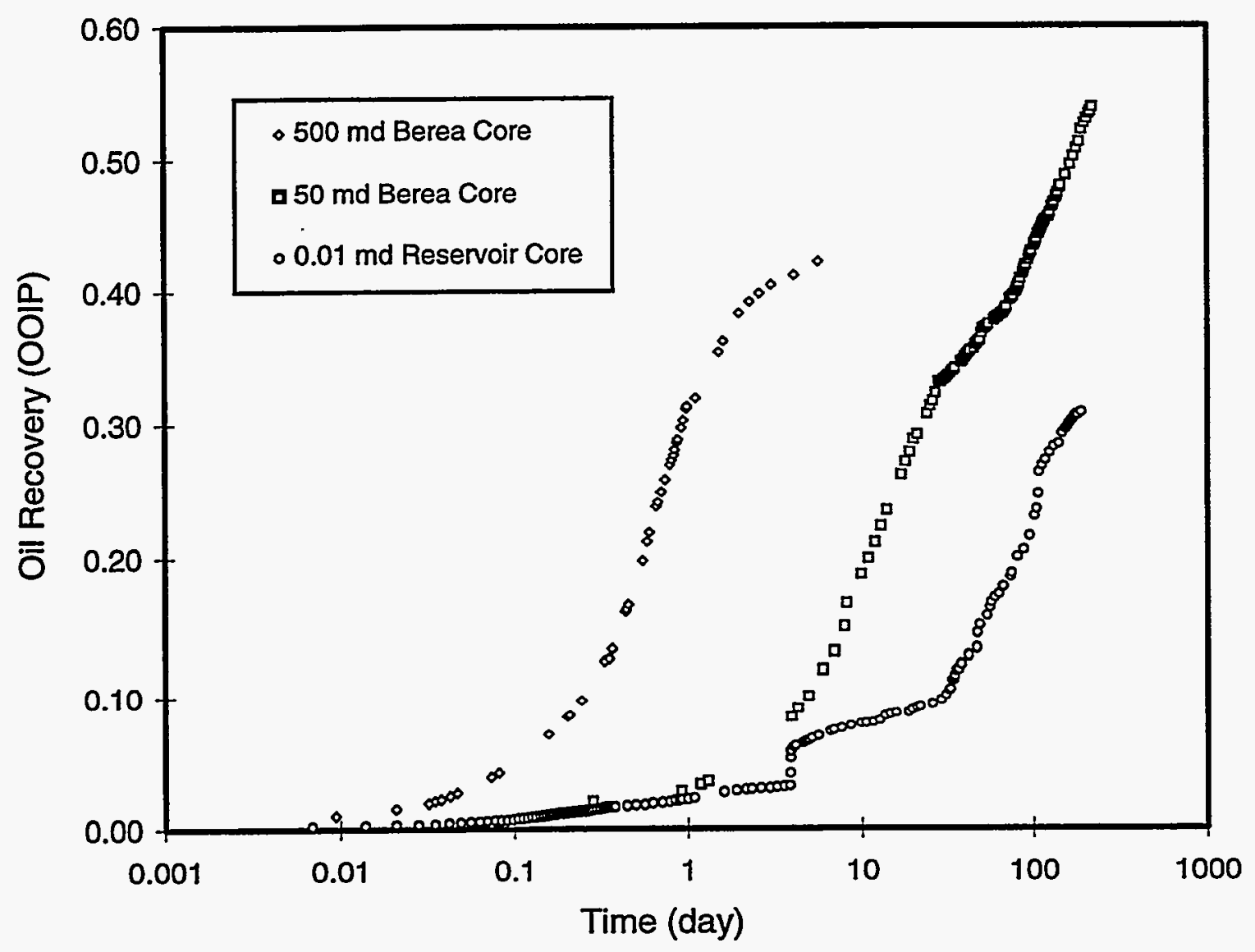

Fig. 4.1 - Oil recovery curves obtained from three $\mathrm{CO}_{2}$ injection experiments using cores with low water saturations. 


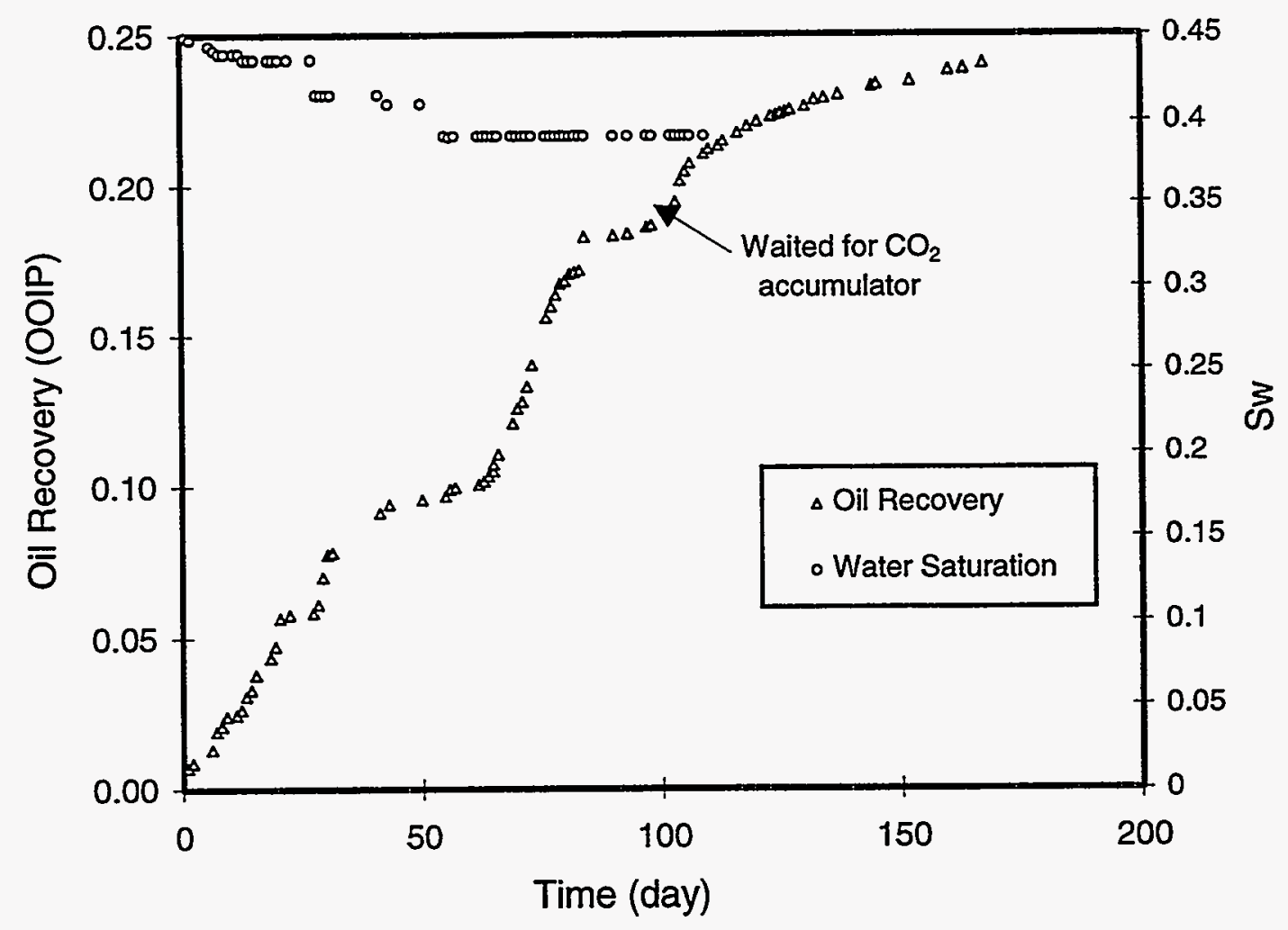

Fig. 4.2 - Oil recovery curve obtained from a $\mathrm{CO}_{2}$ injection experiment using a $0.38 \mathrm{md}$ core with water saturation of 0.45 . 


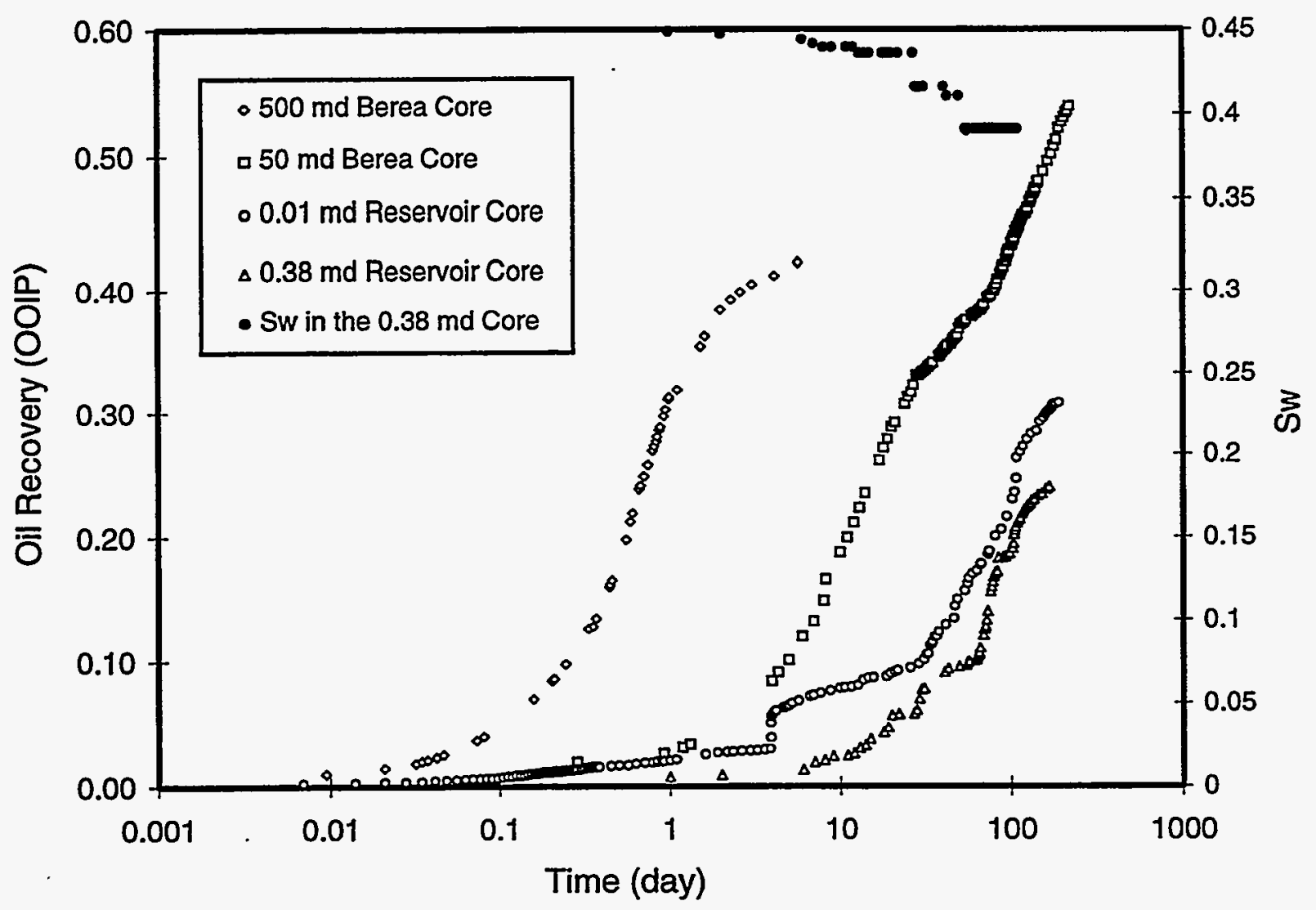

Fig. 4.3 - Comparison of oil recovery curves obtained from four $\mathrm{CO}_{2}$ injection experiments using different cores. 


\section{CONCLUSIONS}

During the second year of the project, we continued to focus on understanding the behavior of the Spraberry reservoirs and the feasibility of $\mathrm{CO}_{2}$ gravity drainage in the reservoirs. We have gained additional knowledge into the behavior of the naturally fractured Spraberry Trend reservoirs through the second year of this project. The following major conclusions are drawn based on the first two years of our investigation:

1. A thorough analysis of open-hole logs and core data indicates that Spraberry reservoir sands can be better described by a shaly-sand rock model integrated with geological and petrophysical data. Spraberry pay zones can be identified from open-hole logs by the model, which consists of volume of shale/effective porosity cross plots. The model has been validated by the analysis of horizontal coring.

2. Horizontal cores obtained from near the pilot area indicate Spraberry is intensively fractured with three distinct fracture sets. Each fracture set has a unique spacing, orientation and degree of mineralization.

3. Experimental investigations and numerical simulation show that the Spraberry reservoirs are weakly water wet, which may be partially responsible for poor performance of waterflooding Spraberry reservoirs. Other factors attributing to poor performance might include stress-sensitivity of the fractures, high gas saturation in the reservoir, and mineralization of fracture faces.

4. Experimental results of oil recovery from two low permeability Spraberry cores during $\mathrm{CO}_{2}$ gravity drainage experiments are promising. Although the efficiency of the $\mathrm{CO}_{2}$ gravity drainage depends on rock permeability and water saturation, this result indicates potential for $\mathrm{CO}_{2}$ flooding Spraberry Trend Area reservoirs and provides the impetus to move this project into Phase II, the actual Field Demonstration. 